\title{
Interactive identification key to all brittle star families (Echinodermata; Ophiuroidea) leads to revised morphological descriptions
}

\author{
Mona GOHARIMANESH ${ }^{\circledR 1}$, Sabine STÖHR ${ }^{\circledR 2, *}$, Omid MIRSHAMSI ${ }^{\circledR 3, *}$, \\ Fereshteh GHASSEMZADEH ${ }^{\circledR 4}$ \& Dominique ADRIAENS ${ }^{\circledR 5}$ \\ ${ }^{1,3,4}$ Ferdowsi University of Mashhad, Faculty of Science, Department of Biology, Mashhad, Iran. \\ ${ }^{2}$ Swedish Museum of Natural History, Department of Zoology, Stockholm, Sweden. \\ ${ }^{3}$ Research Department of Zoological Innovations (RDZI), Institute of Applied Zoology, \\ Faculty of Science, Ferdowsi University of Mashhad, Mashhad, Iran. \\ ${ }^{1,5}$ Ghent University, Research Group Evolutionary Morphology of Vertebrates, Gent, Belgium. \\ "Corresponding authors: Sabine.Stohr@nrm.se (SS), Mirshams@um.ac.ir(OM) \\ 1Email: Mona.goharimanesh@ugent.be \\ ${ }^{4}$ Email: Ghasemzd@um.ac.ir \\ ${ }^{5}$ Email: Dominique.Adriaens@ugent.be \\ ${ }^{1}$ urn:1sid:zoobank.org:author:CA669FA6-7D88-4648-AB18-2EE47C2B5ECA \\ ${ }^{2}$ urn:lsid:zoobank.org:author:412800EB-AACE-4313-9810-61F89B740405 \\ ${ }^{3}$ urn:1sid:zoobank.org:author:DF3B1646-D647-4C89-BA2B-FEB0225ABC5B \\ ${ }^{4}$ urn:lsid:zoobank.org:author:8E35EC47-0572-4CCD-9308-2486A90ACDDC \\ ${ }^{5}$ urn:lsid:zoobank.org:author:C3CF8EFE-3582-4D05-9445-395971CF7661
}

\begin{abstract}
Ophiuroidea is the largest class among extant echinoderms, with over 2000 described species assigned to 33 families. Here, the first identification key to the recently revised classification was developed, and revised morphological descriptions were derived from it, expanding the previous short diagnoses. The key was built by analyzing internal and external skeletal characters of predominantly the type species of each family, including at least two mutually exclusive attributes per family. Various numeric and multistate characters were used to create a traditional as well as an interactive key using the DELTA and Xper software programs. Illustrations (SEM and digital photos) are included in the key to facilitate the assessment of character states by users. Not only is it the first identification key to the families, according to the recently proposed new classification and the examined species, but this interactive key also assists users in understanding the family level taxonomy of brittle stars. The interactive key allows new characters and states to be added, when more species will have been analyzed, without the need to reconfigure the complete key (as may be necessary with conventional keys).
\end{abstract}

Keywords. Morphology, taxonomy, DELTA, interactive key, characters.

Goharimanesh M., Stöhr S., Mirshamsi O., Ghassemzadeh F. \& Adriaens D. 2021. Interactive identification key to all brittle star families (Echinodermata; Ophiuroidea) leads to revised morphological descriptions. European Journal of Taxonomy 766: 1-63. https://doi.org/10.5852/ejt.2021.766.1483 


\section{Introduction}

Ophiuroidea Gray, 1840 is one of the most diverse classes among extant echinoderms (Stöhr et al. 2012), currently including 2096 species (Stöhr et al. 2020). Ophiuroids are an ancient group of marine invertebrates with a fossil record dating back to the early Ordovician, about 480 ma (Shackleton 2005). They occupy marine habitats, ranging from the poles to the equator, from intertidal reefs to hadal depths of at least $6500 \mathrm{~m}$ (Smith et al. 1995; O'Hara et al. 2017). From the mid-eighteenth century, there has been a rise in the discovery rate of ophiuroid species, which has remained relatively high (Stöhr et al. 2012). Since the early-twentieth century, ophiuroid taxonomy has received more attention, as is evidenced by the production of traditional identification keys for various geographical areas (Mortensen 1927; Clark \& Rowe 1971; Paterson 1985; Smirnov et al. 2006; Pomory 2007; Martynov 2010a; Gondim et al. 2013), but all of these keys are based on a now-outdated classification, which limits their use above the genus level. Matsumoto $(1915,1917)$ suggested the first comprehensive classification for the whole class, separating it into two subclasses, Myophiuroida Matsumoto, 1915, which possesses ventral arm plates that cover the ambulacral groove, and Oeogophiuroida Matsumoto, 1915, which lacks ventral arm plates. He divided the former into four different orders, Phrynophiurina Matsumoto, 1915, Laemophuirina Matsumoto, 1915, Chilophiurina Matsumoto, 1915, Gnathophiurina Matsumoto, 1915, and 13 families. Matsumoto's (1915, 1917) classification was not universally accepted though, and Mortensen (1927) instead proposed two orders, Euryalae and Ophiurae, based on the articular structures of the vertebrae (streptospondylous vs zygospondylous). He also provided the first traditional dichotomous identification key for 12 families but it was restricted to the British Isles. On the other hand, Murakami (1963) agreed with Matsumoto (1915, 1917), and he identified several new and taxonomically important characters from the examination of dental and oral plates. Fell (1960) included 17 families in his key to the ophiuroid genera, and while it is still useful, users need to be familiar with previous classifications to successfully navigate the key. All of the above-mentioned keys are conventional dichotomous keys. So far, only a single, taxonomically and geographically limited, computerized interactive key for Ophiuroidea is available (Alitto et al. 2018). Interactive keys have been created for many other taxa though, e.g, for Australian aquatic invertebrates using the software LUCID (Lucidcentral 2012), and also for various plants and animals using DELTA (Dallwitz 2019), but none includes echinoderms.

Eighty years after Matsumoto's (1915) work, Smith et al. (1995) proposed a new phylogeny, based on a cladistic analysis of all Ophiuroidea, including mostly morphological (43 characters) and limited molecular data, proposing 17 families. This study split the Ophiuroidea into the orders Euryalida Lamarck, 1816 and Ophiurida Müller \& Troschel, 1840, based on vertebral articulation type, as Mortensen (1927) had done. Although the molecular study provided some support for the morphological tree, it left most of the deep branches unresolved (Smith et al. 1995) and was debated for methodological shortcomings (Stöhr 2012). Thanks to the studies on arm spine articulations (Martynov 2010b) and lateral arm plates (Thuy \& Stöhr 2011), new phylogenetically informative characters were discovered, which led to a breakthrough with the successful inference of the ophiuroid phylogeny from morphological characters in great congruence with the molecular phylogeny (Thuy \& Stöhr 2016), proposed two years earlier (O'Hara et al. 2014). At that time, the ophiuroid classification comprised 19-20 families (Thuy \& Stöhr 2016). Recently, O'Hara et al. (2017) presented a new molecular phylogeny, which resulted in a new and revised classification that increased the number of families to 33 (O'Hara et al. 2018). The new phylogeny found several of the previous families to be paraphyletic or polyphyletic (O'Hara et al. 2017), which were revised in the new classification, and many genera were transferred to other families than their traditional placement (O'Hara et al. 2018). Consequently, existing identification keys to the previous families can no longer be used. One might argue that species identification keys are more useful than family keys, but 1) these are lacking or outdated for the majority of species, 2) they are usually geographically limited, 3) identification to high ranks is useful for an estimate of diversity and can speed up faunal inventory studies, and 4) the new classification differs greatly from all previous ones and a key can make it more 
accessible to users. Therefore, the present study aims to develop a new identification key for the currently accepted ophiuroid families (O'Hara et al. 2018), while at the same time expanding the short diagnoses provided by O'Hara et al. (2018) into detailed descriptions using previously rarely considered characters.

The family level taxa of Ophiuroidea are based on nodes of similar age $( \pm 110 \mathrm{ma})$ on the recent phylogeny (O'Hara et al. 2017), but as ranks in a classification they are of course artificial constructs by and for humans to conceptualize the diversity. During the evolution within a family clade, many changes happened: some genera/species lost the synapomorphies that support the monophyly of each node on the phylogenetic tree, others kept some of them as plesiomorphies, and most evolved novelties/autapomorphies that may or may not need to be included in the family description. Also, the within-family phylogeny has not been analyzed yet, apart from few exceptions (e.g., Ophiocomidae Ljungman, 1867; O'Hara et al. 2019), and the support for each family is biased towards molecular data. Previous descriptions of many families no longer reflect the morphological diversity of the included genera, e.g., the family Ophiomyxidae Ljungman, 1867 now includes several genera that were previously assigned to Ophiodermatidae Ljungman, 1867, whereas several former ophiomyxids have been transferred to the resurrected Ophioscolecidae Lütken, 1869 (which is currently paraphyletic). The assemblage of genera included in Ophiomyxidae now share rather few characters. This complicates the identification of family-specific characters that allow the correct familial assignment of all species by morphology, which was emphasized also by O'Hara et al. (2018), who limited the family descriptions to a few diagnostic characters based on the type genera. Pending full taxonomic revisions of all families, the present study aims to provide revised descriptions, based on the characters used for the creation of an interactive identification key.

A conventional (often dichotomous) key has a single access point and is fixed in the order in which the characters need to be assessed, and with an increasing number of steps, it quickly becomes unwieldy and imprecise, because the probability of making a wrong decision (and then following the wrong path) increases with the number of decisions to be made. Attempts have been made to better structure excessively long keys (with hundreds of couplets to evaluate), but they still have severe limitations for incomplete specimens and human error, problems that can be overcome with computerized multiple access keys (Walter \& Winterton 2007). The main limitation when constructing any kind of key is defining the most suitable characters and states that accurately identify a specific taxon, which can be difficult when the taxa are not sufficiently distinct from each other. To overcome the above-mentioned obstacles, we chose to create a software-based interactive key in which the user chooses/enters the character states of the specimen that can be observed, not limited by a particular order of decisions as in traditional keys, and thus offering multiple access points. The program eliminates taxa to which the chosen character states do not apply, and the process is continued until only one taxon remains (Dallwitz et al. 2000). This allows the inclusion of a large number of characters, and species (or incomplete specimens), which lack some of the typical features, can still be identified. Redundancy also ensures that user errors have less impact on the outcome. It should be noted that the characters used in this key were chosen for family identification purposes, not for phylogenetic inference and also not for identification at lower taxonomic levels (genus, species). This means that homoplastic characters (e.g., madreporite shape, branching arms) can be useful for identification when they can narrow down the selection of possible results, and autapomorphies are particularly useful for identification but not for phylogenetic inference. Characters that vary between species (e.g., disc color, number of distal/proximal spines and tentacle scales) were excluded as not useful for the identification of families. Consequently, the character matrix differs considerably from the one used to infer a phylogeny from morphological characters (Thuy \& Stöhr 2011) and would not be suitable for that purpose.

Traditionally, ophiuroids have been described based on limited external structures, such as disc scales, arm plates and spines, and oral frame skeleton, among others. Modern descriptions also include microscopic structures, observed by scanning electron microscopy, and internal skeletal structures (Martynov 2010a; 
Stöhr 2012; Stöhr \&Martynov 2016; Okanishi et al. 2017), and many other characters have been reevaluated (Thuy \& Stöhr 2016, 2018). Despite this interest, the terminology used for ophiuroid skeletal elements is not standardized and authors have used different terms, which might lead to confusion for readers. Also, the descriptions of the 33 families in the new classification were limited to a few diagnostic characters (O'Hara et al. 2018). Therefore, besides creating the keys, we elaborated on some terminology and expanded the descriptions for each family. These descriptions cannot replace full taxonomic revisions, but since those are time-consuming and will probably not be achieved in the nearest future, the key-derived descriptions are a useful compromise, providing more information than the short diagnoses by O'Hara et al. (2018). To evaluate the differences between interactive and conventional keys, and to provide a tool that can be used without a computer, we used the software to export a conventional polychotomous key, which prioritizes external characters to facilitate usage without the need for extensive preparation of the animals.

\section{Material and methods}

Primarily, the type species of each family was used to find the features that may distinguish the families. When the type species was not available, another species of the type genus was evaluated, and if no member of the type genus was available, other genera in the family were used. Additional species from most families were used to verify the presence of the chosen characters and to test the key. The species assessed in this study are shown in Table 1 . Characters were collected by examining images in publications (Smith et al. 1995; Pomory 2007; Gondim et al. 2013), preserved specimens collected in the Persian Gulf and in the museum collections of the Royal Belgian Institute of Natural Sciences (RBINS), as well as examining scanning electron microscope images (SEM) and 3D images of museum specimens of the Swedish Museum of Natural History (SMNH) and RBINS. We used 54 external and 22 internal characters, amounting to a total of 77 characters and 190 states (Appendix 1), to create the interactive key. The characters and states were defined partially based on O'Hara et al. (2018), modified for the current purpose, and additional characters were selected after specimen/image examination. All characters include at least two mutually exclusive states. The genera included in each family were extracted from O'Hara et al. (2018) and verified for possible later changes in Stöhr et al. (2020).

The primary software package used to develop a traditional and interactive key was DELTA (DEscription Language for TAxonomy) (Dallwitz et al. 2006). It allows the choice of different types of characters such as ordered, unordered, integer, real numeric and text, but we omitted real number characters, e.g., 'disc diameter' as an absolute size, because not only do the animals change size during growth, but also it might not be easy to measure the targeted character precisely while using the key. Instead, using a multiple-choice character with ranges of values or relative size, e.g., 'the arm, is $\times$ times as long as the disc diameter' is more useful. Selected images were uploaded and labeled in the software to enable users to compare to their specimens, to facilitate the choices to be made. To create a key, a great deal of attention must be paid to choose the most powerful characters and states for family discrimination. Regarding character dependency, DELTA has the capability to define dependencies between characters, i.e., if the character ' $\mathrm{A}$ ' is not present in a taxon, the other dependent characters describing character ' $\mathrm{A}$ ' cannot be applied (see characters 42 and 43-45 in Appendix 1). On the other hand, missing data for some states were left blank and written as "no data" in the family description. These may be completed in the future as the project progresses and more morphological traits will be included. This is the main advantage of the interactive key, i.e., that it allows new characters to be added without disrupting the existing structure.

For the creation of the conventional key, of the original 77 characters, 46 characters were found to be sufficient to separate the taxa. We prioritized external characters in the creation of the conventional key as much as possible (without compromising identification accuracy), because these are more easily observed under field conditions. To achieve this, DELTA offers techniques such as weighting and setting reliability values. Weighting in DELTA is not related to weighting in phylogenetic inference. It serves 
Table 1 (continued on next page). List of the species assessed to create the identification key to the ophiuroid families. The type species of each family is marked with a " $T$ ", square brackets [] indicate species that could not be assessed due to lack of material, and those with an asterisk (*) were assessed mainly from literature.

\begin{tabular}{|c|c|c|}
\hline Family & Type genus & Species assessed \\
\hline Amphilepididae & Amphilepis Ljungman, 1867 & Amphilepis norvegica (Ljungman, 1865) (T) \\
\hline Amphilimnidae & Amphilimna Verrill, 1899 & Amphilimna olivacea (Lyman, 1869) $(\mathrm{T})$ \\
\hline Amphiuridae & Amphiura Forbes, 1843 & $\begin{array}{l}\text { Amphiura chiajei Forbes, } 1843 \text { (T) } \\
\text { Amphiura atlantidea Madsen, 1970 } \\
\text { Amphiura filiformis (O.F. Müller, 1776) } \\
\text { Acrocnida brachiata (Montagu, 1804) } \\
\text { Amphioplus aurensis A.M. Clark, 1955 } \\
\text { Amphioplus congensis (Studer, 1882) } \\
\text { Amphipholis nudipora Koehler, 1914 } \\
\text { Amphipholis squamata (Delle Chiaje, 1828) } \\
\text { Amphipholizona delicata H.L. Clark, 1915 } \\
\text { Amphipholizona perplexa (Nielsen, 1932) } \\
\text { Ophiophragmus acutispina (Koehler, 1914) }\end{array}$ \\
\hline Asteronychidae & $\begin{array}{l}\text { Asteronyx Müller \& } \\
\text { Troschel, } 1842\end{array}$ & Asteronyx loveni Müller \& Troschel, $1842(\mathrm{~T})$ \\
\hline Astrophiuridae & Astrophiura Sladen, 1879 & $\begin{array}{l}\text { Astrophiura permira Sladen, } 1879(\mathrm{~T}) \\
\text { Ophiomisidium tommasii Borges, Monteiro \& Amaral, } \\
2006\end{array}$ \\
\hline Clarkcomidae & Clarkcoma Devaney, 1970 & Clarkcoma canaliculata (Lütken, 1869)* (T) \\
\hline Euryalidae & Euryale Lamarck, 1816 & Euryale aspera Lamarck, $1816(\mathrm{~T})$ \\
\hline Gorgonocephalidae & Gorgoncephalus Leach, 1815 & Gorgonocephalus caputmedusae (Linnaeus, 1758) (T) \\
\hline Hemieuryalidae & Hemieuryale von Martens, 1867 & $\begin{array}{l}\text { Hemieuryale pustulata v. Martens, } 1867 \text { (T) } \\
\text { Actinozonella texturata (Lyman, 1883) } \\
\text { Ophioplus tuberculosus (Lyman, 1883) } \\
\text { Ophiozonella falklandica Mortensen, } 1936 \\
\text { Ophiozonella longispina (H.L. Clark, 1908) } \\
\text { Sigsbeia lineata Lütken \& Mortensen, 1899 } \\
\text { Sigsbeia murrhina Lyman, } 1878\end{array}$ \\
\hline Ophiacanthidae & $\begin{array}{l}\text { Ophiacantha Müller \& } \\
\text { Troschel, } 1842\end{array}$ & $\begin{array}{l}\text { Ophiacantha bidentata (Bruzelius, 1805) (T) } \\
\text { Ophiacantha abyssicola G.O. Sars, } 1872 \\
\text { Ophiocanops multispina } \text { Stöhr, Conand \& Boissin, } 2008 \\
\text { Ophiochondrus stelliger Lyman, } 1879 \\
\text { Ophiolimna bairdi } \text { (Lyman, 1883) } \\
\text { Ophiolimna perfida } \text { (Koehler, 1904) } \\
\text { Ophioplinthaca plicata (Lyman, 1878) }\end{array}$ \\
\hline Ophiactidae & Ophiactis Lütken, 1856 & $\begin{array}{l}\text { Ophiactis savignyi (Müller \& Troschel, 1842) (T) } \\
\text { Ophiactis abyssicola (M. Sars, 1861) }\end{array}$ \\
\hline Ophiernidae & Ophiernus Lyman, 1878 & Ophiernus vallincola Lyman, $1878(\mathrm{~T})$ \\
\hline Ophiobyrsidae & Ophiobyrsa Lyman, 1878 & Ophiobyrsa rudis Lyman, $1878 *(\mathrm{~T})$ \\
\hline Ophiocamacidae & Ophiocamax Lyman, 1878 & Ophiocamax vitrea Lyman, $1878(\mathrm{~T})$ \\
\hline Ophiocomidae & Ophiocoma L. Agassiz, 1836 & $\begin{array}{l}\text { Ophiocoma echinata (Lamarck, 1816) }(\mathrm{T}) \\
\text { Ophiocoma erinaceus Müller \& Troschel, } 1842 \\
\text { Ophiocoma scolopendrina (Lamarck, 1816) }\end{array}$ \\
\hline Ophiodermatidae & $\begin{array}{l}\text { Ophioderma Müller \& } \\
\text { Troschel, } 1840\end{array}$ & Ophioderma longicaudum (Bruzelius, 1805) (T) \\
\hline Ophiohelidae & Ophiohelus Lyman, 1880 & $\begin{array}{l}\text { Ophiohelus umbella Lyman, 1880] (T) } \\
\text { Ophiomyces delata Koehler, } 1904 \\
\text { Ophiotholia spathifer (Lyman, 1879) }\end{array}$ \\
\hline
\end{tabular}


Table 1 (continued). List of the species assessed to create the identification key to the ophiuroid families. The type species of each family is marked with a "T", square brackets [] indicate species that could not be assessed due to lack of material, and those with an asterisk $\left(^{*}\right)$ were assessed mainly from literature.

\begin{tabular}{|c|c|c|}
\hline Family & Type genus & Species assessed \\
\hline Ophiolepididae & $\begin{array}{l}\text { Ophiolepis Müller \& Troschel, } \\
1840\end{array}$ & Ophiolepis superba H.L. Clark, 1915 (T) \\
\hline Ophioleucidae & Ophioleuce Koehler, 1904 & $\begin{array}{l}\text { Ophioleuce seminudum Koehler, } 1904 \text { (T) } \\
\text { Ophiopallas paradoxa Koehler, } 1904\end{array}$ \\
\hline Ophiomusaidae & Ophiomusa Hertz, 1927 & Ophiomusa lymani (Wyville-Thomson, 1873) (T) \\
\hline Ophiomyxidae & $\begin{array}{l}\text { Ophiomyxa Müller \& Troschel, } \\
1842\end{array}$ & $\begin{array}{l}\text { Ophiomyxa pentagona (Lamarck, 1816) }(\mathrm{T}) \\
\text { Ophiarachna incrassata (Lamarck, 1816) }\end{array}$ \\
\hline Ophionereididae & Ophionereis Lütken, 1859 & $\begin{array}{l}\text { [Ophionereis reticulata }(\text { Say, } 1825)](\mathrm{T}) \\
\text { Ophionereis porrecta Lyman, } 1860 \\
\text { Ophiochiton fastigatus Lyman, } 1878 \\
\text { Ophiodoris malignus Koehler, } 1904 \\
\text { Ophioplax lamellosa Matsumoto, } 1915 \\
\end{array}$ \\
\hline Ophiopezidae & Ophiopeza Peters, 1851 & $\begin{array}{l}\text { Ophiopeza fallax Peters, } 1851 \text { (T) } \\
\text { Ophiopeza spinosa (Ljungman, 1867)* }\end{array}$ \\
\hline Ophiopholidae & $\begin{array}{l}\text { Ophiopholis Müller \& Troschel, } \\
1842\end{array}$ & Ophiopholis aculeata (Linnaeus, 1767) (T) \\
\hline Ophiopsilidae & Ophiopsila Forbes, 1843 & $\begin{array}{l}\text { Ophiopsila aranea Forbes, } 1843(\mathrm{~T}) \\
\text { Ophiopsila guineensis Koehler, } 1914\end{array}$ \\
\hline Ophiopteridae & Ophiopteris E.A. Smith, 1877 & Ophiopteris antipodum E.A. Smith, 1877 (T) \\
\hline Ophiopyrgidae & Ophiopyrgus Lyman, 1878 & $\begin{array}{l}\text { Ophiopyrgus wyvillethomsoni Lyman, } 1878(\mathrm{~T}) \\
\text { Ophiopyrgus saccharatus Studer, 1882 } \\
\text { Amphiophiura insolita (Koehler, 1904) } \\
\text { Amphiophiura latro (Koehler, 1904) } \\
\text { Ophiopleura borealis Danielssen \& Koren, } 1877 \\
\text { Ophioplinthus tessellata (Verrill, 1894) } \\
\text { Ophiosparte gigas Koehler, 1922 }\end{array}$ \\
\hline Ophioscolecidae & $\begin{array}{l}\text { Ophioscolex Müller \& Troschel, } \\
1842\end{array}$ & $\begin{array}{l}\text { Ophioscolex glacialis Müller \& Troschel, } 1842 \text { (T) } \\
\text { Ophiolycus purpureus (Düben \& Koren, 1846) }\end{array}$ \\
\hline Ophiosphalmidae & Ophiosphalma H.L. Clark, 1941 & $\begin{array}{l}\text { OO. planum (Lyman, } 1878)=\text { O. armigerum (Lyman, } \\
\text { 1878] }(\mathrm{T}) \\
\text { Ophiosphalma glabrum (Lütken \& Mortensen, 1899) }\end{array}$ \\
\hline Ophiothamnidae & Ophiothamnus Lyman, 1869 & $\begin{array}{l}\text { [Ophiothamnus vicarius Lyman, 1869] (T) } \\
\text { Histampica duplicata (Lyman, 1875) }\end{array}$ \\
\hline Ophiotomidae & Ophiotoma Lyman, 1883 & $\begin{array}{l}\text { Ophiotoma coriacea Lyman, 1883] (T) } \\
\text { Ophiocomina nigra (Abildgaard in O.F. Müller, 1789) } \\
\text { Ophiocopa spatula Lyman, } 1883 \\
\text { Ophiotreta valenciennesi (Lyman, 1879) }\end{array}$ \\
\hline Ophiotrichidae & $\begin{array}{l}\text { Ophiothrix Müller \& Troschel, } \\
1840\end{array}$ & $\begin{array}{l}\text { Ophiothrix fragilis (Abildgaard in O.F. Müller, 1789) (T) } \\
\text { Macrophiothrix elongata H.L. Clark, } 1938 \\
\text { Macrophiothrix hirsuta cheneyi (Lyman, 1861) }\end{array}$ \\
\hline Ophiuridae & Ophiura Lamarck, 1801 & $\begin{array}{l}\text { Ophiura ophiura (Linneaus, 1758) (T) } \\
\text { Ophiura carnea skoogi (Koehler, 1923) } \\
\text { Ophiura sarsii Lütken, } 1855 \\
\text { Ophiocten sericeum (Forbes, 1852) }\end{array}$ \\
\hline
\end{tabular}

*citations: Clarkcomidae (Devaney 1970; Hendler 2018), Ophiobyrsidae (Martynov 2010a; O’Hara et al. 2018) and Ophiopezidae (Martynov 2010a). 
the purpose of letting characters with high reliability be used more in the key compared to those with lower reliability. Reliable characters are those whose state values can easily be assigned to a specimen and thus most accurately separate the taxa. We used a higher reliability value (8) for external characters and a lower value (1) for internal and difficult characters in the creation of the conventional key. For the interactive key the reliability value was set as the default (5). We assigned weights to characters that are more reliable for identification, which causes them to appear first in the interactive key and increases their likelihood of being used in the creation of the conventional key. As an alternative to DELTA, the same dataset was transferred to Xper2 (desktop application, ver. 2.3.2) and Xper3 (online application), in which we applied character weights (= reliability) ranging between 1 and 5, to create conventional and interactive keys. The character reliability in DELTA for characters 1-77 was as follows: 1,8 2,1 3-8,8 9,1 10-22,8 23-33,1 34,8 35,1 36-45,8 46,1 47-50,8 51-62,1 63,8 64,1 65-67,8 68-77,1, in which the value of each character reliability is next to the character number(s) separated by a comma (e.g., 3-8,8: the value of 8 was assigned to characters 3 to 8 ). The character weights in Xper were as follows: 1,5 2,1 3-8,5 9,1 10-22,5 23-33,1 34,5 35,1 36-45,5 46,1 47-50,5 51-62,1 63,5 64,1 65-67,5 68-77,1.

Since the terminology used for ophiuroid characters varied between authors and has subsequently caused confusion, we have prepared a glossary that explains the more difficult characters used in the present study.

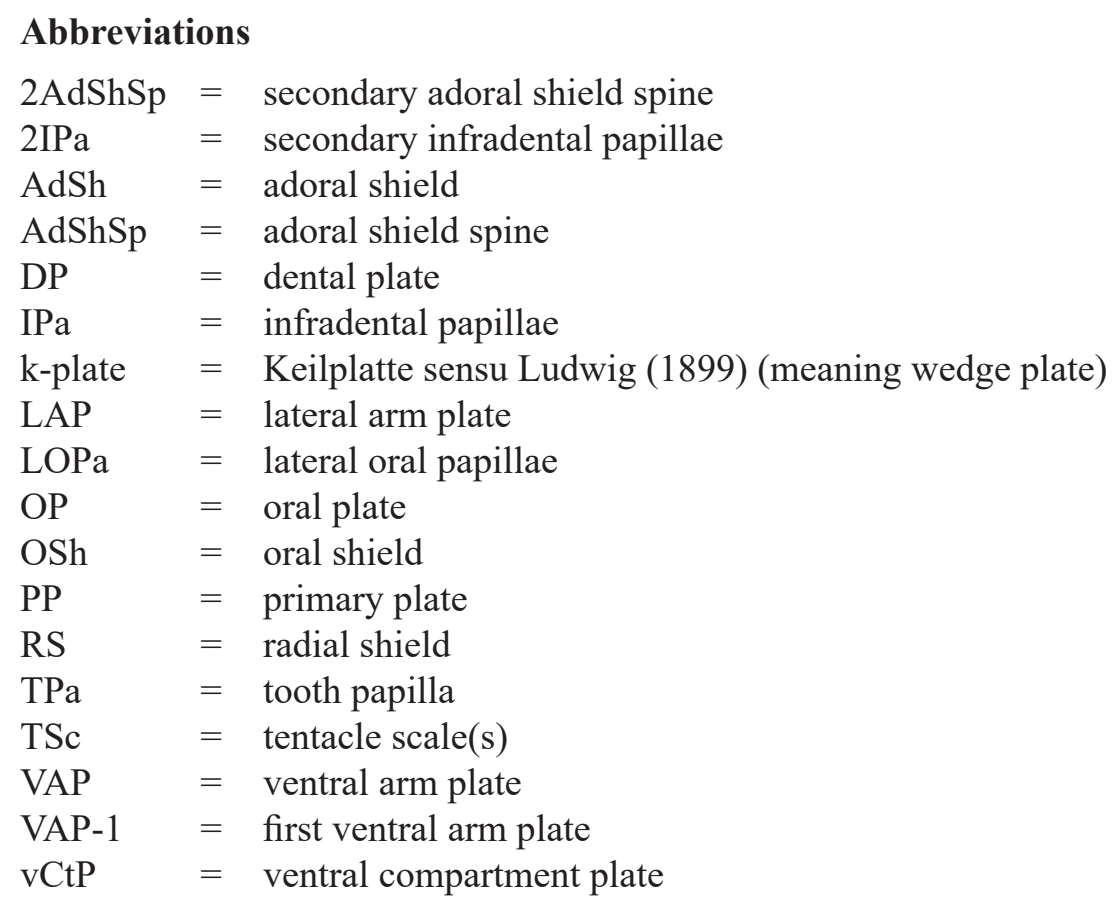

\section{Terminology}

Disc (flat/high)

Flat or high stands for the height of the disc relative to the level of the arms; if it is at about the same level as the arms, such as in Ophiura Lamarck, 1801, it is considered flat; in e.g., Amphiophiura Matsumoto, 1915 it is considered as high. Sac-like refers to a soft, floppy disc that is much higher than wide, e.g., as in Ophiomyces Lyman, 1869, where it may be caused by the absence of the radial shields. See character 35 and Fig. $1 \mathrm{~A}-\mathrm{C}$.

\section{Integument}

This is the skin of the whole animal, but in this study, only integument characters of the disc (thick or thin skin) are used. Thick skin is defined by the thickened epidermis and may be compared with thin skin in cross-sectional slides. For practical reasons, if the skin is transparent enough for the plates/scales to 
be visible in a stereo microscope, we use the term 'thin'. If the plates are obscured, the skin is 'thick'. Granules can be present on both thick and thin skin. Hence, the integument can be described in terms of whether the skin is obscuring the plates (RS, PP, k-plate) or not. See character 36 and Fig. 1D-F.

Scales (thick/thin)

Thin scales are translucent, while thick scales are opaque and often raised. Scales may bear spines/granules or may have tubercles growing out of them. See Fig. 1E-F.

Dorsal disc (granules, tubercles, spines, scales, plates)

Spines and granules are articulating structures on top of the plates/scales, and can be removed mechanically. 'Tubercles' are outgrowths of the stereom (non-articulating) and thus part of the scales and plates and can be either macroscopic or microscopic. Generally, we distinguish between macroscopic tubercles that are visible at low magnification, whereas a tuberculous stereom structure is visible at high magnification or by SEM and after removal of the skin (e.g., by bleaching or enzyme treatment). The term 'plates' is applied to various ossicles that have a fixed (predictable) position; on the disc, these are the primary plates and radial shields, as well as the k-plate (when present), which separates a pair of radial shields proximally. Other plate-like ossicles are termed 'scales', and these do not have a fixed position. Radial shields often differ in covering (with granules/spines) from the rest of the disc and therefore, we apply 'covering of radial shields' as separate characters. See characters 37-45 and Fig. 2A-B, D.

\section{Ventral disc}

The ventral disc can have spines, granules or none. We created another character for the presence/absence of scales, since their distribution on ventral interradii varies, from covering the whole area of an interradius

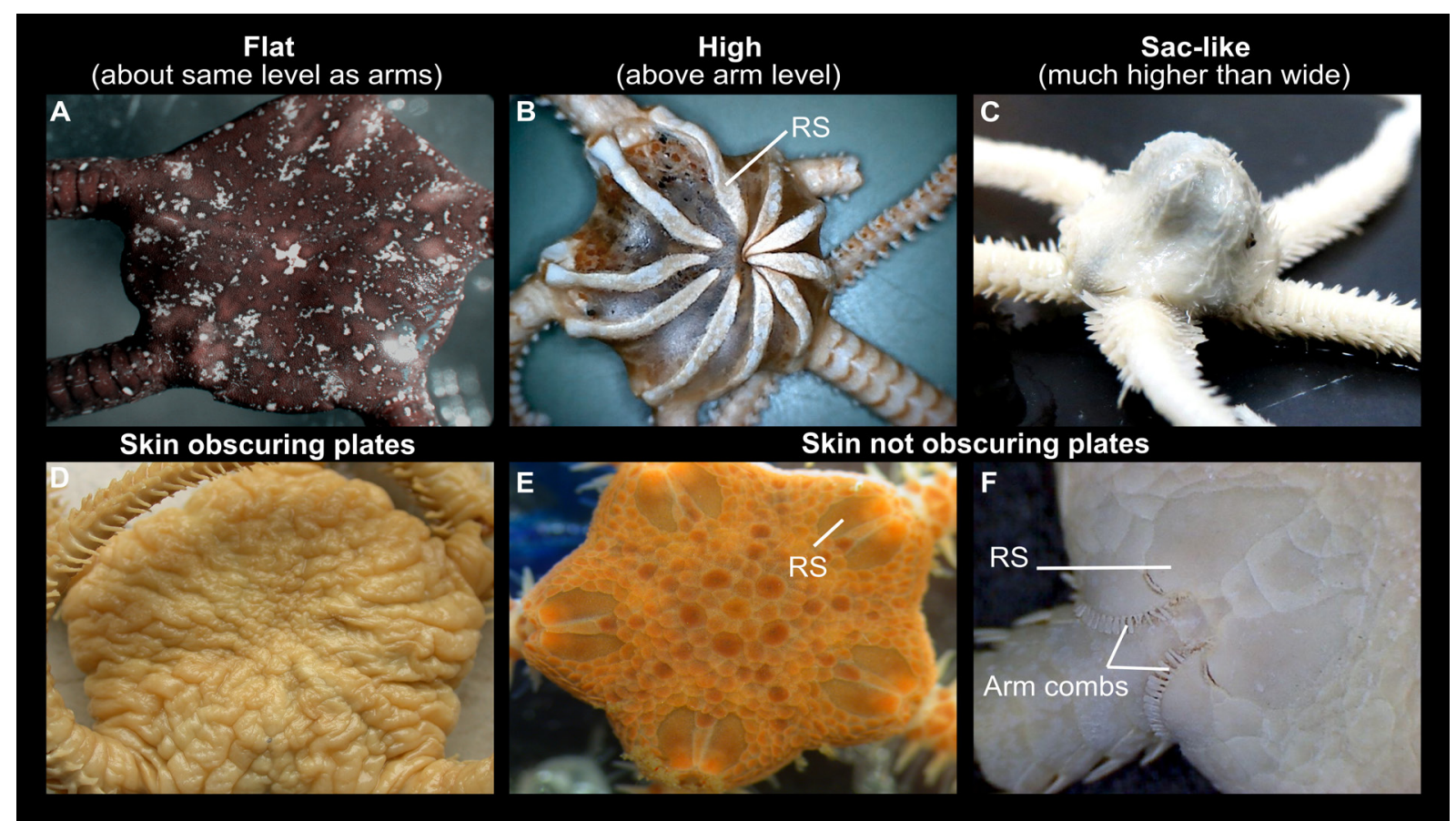

Fig. 1. Dorsal disc shapes and radial shields in brittle stars as defined for the purpose of this study. A. Flat (Ophioderma sp.). B. High, with bar-like radial shields (Asteronyx loveni Müller \& Troschel, 1842 (dry specimen)). C. Sac-like, radial shields absent (Ophiotholia spathifer (Lyman, 1879)). D. Thick skin obscuring scales and plates (Ophiosparte gigas Koehler, 1922). E. Flat, radial shield scalene triangular to half circle (Amphiura chiajei Forbes, 1843). F. Arm combs, radial shields isosceles triangular to pearshaped (Ophiura ophiura (Linnaeus, 1758)). 
to half/less than half or none. To estimate the size of the scales, we considered the interradius as a triangle and counted the scales on the $\mathrm{H}$ line of the triangle. The state 'few scales with whole coverage' implies that the size of the scales is greater than with 'many scales and whole/half coverage'. See characters 47-49 and Fig. 2C.

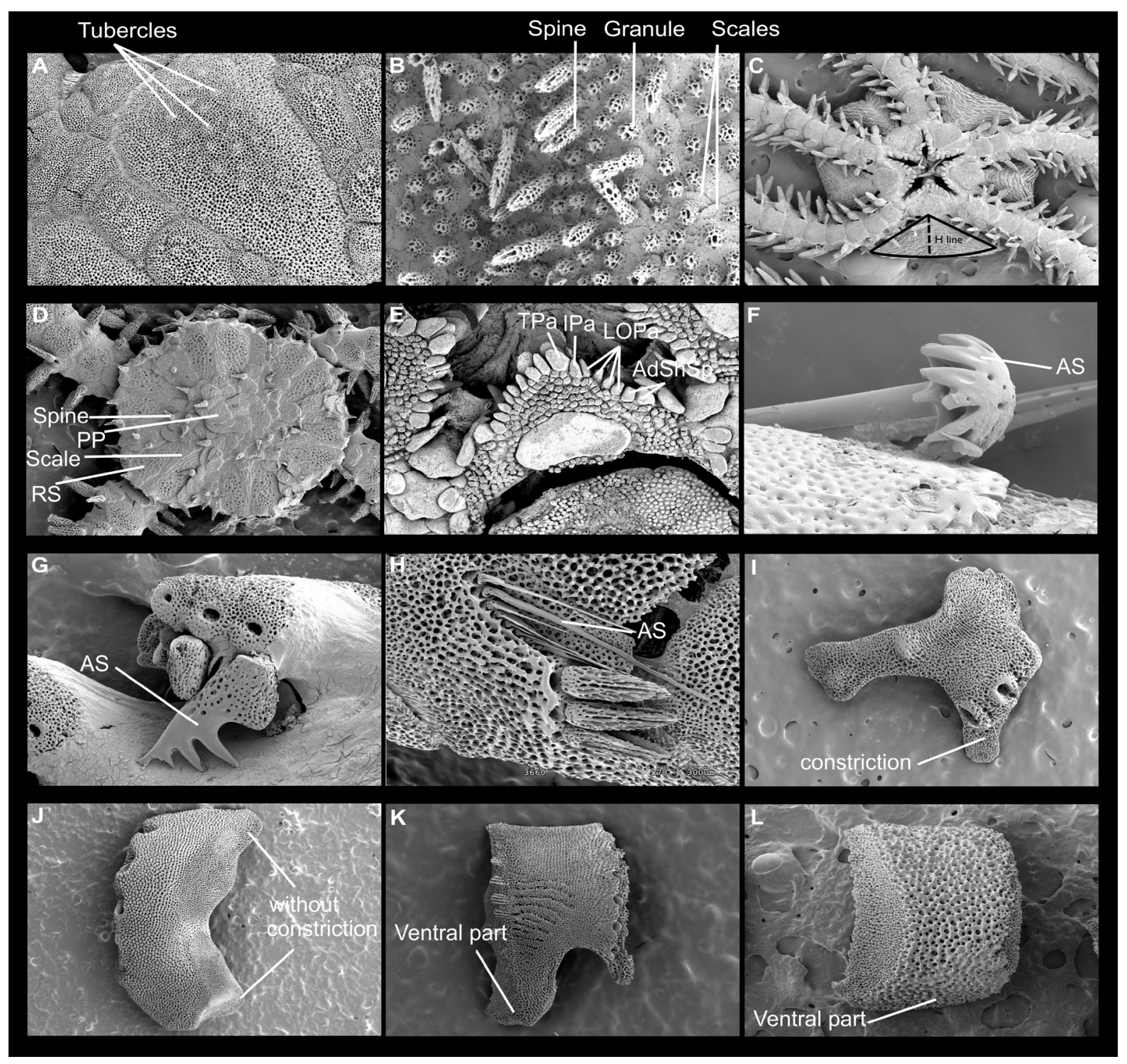

Fig. 2. SEM images of various brittle star ossicles. A-E. Disc structures. A. Dorsal disc, radial shield with tubercles (Ophiomusa lymani (Wyville-Thomson, 1873)). B. Dorsal disc (Ophiolimna bairdi (Lyman, 1883)). C. Ventral disc (Ophionereis porrecta Lyman, 1860), the interradius is assumed as a triangle and $\mathrm{H}$ gives its height. D. Dorsal disc, triangular radial shield (Ophiactis savignyi (Müller \& Troschel, 1842)). E. Ventral disc, mouth (Ophioderma sp.). - F-H. Atypical arm spines. F. Umbrella-shaped arm spine (Ophiotholia spathifer (Lyman, 1879)). G. Hook-shaped arm spine (Asteronyx loveni Müller \& Troschel, 1842). H. Bristle spines (Ophiernus vallincola Lyman, 1878). - I-L. Lateral arm plates (LAP). I. LAP with constriction (Ophioscolex glacialis Müller \& Troschel, 1842). J. Dorsal and ventral part of LAP without constriction (Ophiura ophiura (Linneaus, 1758)). K. Ventral part of LAP projecting ventro-proximalwards (Ophiopallas paradoxa Koehler, 1904). L. Ventral part of LAP not projecting ventro-proximalwards (Ophiosphalma fimbriatum (Koehler, 1922)). 
Oral papillae sensu lato (according to Hendler 2018)

One angle of the oral frame includes a dental plate (DP), two oral plates (= half-jaws) (OP), two adoral shields (AdSh), and one oral shield (OSh), positioned from proximal towards distal. The terminology for the articulated ossicles situated at the jaws has been clarified by Hendler (2018). Oral papillae sensu lato are small ossicles (papilliform, or spiniform) attached to the edges of the plates (DP, OP, AdSh, VAP-1, and vCtP) around the ophiuroid oral frame. We used the following papillae in the key. Those on the DP (described below) include teeth and tooth papillae. Infradental papillae are only the pair that develops later than others on the DP/OP joint and ultimately articulate with the OP, then move under the ventralmost tooth (situated on the most ventral part of the DP). Secondary infradental papillae (2IPas) appear close to the DP/OP joint. Each new ossicle arises proximal to its predecessor on the OP in the same direction. The adoral shield spine (AdShSp) is mainly positioned on the adoral shield (AdSh). However, the position of the AdShSp can vary during ontogenesis. It may remain on the AdSh (as in Ophioderma rubicundum Lütken, 1856), overlap the AdSh and the OP (as in Ophiolepis paucispina (Say, 1825)), or articulate with the OP (as in Ophionereis olivacea H.L. Clark, 1900). The secondary adoral shield spine (2AdShSp) is homologous with the AdShSp, and both are situated next to each other. The buccal scale, which is a plesiomorphy in Ophiuroidea, but might be homologous within several orders (secondarily absent in some taxa), is situated inside the oral slit and next to the oral plate ridge. Lateral oral papillae $(\mathrm{LOPa})$ are all remaining ossicles not named above that develop on the OP distal to the IPa (Hendler 2018). See characters 50-58 and Figs 2E, 4.

\section{Dental plate}

The dental plate sits vertically inside the mouth, covering the proximal edges of two oral plates (halfjaws). We refer to the end closest to the upper/aboral disc as dorsal and the end at the mouth opening, situated below the teeth, as ventral. Since the terms aboral (away from the mouth) and oral (close to the mouth) may be less precise when talking about the mouthparts, ventral/dorsal have been preferred by numerous previous authors, e.g., Hendler (2018) and O'Hara et al. (2018), and could be considered the standard terminology in ophiuroid morphology. Dental sockets on the DP are either a depression or a perforation that may be with/without a septum. A foramen (pl. foramina) is a hole perforating the socket on the DP, and a perforation is a smaller hole than a foramen. Perforating holes are divided into two types, one with distinct borders and the other with indistinct borders (e.g., Ophiolepis superba H.L. Clark, 1915 and Ophiactis savignyi (Müller \& Troschel, 1842), respectively). The geometry of the DP (entire/fragmented) varies from equal width all over to ventral or dorsal half widest. To infer the size of dental sockets, we estimated whether their height is less than $50 \%$ of their width, equal or wider. Another character to describe the DP is the ratio of teeth to tooth papillae on the DP, i.e., whether there is only a single column of teeth, or with a single column on half of the DP and the other half with tooth papillae (e.g., Ophiotrichidae Ljungman, 1867, Ophiopholidae O'Hara, Stöhr, Hugall, Thuy \& Martynov, 2018), or with a single column on $2 / 3$ of the DP and tooth papillae on $1 / 3$ of the DP (e.g., Ophiuridae Müller \& Troschel, 1840), or covering the entire DP with teeth or tooth papillae evenly (e.g., Gorgonocephalidae Ljungman, 1867). See characters $68-74$ and Fig. 3F-I.

\section{Arm spine shape}

Considering the 'tip' and 'cross-section' shape, as well as the 'ratio of distal $1 / 3$ of an arm spine to the maximum proximal thickness' (in a given cross-sectional plane), four states are defined for this study (Fig. 5). Tapering/conical (distally less than half as thick as proximal diameter with round cross-section and tapering tip); flat (distally half as thick as proximal diameter or same with oval cross-section); cylindrical (same thickness at both ends with flat/round tip); pointed (distally half to equally as thick as proximal diameter with round cross-section and pointed tip). See characters 12-17 and Fig. 5.

\section{Tentacle scales}

TSc develop later than arm spines and are situated next to the tube foot (= tentacle) pore, often at the LAP, sometimes on the VAP or both. The spines have visible articulations on the LAP, while the TSc has 
no articulation (except in Ophiomyces). The pores may be visible along the arm or only on the proximal part (e.g., in Ophiomusa Hertz, 1927 only the first two are visible, while in Ophiosphalma H.L. Clark, 1941 the pores are visible on more than two proximal segments, and in most other genera they are present along the entire arm). We also described the tentacle scale length (compared with the nearest spine) and shape (comparing the length with TSc width) accompanied by the oval/round estimated cross-section. See characters $18-22$.

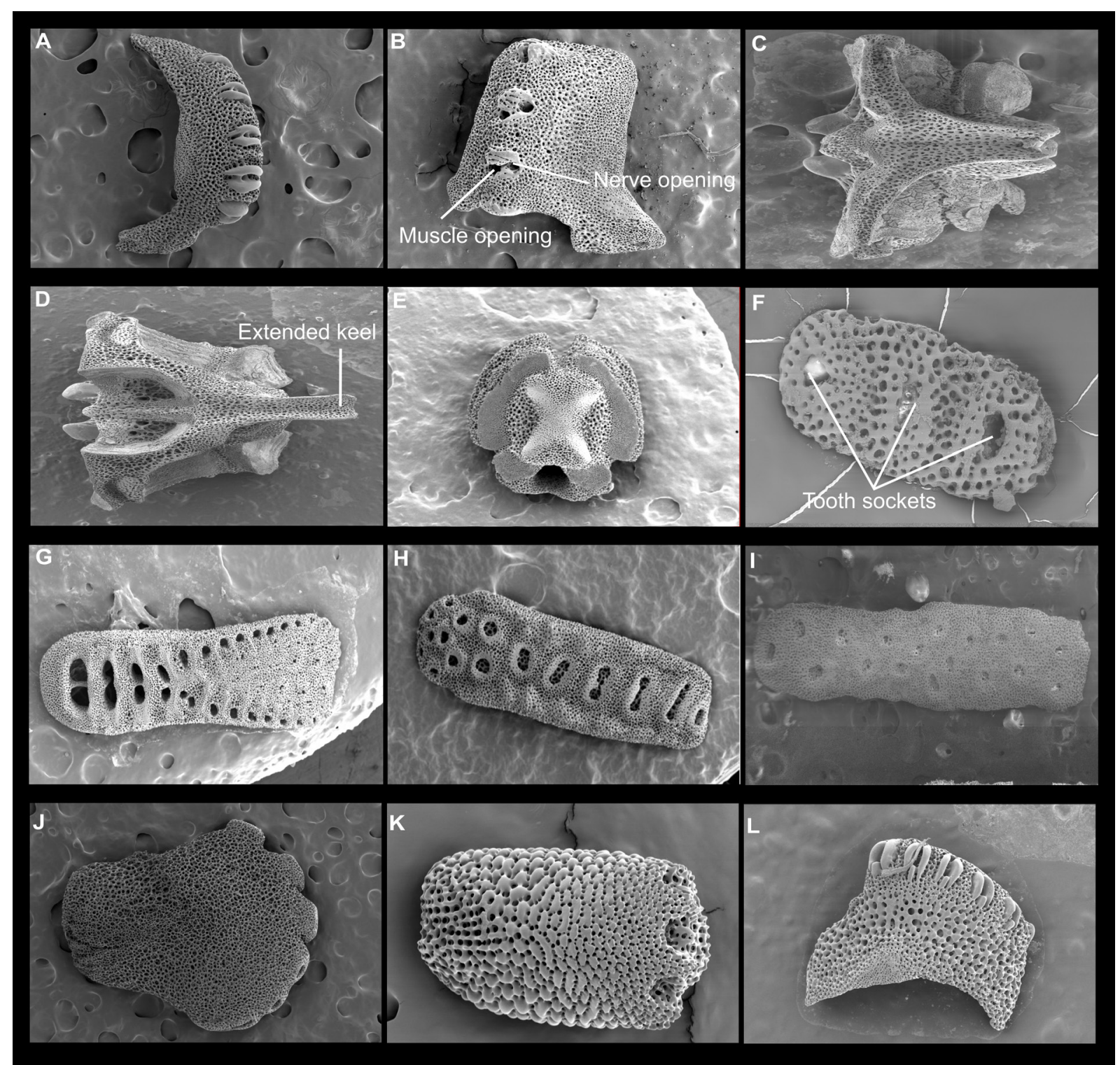

Fig. 3. SEM images of various ossicle structures in brittle stars. A. Muscle and nerve opening on LAP separated by small ridge if at all (Amphiura chiajei Forbes, 1843). B. Muscle and nerve opening on LAP separated by large, prominent ridge or regular stereom (Ophiolycus purpureus (Düben \& Koren, 1846)). C. Non-keeled vertebra (Amphiura chiajei). D. Keeled vertebra (Ophiothrix fragilis Abildgaard, 1789). E. Vertebra with oral bridge (Euryale aspera Lamarck, 1816). F. Sockets indicate teeth and tooth papillae on dental plate as single row (Amphilepis norvegica (Ljungman, 1865)). G. $1 / 2$ single row of teeth and $1 / 2$ tooth papillae (Ophiothrix fragilis). H. $2 / 3$ single row of teeth and $1 / 3$ tooth papillae (Ophiocamax vitrea Lyman, 1878). I. Sockets on dental plate covering evenly (Asteronyx loveni Müller \& Troschel, 1842). $\mathbf{J}-\mathbf{K}$. LAP not arched $=$ position lateral. L. LAP arched $=$ wrapped around the arm. 


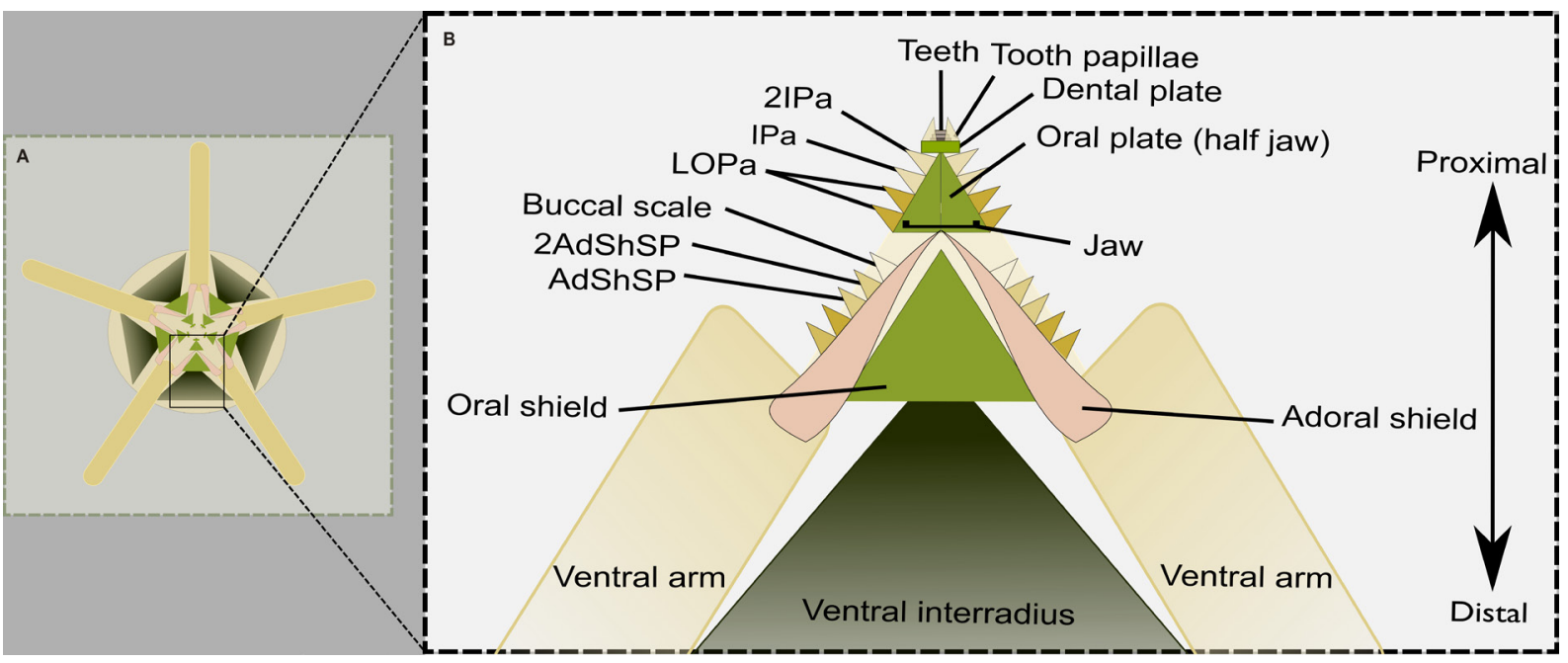

Fig. 4. Oral papillae sensu lato. A. Ventral side of a schematic brittle star. B. One angle of the oral frame includes a dental plate (DP), two oral plates (= half-jaws) (OP), two adoral shields (AdSh), and one oral shield (OSh), positioned from proximal towards distal. The typical position of teeth, tooth papillae, secondary infradental papillae (2IPa), infradental papillae (IPa), buccal scale, secondary adoral shield spine (2AdShSp), adoral shield spine (AdShSp) on DP, OP and AdSh are illustrated, respectively. The presence/absence, number and shape of each papilla vary among different taxa.

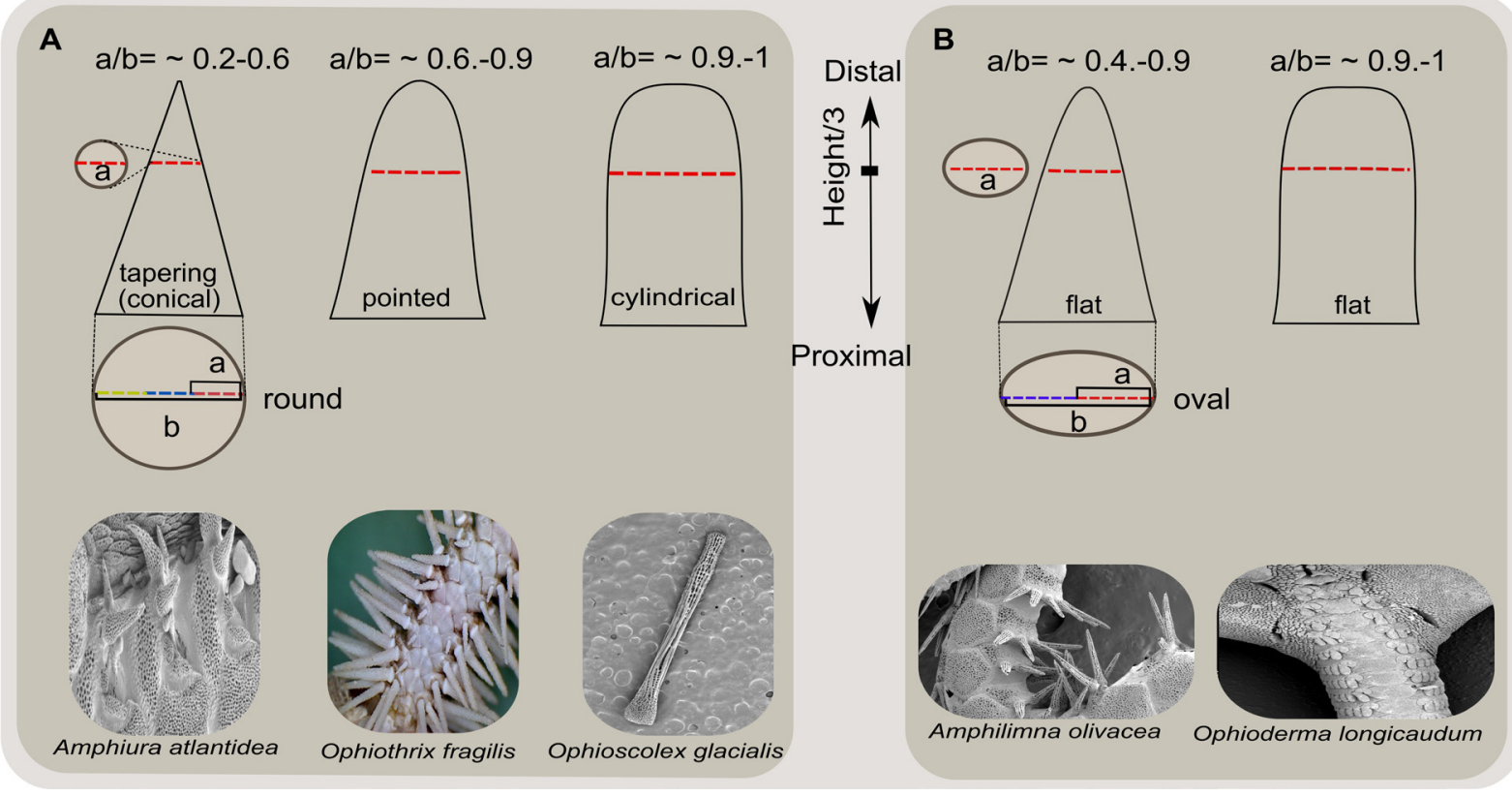

Fig. 5. Typical arm spine shape. A. Tapering (conical): distally $1 / 3$ as thick as proximal diameter with a round cross-section; Pointed: distally half as thick as proximal diameter with a round cross-section; Cylindrical: same thickness at both ends with flat/round tip. B. Flat: distally half as thick as proximal diameter with oval cross-section. Red dashed lines show the $1 / 3$ distal cross-section. The letters ' $a$ ' and ' $b$ ' illustrate the diameter of $1 / 3$ distal and basal cross-sections, respectively. ' $a / b$ ' shows the approximate ratio of these diameters. 


\section{Keel}

A keel is a longitudinal, median and often raised structure on the dorso-distal part of the vertebrae. The vertebral keel was originally introduced by LeClair (1996) as the structure projecting distally from the dorsal groove of the vertebrae, extending beyond the length of the articulating structures and matched by a large depression (socket) on the proximal face of the adjacent vertebra. It is only found in Ophiotrichidae, Ophionereididae Ljungman, 1867 and Ophiopholidae. This definition was applied by most later authors (LeClair \& LaBarbera 1997; O'Hara et al. 2018;), whereas Martynov et al. (2015) used a broader definition, including short structures protruding from the dorso-distal part of the vertebrae in Ophiacanthidae Ljungman, 1867 and forming an arrow-shaped structure, but not extending beyond the articulating structures and not matched by a proximal deep socket. The latter broader definition reduces the taxonomic value of the keel and is rejected here. To avoid misunderstandings, we modified the term to 'extended keel', meaning the original definition of a long distal process with matching proximal socket. See character 76 and Fig. 3C-D.

\section{Results}

This study resulted in traditional and interactive keys for the families of Ophiuroidea, based on the classification proposed by O'Hara et al. (2018) and the examined species listed in Table 1. The key is based on a limited number of species and only on adult specimens, which may limit its usefulness for other species and juvenile stages. Although we assigned highest and lowest weight to the same characters in DELTA and Xper, the resulting keys were different. Giving lower scores to some characters increased the length of the conventional key on both platforms. The interactive keys are available as a DELTA file package (https://zenodo.org/record/4563203) and as an Xper3 online application (http://xper3.fr/xper3GeneratedFiles/publish/identification/7495441984259574364/). Below we present the conventional key created by DELTA. In Appendix 2, a condensed tabular key is available; its full text version is provided as Supp. file 1. The full character and item matrix (tabular key) is provided as Supp. file 2. The conventional key produced by Xper 3 is available as Supp. file 3. A comparison of both software programs and their features is provided in Supp. file 4.

Below, all 33 families are described as we understand them by the examined species. The descriptions were generated with the aid of DELTA Intkey (Dallwitz et al. 2000) and edited manually.

\section{Interactive Key in DELTA format}

We recommend the usage of the CSIRO version of DELTA Intkey for better performance and compatibility. When the interactive key is running, the characters are listed on the left (it is also possible to ask the software to show all or the best characters to separate the taxa). In addition, on the upper right, all taxa, and on the lower half, only eliminated ones are shown (Fig. 6). By clicking on a character, the states will be shown to choose from and images can be requested to distinguish the states precisely. After selecting the states, the software eliminates some taxa. The remaining taxa are then shown in the upper right half of the window. The user can continue the identification process based on the characters that are possible to observe on the specimen and narrow the identification until one taxon remains. Moreover, characters can be used in any sequence. Some family characters may not be present or ambiguous in some species. Therefore, it is possible to skip ahead, facilitating faster identification. 


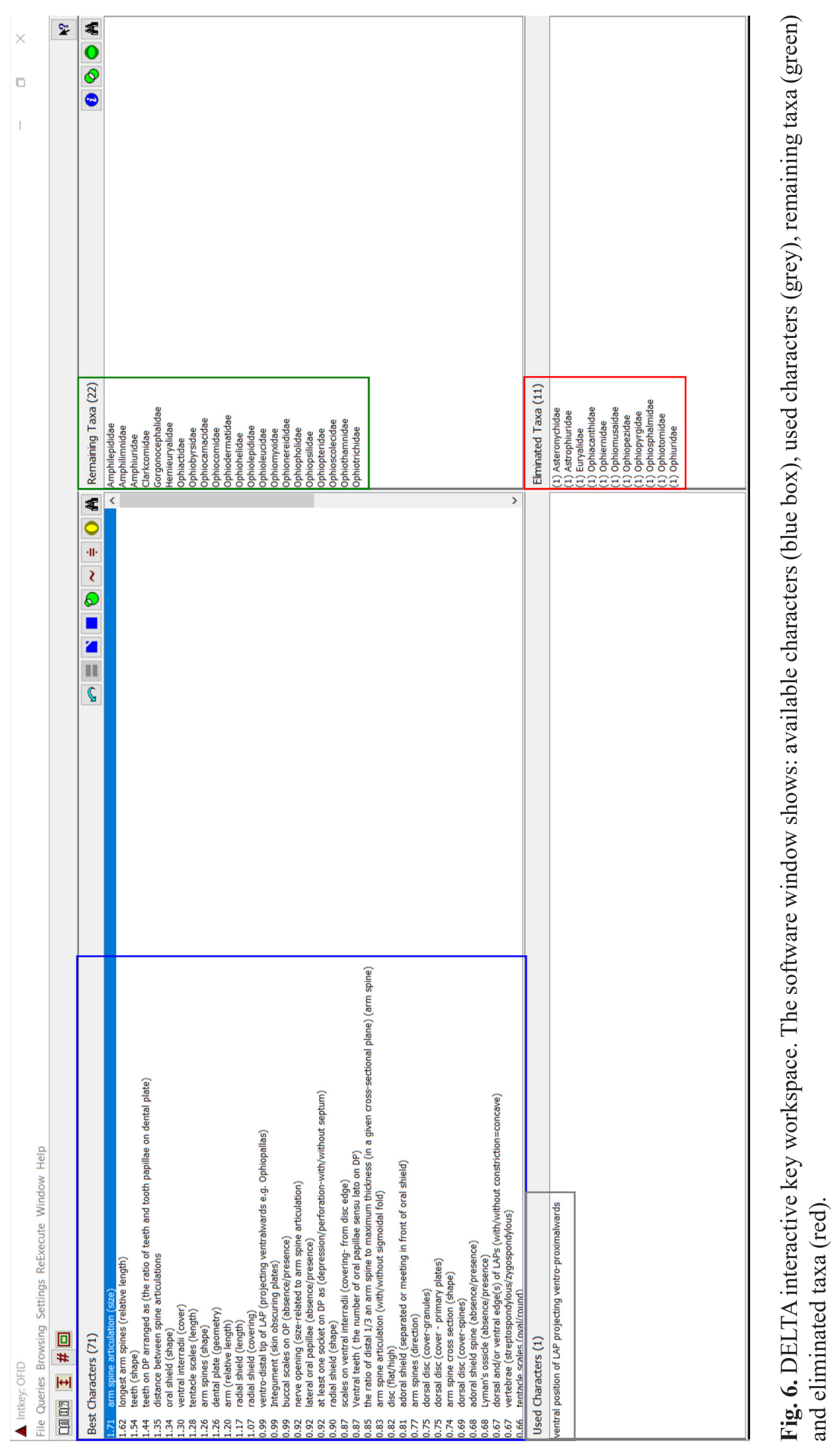




\section{Conventional identification key to the families of the Ophiuroidea with respect to the species listed in Table 1}

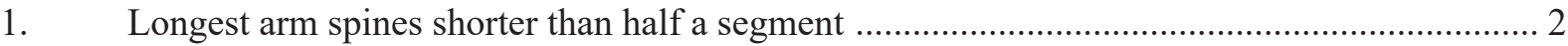

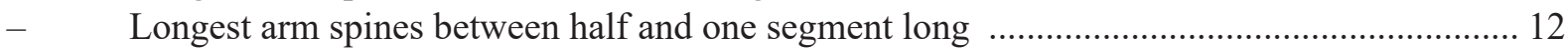

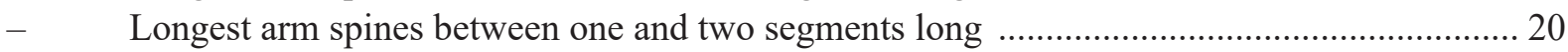

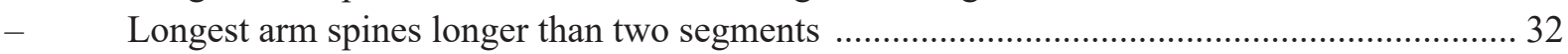

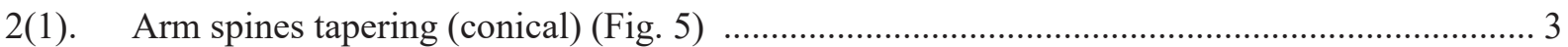

- $\quad$ Arm spines flat (Fig. 5) …………………………... Ophiodermatidae Ljungman, 1867 [p. 34]

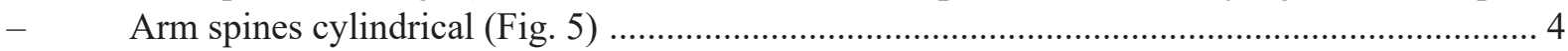

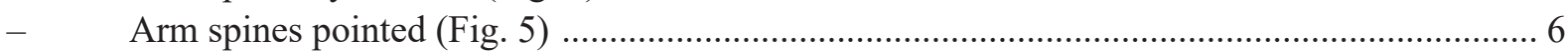

3(2). Arm combs present (Fig. 1F); dorsal arm plate present; spines all similar in shape (Fig. 5); arm spines mainly lateral Ophiopyrgidae Perrier, 1893 [p. 25] Arm combs absent; dorsal arm plate absent; spines not all similar in shape (Fig. 2F-H); arm spines at proximal segments only on ventral side of arms .....Asteronychidae Ljungman, 1867 [p. 19]

4(2). Radial shield scalene (oblique) triangular (Fig. 1E) .........Astrophiuridae Sladen, 1879 [p. 24] Radial shield isosceles (mirror-symmetric) triangular to pear-shaped (Fig. 1F) ..................... 5 Radial shield bar-like (Fig. 1B) Euryalidae Gray, 1840 [p. 20]

5(4). Arm combs present (Fig. 1F); arm spines mainly lateral; tentacle scales more than two times as long as wide; dorsal disc scale/plate without tubercles (Fig. 2B-D)

Ophiopyrgidae Perrier, 1893 [p. 25]

Arm combs absent; arm spines at proximal segments only on ventral side of arms; tentacle scales nearly as long as wide; dorsal disc scale/plate with tubercles (Fig. 2A)

Hemieuryalidae Verrill, 1899 [p. 40]

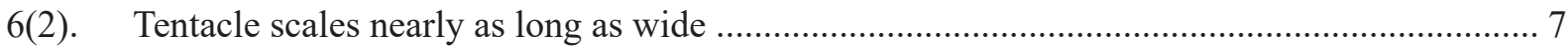

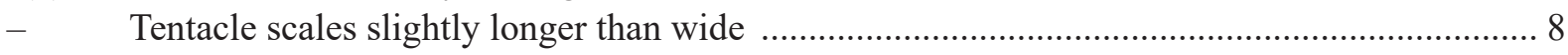

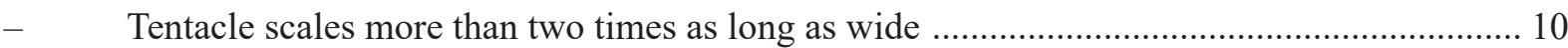

7(6). Tentacle scales shorter than the spine nearby; tentacle scales cross section round; disc pentagonal; dorsal disc with spines (Fig. 2B-D) Ophiosphalmidae O'Hara et al., 2018 [p. 22] Tentacle scales as long as the spine nearby; tentacle scales cross section oval; disc circular; dorsal disc without spines (Fig. 1A-B, D-F) Astrophiuridae Sladen, 1879 [p. 24]

8(6). Accessory dorsal arm plate present; dorsal disc with obvious primary plates (Fig. 2D); adoral shield meeting in front of the oral shield; distance between spine articulations dorsalwards increasing ...... Ophiolepididae Ljungman, 1867 [p. 39] Accessory dorsal arm plate absent; dorsal disc with concealed primary plates (Fig. 1A-D); adoral shield separated (Fig. 4); distance between spine articulations equal

9(8). Arm spines predominantly parallel to arm axis (adpressed); integument obscuring plates (Fig. 1D); dorsal disc without scales; dorsal disc with spines (Fig 2B, D)

Ophiopezidae O'Hara et al., 2018 [p. 35]

- Arm spines predominantly erect, standing perpendicular to arm axis; integument not obscuring plates (Fig. 1E-F); dorsal disc with scales (Fig. 2B, D); dorsal disc without spines (Fig.1A-B, D-F)

Ophiomyxidae Ljungman, 1867 [p. 36] 
10(6). Arm combs present (Fig. 1F); disc circular; genital papillae present; distance between spine articulations dorsalwards increasing. Ophiopyrgidae Perrier, 1893 [p. 25]

- $\quad$ Arm combs absent; disc pentagonal; genital papillae absent; distance between spine articulations equal

11(10). Arm spines predominantly parallel to arm axis (adpressed); tentacle scales longer than the spine nearby; tentacle pores visible only on proximal arm; dorsal disc with obvious primary plates (Fig. 2D)

Ophiomusaidae O'Hara et al., 2018[p. 23]

- $\quad$ Arm spines predominantly erect, standing perpendicular to arm axis; tentacle scales shorter than the spine nearby; tentacle pores visible along most of the arm; dorsal disc with concealed primary plates (Fig. 1B-D)

Ophiomyxidae Ljungman, 1867 [p. 36]

12(1). Arm spines predominantly parallel to arm axis (adpressed) 13

- $\quad$ Arm spines predominantly erect, standing perpendicular to arm axis 16

13(12). Tentacle scales nearly as long as wide

- $\quad$ Tentacle scales slightly longer than wide

- $\quad$ Tentacle scales more than two times as long as wide Ophiopyrgidae Perrier, 1893 [p. 25]

14(13). Arm spines cylindrical (Fig. 5); radial shield isosceles (mirror-symmetric) triangular to pearshaped (Fig. 1F); the ratio of thickness of distal $1 / 3$ of arm spine to maximum thickness (in a given cross-sectional plane) 0.9-1 (Fig. 5); arm spines at proximal segments only on ventral side of arms

Hemieuryalidae Verrill, 1899 [p. 40]

- $\quad$ Arm spines pointed (Fig. 5); radial shield scalene (oblique) triangular (Fig. 1F); the ratio of thickness of distal $1 / 3$ of arm spine to maximum thickness (in a given cross-sectional plane) 0.6-0.9 (Fig. 5); arm spines mainly lateral

Ophioleucidae Matsumoto, 1915 [p. 38]

15(13). Arm combs present (Fig. 1F); spines all similar in shape; arm spine cross section round (Fig. 5); integument not obscuring plates (Fig. 1E-F) ...... Ophiuridae Müller \& Troschel, 1840 [p. 24] Arm combs absent; spines not all similar in shape (Fig. 2F-H); arm spine cross section oval (Fig. 5); integument obscuring plates (Fig. 1D) ......... Ophiernidae O’Hara et al., 2018 [p. 37]

16(12). Integument not obscuring plates (Fig. 1E-F); nerve opening approximately as large as muscle opening

Integument obscuring plates (Fig. 1D); nerve opening smaller than muscle opening …........ 18

17(16). Tentacle scales nearly as long as wide; radial shield length between one third and half of the disc radius; arm spine articulation ventralwards increasing in size

Amphiuridae Ljungman, 1867 [p. 44]

- $\quad$ Tentacle scales slightly longer than wide; radial shield length more than half of the disc radius; arm spine articulation larger in middle of arm

Ophiactidae Matsumoto, 1915 [p. 46]

18(16). Arm covering without granules/spines/tubercles; arm spine cross section round (Fig. 5); arm spines mainly lateral; genital slit longer than half the length of an interradius

- $\quad$ Arm covering with granules; arm spine cross section oval (Fig. 5); arm spines at proximal segments only on ventral side of arms; genital slit shorter than half the length of an interradius

Gorgonocephalidae Ljungman, 1867 [p. 21]

19(18). Tentacle scales present; dorsal disc with scales (Fig. 2B, D); radial shield without granules/spines (Fig. 1B); ventral teeth single (Fig. 4)

Ophionereididae Ljungman, 1867 [p. 42] Tentacle scales absent; dorsal disc without scales; radial shield with granules (Fig. 1A); ventral teeth several (tooth papillae) (Fig. 4)

Ophiobyrsidae Matsumoto, 1915 [p. 29] 


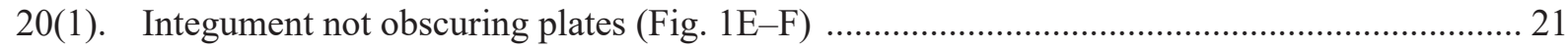

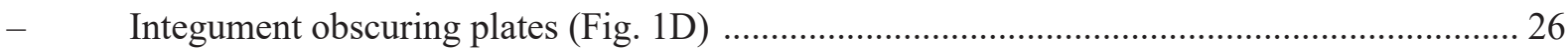

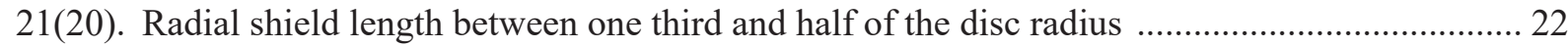

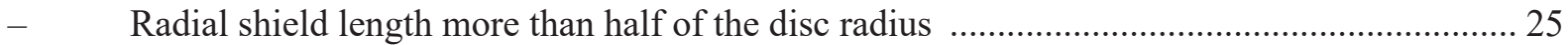

22(21). Arm combs present (Fig. 1F); arm spines predominantly parallel to arm axis (adpressed); tentacle scales slightly longer than wide; ventral teeth several (tooth papillae) (Fig. 4)

Ophiuridae Müller \& Troschel, 1840 [p. 24]

- $\quad$ Arm combs absent; arm spines predominantly erect, standing perpendicular to arm axis; tentacle scales nearly as long as wide; ventral teeth single (Fig. 4)

23(22). Accessory dorsal arm plate present; accessory ventral arm plate present; spines not all similar in shape (Fig. 2F-H); dorsal and/or ventral edge(s) of LAPs with constriction (Fig. 2I)

Ophiopholidae O'Hara et al., 2018 [p. 47]

- $\quad$ Accessory dorsal arm plate absent; accessory ventral arm plate absent; spines all similar in shape; dorsal and/or ventral edge(s) of LAPs without constriction (Fig. 2J)

24(23). The number of scales on $\mathrm{H}$ line (Fig. 2C) of an interradius about 7-14; arm spine articulation larger in middle of arm; dental plate ventral half widest; dental sockets less than $50 \%$ of the width

Ophiothamnidae O'Hara et al., 2018 [p. 46]

- The number of scales on $\mathrm{H}$ line (Fig. 2C) of an interradius about 14-21; arm spine articulation ventralwards increasing in size; dental plate dorsal half widest; dental sockets equal to or more than $50 \%$ of the width

Amphiuridae Ljungman, 1867 [p. 44]

25(21). Tentacle scales present; dorsal disc with spines (Fig. 2B, D); arm spine articulation larger in middle of arm; nerve opening approximately as large as muscle opening

Ophiactidae Matsumoto, 1915 [p. 46]

- Tentacle scales absent; dorsal disc without spines (Fig. 1A-B, D-F); arm spine articulation ventralwards increasing in size; nerve opening smaller than muscle opening

Amphilepididae Matsumoto, 1915 [p. 45]

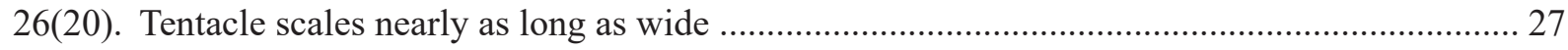

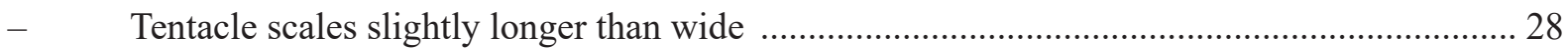

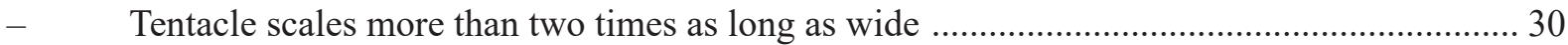

27(26). Arm spines flat; the number of scales on H line (Fig. 2C) of an interradius more than 21; arm spine cross section oval (Fig. 5); ventral teeth several (tooth papillae) (Fig. 4)

Ophiotomidae Paterson, 1985 [p. 30]

- $\quad$ Arm spines pointed (Fig. 5); the number of scales on H line (Fig. 2C) of an interradius about 7-14; arm spine cross section round (Fig. 5); ventral teeth single (Fig. 4)

Ophiacanthidae Ljungman, 1867 [p. 33]

28(26). Arm spines predominantly parallel to arm axis (adpressed); radial shield absent (Fig. 1C); ventral interradii with spines; ventro-distal tip of LAP projecting ventralwards (Fig. 2K)

Ophiohelidae Perrier, 1893 [p. 27]

- $\quad$ Arm spines predominantly erect, standing perpendicular to arm axis; radial shield present; ventral interradii with granules; ventro-distal tip of LAP not projecting ventralwards (Fig. 2L) ....... 29 
29(28). Radial shield scalene (oblique) triangular; the number of scales on H line (Fig. 2C) of an interradius more than 21; arm spine cross section oval (Fig. 5); radial shield with granules ......

..Ophiotomidae Paterson, 1985 [p. 30]

Radial shield isosceles (mirror-symmetric) triangular to pear-shaped (Fig. 1F); the number of scales on $\mathrm{H}$ line (Fig. 2C) of an interradius about 14-21; arm spine cross section round (Fig. 5); radial shield without granules/spines (Fig. 1B) ....... Ophionereididae Ljungman, 1867 [p. 42]

30(26). Tentacle scales shorter than the spine nearby; the number of scales on $\mathrm{H}$ line (Fig. 2C) of an interradius about 14-21; oral shield covering less than one third of interradius; at least one socket on DP as depression or perforation without septum ………................................................. 31

- $\quad$ Tentacle scales longer than the spine nearby; the number of scales on H line (Fig. 2C) of an interradius more than 21; oral shield covering more than one third of the length of an interradius; at least one socket on DP as perforation with septum

Ophiopsilidae Matsumoto, 1915 [p. 43]

31(30). Arm spine cross section round (Fig. 5); tentacle scales cross section oval; radial shield absent (Fig. 1C); ventral interradii without granules/spines ....Ophioscolecidae Lütken, 1869 [p. 28] Arm spine cross section oval (Fig. 5); tentacle scales cross section round; radial shield present (Fig. 1C); ventral interradii with spines .Amphilimnidae O’Hara et al., 2018 [p. 41]

32(1). Radial shield length less than one third of the disc radius ................................................... 33

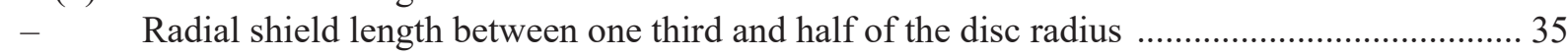

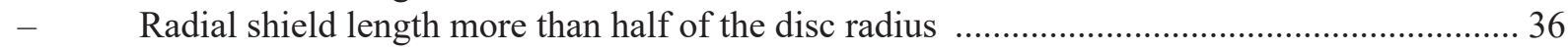

33(32). Radial shield scalene (oblique) triangular (Fig. 1E); arm spine cross section oval (Fig. 5); integument obscuring plates (Fig. 1D); radial shield with granules (Fig. 1A) ....................... 34

- $\quad$ Radial shield isosceles (mirror-symmetric) triangular to pear-shaped (Fig. 1F); arm spine cross section round (Fig. 5); integument not obscuring plates (Fig. 1E-F); radial shield without granules/spines (Fig. 1B) ........................................ Ophiomyxidae Ljungman, 1867 [p. 36]

34(33). Adoral shield separated; ventral position of LAP projecting ventro-proximalwards (Fig. 2K); disc flat (about same level as arms); lateral oral papillae multiple rows of lateral papillae

Ophiocomidae Ljungman, 1867 [p. 36]

- $\quad$ Adoral shield meeting in front of the oral shield; ventral position of LAP not projecting ventroproximalwards (Fig. 2L); disc high (above arm level); lateral oral papillae single row of lateral papillae (Fig. 2E)

..Ophiotomidae Paterson, 1985 [p. 30]

35(32). Arm covering without granules/spines/tubercles; arm spines pointed (Fig. 5); tentacle scales nearly as long as wide; integument obscuring plates (Fig. 1D)

Ophiacanthidae Ljungman, 1867 [p. 33]

- $\quad$ Arm covering with tubercles grown out of scales/plates; arm spines cylindrical (Fig. 5); tentacle scales slightly longer than wide; integument not obscuring plates (Fig. 1E-F)

Ophiocamacidae O'Hara et al., 2018 [p. 29]

36(32). Tentacle scales nearly as long as wide

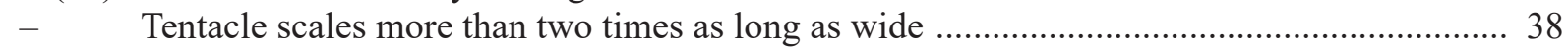

37(36). Accessory ventral arm plate present; tentacle scales cross section round; scales on ventral interradii absent; ventral teeth several (tooth papillae) (Fig. 4)

Ophiopteridae O'Hara et al., 2018 [p. 31]

- $\quad$ Accessory ventral arm plate absent; tentacle scales cross section oval; scales on ventral interradii covering the whole area of an interradius; ventral teeth single (Fig. 4)

Ophiacanthidae Ljungman, 1867 [p. 33] 
38(36). Arm spines flat (Fig. 5); tentacle scales shorter than the spine nearby; arm spine cross section oval (Fig. 5); tentacle scales cross section oval ........Clarkcomidae O'Hara et al., 2018 [p. 32]

- $\quad$ Arm spines pointed (Fig. 5); tentacle scales as long as the spine nearby; arm spine cross section round (Fig. 5); tentacle scales cross section round ..... Ophiotrichidae Ljungman, 1867 [p. 48]

\section{Morphological descriptions of each family with respect to the species listed in Table 1}

In total, there are 33 characters for the arm, 29 for the ventral part of the disc, including the oral frame, 12 for the dorsal disc, and three characters for vertebrae. The language is software generated, slightly human-modified.

Phylum Echinodermata Bruguière, 1791

Subphylum Asterozoa von Zittel, 1895

Class Ophiuroidea Gray, 1840

Subclass Myophiuroidea Matsumoto, 1915

Infraclass Metophiurida Matsumoto, 1913

Superorder Euryophiurida O’Hara, Hugall, Thuy, Stöhr \& Martynov, 2017

Order Euryalida Lamarck, 1816

Type genus

Family Asteronychidae Ljungman, 1867

Asteronyx Müller \& Troschel, 1842

\section{Other genera}

Astrodia Verrill, 1899; Astronebris Downey, 1967; Ophioschiza H.L. Clark, 1911.

\section{Description}

ARM. Arm shape unbranched; length more than $4 \times$ disc diameter; covering without granules/spines/tubercles. Arm combs absent. Dorsal arm plate absent. Accessory dorsal arm plate absent. Ventral arm plate present. Accessory ventral arm plate absent. Girdle of tiny hooks on the arms absent. Spines not all similar in shape (Fig. 2F-H). The atypical spines are hook-shaped (Fig. 2G). Arm spine cross section round. The ratio of thickness of distal $1 / 3$ of arm spine to maximum thickness (in a given cross-sectional plane) 0.2-0.6. Arm spines tapering (conical); at proximal segments only on ventral side of arms; predominantly erect, standing perpendicular to arm axis. Longest arm spines shorter than half a segment. Tentacle scales absent. Position of lateral arm plate (LAP) only lateral (Fig. 3J-K). Dorsal and/or ventral edge(s) of LAPs without constriction. Ventral position of LAP not projecting ventro-proximalwards. Ventro-distal tip of LAP not projecting ventralwards (Fig. 2L). Arm spine articulation without dorsal and ventral lobes; arranged over entire distal LAP edge; all similar. Distance between spine articulations ventralwards increasing. Nerve and muscle openings separated by large, prominent ridge or regular stereom. Nerve opening smaller than muscle opening.

DoRSAL DISC. Disc pentagonal to circular; high (above arm level). Integument obscuring plates. Dorsal disc without granules; with concealed primary plates; without scales (A. loveni Müller \& Troschel, 1842) or a few (O'Hara et al. 2018); without spines. Dorsal disc scale/plate without tubercles. Radial shield present; without granules/spines; length more than half of the disc radius; bar-like.

VENTRAL DISC. Gonads restricted to the disc. Ventral interradii without granules/spines. Scales on ventral interradii absent. Ventral teeth several (tooth papillae). Infradental papillae on oral plate absent. Buccal scales on OP absent. Accessory oral papillae on OP present. Lateral oral papillae on OP absent. Adoral shield spine absent. Lyman's ossicle absent. Oral shield covering less than one third of interradius; about 
as long as wide. Madreporite one; with numerous pores. Adoral shield meeting in front of the oral shield. Abradial genital plate not twisted. Number of genital slits one per bursa. Genital slit shorter than half interradius. Genital papillae absent. Dental plate of equal width all over; entire (single plate). Dental sockets slit-shaped to circular; less than $50 \%$ of the width. At least one socket on DP as depression or perforation without septum. Teeth spine-shaped. Teeth on DP arranged as covering the entire dental plate evenly.

VERTEBRAE. Vertebrae hourglass-shaped (streptospondylous); beyond segment 5 with short keel (Fig. 3C, E); without oral bridge.

Family Euryalidae Gray, 1840

\section{Type genus}

Euryale Lamarck, 1816.

\section{Other genera}

Asteromorpha Lütken, 1869; Asteroschema Örstedt \& Lütken, 1856; Asterostegus Mortensen, 1933; Astrobrachion Döderlein, 1927; Astroceras Lyman, 1879; Astrocharis Koehler, 1904; Ophiocreas Lyman, 1869; Squamophis Okanishi Okanishi, O'Hara \& Fujita, 2011; Sthenocephalus Koehler, 1898; Trichaster Agassiz, 1836.

\section{Description}

ARM. Arm shape branched; length more than $4 \times$ disc diameter; covering with granules. Arm combs absent. Dorsal arm plate absent. Accessory dorsal arm plate absent. Ventral arm plate present or absent. Accessory ventral arm plate absent. Girdle of tiny hooks on the arms absent. Spines not all similar in shape. Atypical arm spines are hook-shaped. Arm spine cross section round. The ratio of thickness of distal $1 / 3$ of arm spine to maximum thickness (in a given cross-sectional plane) $0.9-1$. Arm spines cylindrical; at proximal segments only on ventral side of arms; predominantly erect, standing perpendicular to arm axis. Longest arm spines shorter than half a segment. Tentacle scales present; pores visible along the arm; nearly as long as wide; shorter than the spine nearby; cross section round. Position of lateral arm plate (LAP) only lateral. Dorsal and/or ventral edge(s) of LAPs without constriction (Fig. 2J). Ventral position of LAP not projecting ventro-proximalwards. Ventro-distal tip of LAP not projecting ventralwards. Arm spine articulation without dorsal and ventral lobes; restricted to (the ventral or central) portion of the distal edge; all similar. Distance between spine articulations not applicable (two spine articulation). Nerve and muscle openings separated by large, prominent ridge or regular stereom. Nerve opening approximately as large as muscle opening (Fig. 3A-B).

DoRSAL DISC. Disc pentagonal; flat (about same level as arms). Integument not obscuring plates. Dorsal disc with granules; with concealed primary plates; without scales; without spines. Dorsal disc scale/plate without tubercles. Radial shield present; with tubercles grown out of plate; length more than half of the disc radius; bar-like.

VENTRAL DISC. Gonads not restricted to the disc (extending into the basal portion of the arms) or restricted to the disc (Asteroschema). Ventral interradii without granules/spines. Scales on ventral interradii absent. Ventral teeth single. Infradental papillae on oral plate present. Buccal scales on OP absent. Accessory oral papillae on OP absent. Lateral oral papillae on OP absent. Adoral shield spine absent. Lyman's ossicle absent. Oral shield covering less than one third of interradius; about as long as wide. Madreporite multiple; with one pore, or with numerous pores. Adoral shield meeting in front of the oral shield. Abradial genital plate not twisted. Number of genital slits one per bursa. Genital slit shorter than half interradius. Genital 
papillae absent. Dental plate of equal width all over; fragmented. Dental sockets slit-shaped; equal to or more than $50 \%$ of the width. At least one socket on DP as depression or perforation without septum. Teeth flat (with round or slightly pointed tip, but never spine-like). Teeth on DP arranged as single row.

VERTEBRAE. Vertebrae hourglass-shaped (streptospondylous); beyond segment 5 non-keeled; with oral bridge (Fig. 3E).

Family Gorgonocephalidae Ljungman, 1867

\section{Type genus}

Gorgonocephalus Leach, 1815.

\section{Other genera}

Asteroporpa Örstedt \& Lütken, 1856; Astracme Döderlein, 1927; Astroboa Döderlein, 1911; Astrocaneum Döderlein, 1911; Astrochalcis Koehler, 1905; Astrochele Verrill, 1878; Astrochlamys Koehler, 1912; Astrocladus Verrill, 1899; Astroclon Lyman, 1879; Astrocnida Lyman, 1872; Astrocrius Döderlein, 1927; Astrocyclus Döderlein, 1911; Astrodendrum Döderlein, 1911; Astrodictyum Döderlein, 1927; Astroglymma Döderlein, 1927; Astrogomphus Lyman, 1869; Astrogordius Döderlein, 1911; Astrohamma Döderlein, 1930; Astrohelix Döderlein, 1930; Astroniwa McKnight, 2000; Astrophyton Fleming, 1828; Astroplegma Döderlein, 1927; Astrosierra Baker, 1980; Astrospartus Döderlein, 1911; Astrothamnus Matsumoto, 1915; Astrothorax Döderlein, 1911; Astrothrombus H.L. Clark, 1909; Astrotoma Lyman, 1875; Astrozona Döderlein, 1930; Conocladus H.L. Clark, 1909; Ophiocrene Bell, 1894; Ophiozeta Koehler, 1930; Schizostella A.H. Clark, 1952.

\section{Description}

ARM. Arm shape unbranched, or shape branched; length more than $4 \times$ disc diameter; covering with granules. Arm combs absent. Dorsal arm plate present. Accessory dorsal arm plate absent. Ventral arm plate present. Accessory ventral arm plate absent. Girdle of tiny hooks on the arms present (Gorgonocephalus caputmedusae (Linnaeus, 1758)) or absent in some genera. Spines all similar in shape. Arm spine cross section oval. The ratio of thickness of distal $1 / 3$ of arm spine to maximum thickness (in a given crosssectional plane) $0.9-1$. Arm spines flat; at proximal segments only on ventral side of arms; predominantly erect, standing perpendicular to arm axis. Longest arm spines between half and one segment long. Tentacle scales present; pores visible along the arm; slightly longer than wide; shorter than the spine nearby; cross section round. Position of lateral arm plate (LAP) only lateral. Dorsal and/or ventral edge(s) of LAPs without constriction. Ventral position of LAP projecting ventro-proximalwards. Ventro-distal tip of LAP not projecting ventralwards. Arm spine articulation without dorsal and ventral lobes; restricted to (the ventral or central) portion of the distal edge; all similar. Distance between spine articulations ventralwards increasing. Nerve and muscle openings separated by large, prominent ridge or regular stereom. Nerve opening smaller than muscle opening.

DoRSAL DISC. Disc circular; flat (about same level as arms). Integument obscuring plates. Dorsal disc with granules; with concealed primary plates; with scales; without spines. Dorsal disc scale/plate without tubercles. Radial shield present; with/without granules; length more than half of the disc radius; bar-like.

VENTRAL DISC. Gonads restricted to the disc. Ventral interradii with granules. Scales on ventral interradii absent. Ventral teeth several (tooth papillae). Infradental papillae on oral plate absent. Buccal scales on OP absent. Accessory oral papillae on OP present. Lateral oral papillae on OP absent. Adoral shield spine absent. Lyman's ossicle absent. Oral shield covering less than one third of interradius; much wider than long. Madreporite one; with numerous pores. Adoral shield meeting in front of the oral shield. Abradial 
genital plate not twisted. Number of genital slits one per bursa. Genital slit shorter than half interradius. Genital papillae absent. Dental plate of equal width all over; fragmented. Dental sockets circular; equal to or more than $50 \%$ of the width. At least one socket on DP as depression or perforation without septum. Teeth spine-shaped. Teeth on DP arranged as covering the entire dental plate evenly.

VERTEBRAE. Vertebrae hourglass-shaped (streptospondylous); beyond segment 5 with short keel; without oral bridge.

Order Ophiurida Müller \& Troschel, 1840, restricted sensu O’Hara et al. (2017)

Suborder Ophiomusina O’Hara, Hugall, Thuy, Stöhr \& Martynov, 2017

Family Ophiosphalmidae O’Hara, Stöhr, Hugall, Thuy \& Martynov, 2018

\section{Type genus}

Ophiosphalma H.L. Clark, 1941.

\section{Other genera}

Ophiolipus Lyman, 1878; Ophiomusium Lyman, 1869.

\section{Description}

ARM. Arm shape unbranched; length 3-4× disc diameter; covering with spines distal to the genital slit around the disc margin but without granules/spines/tubercles. Arm combs absent. Dorsal arm plate present. Accessory dorsal arm plate absent. Ventral arm plate present. Accessory ventral arm plate absent. Girdle of tiny hooks on the arms absent. Spines all similar. Arm spine cross section round. The ratio of thickness of distal $1 / 3$ of arm spine to maximum thickness (in a given cross-sectional plane) 0.6-0.9. Arm spines pointed; mainly lateral; predominantly parallel to arm axis (adpressed). Longest arm spines shorter than half a segment. Tentacle scales present; pores visible only on proximal arm; nearly as long as wide; shorter than the spine nearby; cross section round. Position of lateral arm plate (LAP) arched (wrapped around the arm) (Fig. 3L). Dorsal and/or ventral edge(s) of LAPs without constriction. Ventral position of LAP not projecting ventro-proximalwards. Ventro-distal tip of LAP not projecting ventralwards. Arm spine articulation without dorsal and ventral lobes; arranged over entire distal LAP edge; ventralwards increasing in size. Distance between spine articulations dorsalwards increasing. Nerve and muscle openings separated by large, prominent ridge or regular stereom. Nerve opening approximately as large as muscle opening.

DorSAL DISC. Disc pentagonal; flat (about same level as arms). Integument not obscuring plates. Dorsal disc without granules; with obvious primary plates; with scales; without spines. Dorsal disc scale/plate without tubercles. Radial shield present; without granules/spines; length more than half of the disc radius; scalene (oblique) triangular.

VENTRAL DISC. Gonads restricted to the disc. Ventral interradii without granules/spines. Scales on ventral interradii covering the whole area of an interradius. The number of scales on $\mathrm{H}$ line of an interradius fewer than 7. Ventral teeth several (tooth papillae). Infradental papillae on oral plate present. Buccal scales on OP present. Accessory oral papillae on OP absent. Lateral oral papillae on OP absent. Adoral shield spine present. Lyman's ossicle absent. Oral shield covering less than one third of interradius; much longer than wide. Madreporite no data. Adoral shield meeting in front of the oral shield. Abradial genital plate not twisted. Number of genital slits one per bursa. Genital slit longer than half the length of an interradius. Genital papillae present. Dental plate of equal width all over; entire (single plate). Dental sockets slit-shaped; equal to or more than $50 \%$ of the width. At least one socket on DP as depression or 
perforation without septum. Teeth flat (with round or slightly pointed tip, but never spine-like). Teeth on DP arranged as single row.

VERTEBRAE. Vertebrae zygospondylous; beyond segment 5 with short keel; without oral bridge.

Family Ophiomusaidae O’Hara, Stöhr, Hugall, Thuy \& Martynov, 2018

\section{Type genus}

Ophiomusa Hertz, 1927. (No other genera)

\section{Description}

Arm. Arm shape unbranched; length $3 \times$ disc diameter; covering without granules/spines/tubercles. Arm combs absent. Dorsal arm plate present. Accessory dorsal arm plate absent. Ventral arm plate absent or present in some species on a few proximal arm joints only (O'Hara et al. 2018). Accessory ventral arm plate absent. Girdle of tiny hooks on the arms absent. Spines all similar in shape. Arm spine cross section round. The ratio of thickness of distal $1 / 3$ of arm spine to maximum thickness (in a given cross-sectional plane) $0.6-0.9$. Arm spines pointed; mainly lateral; predominantly parallel to arm axis (adpressed). Longest arm spines shorter than half a segment. Tentacle scales present; pores visible only on proximal arm; more than two times as long as wide; longer than the spine nearby; cross section oval. Position of lateral arm plate (LAP) arched (wrapped around the arm). Dorsal and/or ventral edge(s) of LAPs without constriction. Ventral position of LAP not projecting ventro-proximalwards. Ventro-distal tip of LAP not projecting ventralwards. Arm spine articulation without dorsal and ventral lobes; arranged over entire distal LAP edge; all similar. Distance between spine articulations equal. Nerve and muscle openings separated by large, prominent ridge or regular stereom. Nerve opening approximately as large as muscle opening.

DorSAL DISC. Disc pentagonal; high (above arm level). Integument not obscuring plates. Dorsal disc without granules; with obvious primary plates; with scales; without spines. Dorsal disc scale/plate with tubercles. Radial shield present; with tubercles, without granules/spines; length more than half of the disc radius; isosceles (mirror-symmetric) triangular to pear-shaped.

VenTRAL DISC. Gonads restricted to the disc. Ventral interradii without granules/spines. Scales on ventral interradii covering the whole area of an interradius. The number of scales on $\mathrm{H}$ line of an interradius fewer than 7. Ventral teeth single. Infradental papillae on oral plate present. Buccal scales on OP present. Accessory oral papillae on OP absent. Lateral oral papillae on OP absent. Adoral shield spine present. Lyman's ossicle absent. Oral shield covering more than one third of the length of an interradius; much longer than wide. Madreporite no data. Adoral shield meeting in front of the oral shield. Abradial genital plate not twisted. Number of genital slits one per bursa. Genital slit shorter than half interradius. Genital papillae absent. Dental plate dorsal half widest; entire (single plate). Dental sockets slit-shaped and circular; equal to or more than $50 \%$ of the width. At least one socket on DP as depression or perforation without septum. Teeth flat (with round or slightly pointed tip, but never spine-like). Teeth on DP arranged as single row.

VERTEBRAE. Vertebrae zygospondylous; beyond segment 5 with short keel; without oral bridge. 
Suborder Ophiurina Müller \& Troschel, 1840 sensu O'Hara et al. (2017)

Family Astrophiuridae Sladen, 1879

\section{Type genus}

Astrophiura Sladen, 1879.

\section{Other genera}

Ophiomisidium Koehler, 1914; Ophiophycis Koehler, 1901.

\section{Description}

ARM. Arm shape unbranched; length less than $2 \times$ disc diameter; covering without granules/spines/tubercles. Arm combs absent. Dorsal arm plate present. Accessory dorsal arm plate absent. Ventral arm plate present. Accessory ventral arm plate absent. Girdle of tiny hooks on the arms absent. Spines all similar in shape. Arm spine cross section round. The ratio of thickness of distal $1 / 3$ of arm spine to maximum thickness (in a given cross-sectional plane) $0.6-0.9$, or $0.9-1$. Arm spines cylindrical or pointed; mainly lateral; predominantly parallel to arm axis (adpressed). Longest arm spines shorter than half a segment. Tentacle scales present; pores visible only on proximal arm; nearly as long as wide; as long as the spine nearby; cross section oval. Position of lateral arm plate (LAP) only lateral. Dorsal and/or ventral edge(s) of LAPs without constriction. Ventral position of LAP not projecting ventro-proximalwards. Ventro-distal tip of LAP not projecting ventralwards. Arm spine articulation without dorsal and ventral lobes, or with dorsal and ventral lobes; without sigmoidal fold; arranged over entire distal LAP edge; all similar. Distance between spine articulations equal. Nerve and muscle openings separated by small ridge if at all.

DorSAL DISC. Disc circular; high (above arm level). Integument not obscuring plates. Dorsal disc without granules; with obvious primary plates; without scales or with a few scales (O'Hara et al. 2018); without spines. Dorsal disc scale/plate without tubercles. Radial shield present; without granules/spines; length between one third and half of the disc radius; scalene (oblique) triangular.

VENTRAL DISC. Gonads restricted to the disc. Ventral interradii without granules/spines. Scales on ventral interradii absent. Ventral teeth several (tooth papillae). Infradental papillae on oral plate present. Buccal scales on OP present. Accessory oral papillae on OP absent. Lateral oral papillae on OP present; single row of lateral papillae; block-shaped and spiniform. Adoral shield spine present. Lyman's ossicle absent. Oral shield covering less than one third of interradius; much wider than long. Madreporite no data. Adoral shield meeting in front of the oral shield. Abradial genital plate not twisted. Number of genital slits one per bursa. Genital slit longer than half the length of an interradius. Genital papillae absent. Dental plate and teeth no data.

VERTEBRAE. Vertebrae zygospondylous; beyond segment 5 with short keel; without oral bridge.

Family Ophiuridae Müller \& Troschel, 1840, restricted sensu O’Hara et al. (2017)

\section{Type genus}

Ophiura Lamarck, 1801.

\section{Other genera}

Ophiocrossota H.L. Clark, 1928; Ophiocten Lütken, 1855; Ophioctenella Tyler, Paterson, Sibuet, Guille, Murton \& Segonzac, 1995; Ophionotus Bell, 1902. 


\section{Description}

ARM. Arm shape unbranched; length $3 \times$ disc diameter; covering without granules/spines/tubercles. Arm combs present. Dorsal arm plate present. Accessory dorsal arm plate absent. Ventral arm plate present. Accessory ventral arm plate absent. Girdle of tiny hooks on the arms absent. Spines all similar in shape. Arm spine cross section round. The ratio of thickness of distal $1 \frac{1}{3}$ of arm spine to maximum thickness (in a given cross-sectional plane) 0.6-0.9. Arm spines pointed; mainly lateral and at proximal segments only on ventral side of arms; predominantly parallel to arm axis (adpressed). Longest arm spines between half and one segment long, or between one and two segments long (Ophiura sarsii Lütken, 1855). Tentacle scales present or absent; pores visible along most of the arm; slightly longer than wide; shorter than the spine nearby; cross section oval. Position of lateral arm plate (LAP) arched (wrapped around the arm). Dorsal and/ or ventral edge(s) of LAPs without constriction. Ventral position of LAP not projecting ventroproximalwards. Ventro-distal tip of LAP not projecting ventralwards. Arm spine articulation without dorsal and ventral lobes; restricted to (the ventral or central) portion of the distal edge; all similar. Distance between spine articulations ventralwards increasing. Nerve and muscle openings separated by large, prominent ridge or regular stereom. Nerve opening approximately as large as muscle opening.

DorSAL DISC. Disc circular; flat (at arm level). Integument not obscuring plates. Dorsal disc without granules; with obvious primary plates; with scales; without spines. Dorsal disc scale/plate without tubercles. Radial shield present; without granules/spines; length between one third and half of the disc radius; isosceles (mirror-symmetric) triangular to pear-shaped.

VENTRAL DISC. Gonads restricted to the disc. Ventral interradii without granules/spines. Scales on ventral interradii covering the whole area of an interradius. The number of scales on $\mathrm{H}$ line of an interradius fewer than 7, or 7-14 (Ophiocten). Ventral teeth several (tooth papillae). Infradental papillae on oral plate present. Buccal scales on OP present. Accessory oral papillae on OP absent. Lateral oral papillae on OP absent. Adoral shield spine present. Lyman's ossicle absent. Oral shield covering more than one third of the length of an interradius; much longer than wide or about as long as wide (Ophiocten). Madreporite one; with one pore or with numerous pores. Adoral shield meeting in front of the oral shield. Abradial genital plate not twisted. Number of genital slits one per bursa. Genital slit longer than half the length of an interradius. Genital papillae present. Dental plate of equal width all over, or ventral half widest (Ophiura sarsii, Ophiocten); entire (single plate). Dental sockets circular; equal to or more than $50 \%$ of the width. At least one socket on DP as depression or perforation without septum. Teeth flat (with round or slightly pointed tip, but never spine-like). Teeth on DP arranged as a single row on $2 / 3$ and a cluster of tooth papillae on $1 / 3$ of dental plate (two rows in Ophiocten).

VERTEBRAE. Vertebrae zygospondylous; beyond segment 5 with short keel; without oral bridge.

Family Ophiopyrgidae Perrier, 1893

\section{Type genus}

Ophiopyrgus Lyman, 1878.

\section{Other genera}

Amphiophiura Matsumoto, 1915; Aspidophiura Matsumoto, 1915; Dictenophiura H.L. Clark, 1923; Euvondrea Fell, 1961; Glaciacantha Fell, 1961; Gymnophiura Lütken \& Mortensen, 1899; Ophiogona Studer, 1876; Ophiomages Koehler, 1923; Ophioperla Koehler, 1912; Ophiopleura Danielssen \& Koren, 1877; Ophioplinthus Lyman, 1878; Ophiosparte Koehler, 1922; Ophiosteira Bell, 1902; Ophiuroglypha Hertz, 1927; Spinophiura Stöhr \& Segonzac, 2006; Stegophiura Matsumoto, 1915. 


\section{Description}

ARM. Arm shape unbranched; length $3 \times$ disc diameter; covering without granules/spines/tubercles. Arm combs present. Dorsal arm plate present. Accessory dorsal arm plate absent. Ventral arm plate present. Accessory ventral arm plate absent. Girdle of tiny hooks on the arms absent. Spines all similar in shape. Arm spine cross section round (Amphiophiura, Ophioplinthus), or oval (Ophiosparte). The ratio of distal 1/3 an arm spine to maximum thickness (in a given cross-sectional plane) $0.2-0.6$, or 0.6-0.9 (Amphiophiura), or 0.9-1 (Ophiosparte, Ophioplinthus). Arm spines tapering (conical), or cylindrical (Ophiosparte), or pointed; mainly lateral; predominantly parallel to arm axis (adpressed). Longest arm spines shorter than half a segment (Amphiophiura, Ophioplinthus, Ophiopleura), or between half and one segment (Ophiosparte). Tentacle scales present; pores visible along most of the arm; more than two times as long as wide; shorter than the spine nearby; cross section oval. Position of lateral arm plate (LAP) arched (wrapped around the arm). Dorsal and/or ventral edge(s) of LAPs without constriction. Ventral position of LAP not projecting ventro-proximalwards. Ventro-distal tip of LAP not projecting ventralwards. Arm spine articulation without dorsal and ventral lobes; arranged over entire distal LAP edge; ventralwards increasing in size (Amphiophiura), or all similar (Ophiosparte, Ophiopyrgus, Ophioplinthus). Distance between spine articulations dorsalwards increasing. Nerve and muscle openings separated by large, prominent ridge or regular stereom. Nerve opening approximately as large as muscle opening.

Dorsal DISC. Disc circular; high (above arm level). Integument not obscuring plates (Amphiophiura, Ophiopyrgus, Ophioplinthus, Ophiopleura), or skin obscuring plates (Ophiosparte). Dorsal disc without granules; with obvious primary plates (Amphiophiura, Ophioplinthus), or with concealed primary plates (Ophiosparte, Ophiopleura); with scales (the scales are covered by thickened skin in Ophiosparte and embedded in thickened skin in Ophiopleura) without spines. Dorsal disc scale/plate without tubercles. Radial shield present; without granules/spines; length less than one third of the disc radius, or length between one third and half of the disc radius (Ophiopyrgus), or length more than half of the disc radius (Ophiopleura); isosceles (mirror-symmetric) triangular to pear-shaped.

VeNTRAL DISC. Gonads restricted to the disc. Ventral interradii without granules/spines. Scales on ventral interradii covering the whole area of an interradius, or absent (Ophiosparte, Ophiosparte, Ophiopleura). The number of scales on $\mathrm{H}$ line of an interradius about less than 7. Ventral teeth several (tooth papillae). Infradental papillae on oral plate present. Buccal scales on OP present. Accessory oral papillae on OP present. Lateral oral papillae on OP absent. Adoral shield spine present. Lyman's ossicle absent. Oral shield covering less than one third of interradius; much longer than wide or about as long as wide (e.g., Ophioplinthus tessellata (Verrill, 1894) and Ophiopleura borealis Danielssen \& Koren, 1877). Madreporite no data. Adoral shield meeting in front of the oral shield. Abradial genital plate not twisted. Number of genital slits one per bursa. Genital slit longer than half the length of an interradius (or about equal). Genital papillae present. Dental plate ventral half widest; entire (single plate). Dental sockets circular; less than $50 \%$ of the width. At least one socket on DP as depression or perforation without septum. Teeth spine-shaped. Teeth on DP arranged as a single row on $2 / 3$ and a cluster of tooth papillae on $1 / 3$ of dental plate (Ophioplinthus).

VERTEBRAE. Vertebrae zygospondylous; beyond segment 5 with short keel; without oral bridge. 
GOHARIMANESH M. et al., Revised ophiuroid (Echinodermata) families and key

Superorder Ophintegrida O’Hara, Hugall, Thuy, Stöhr \& Martynov, 2017

Order Ophioscolecida O’Hara, Hugall, Thuy, Stöhr \& Martynov, 2017

Family Ophiohelidae Perrier, 1893

\section{Type genus}

Ophiohelus Lyman, 1880.

\section{Other genera}

Ophiomyces Lyman, 1869; Ophiothauma H.L. Clark, 1938; Ophiotholia Lyman, 1880.

\section{Description}

ArM. Arm shape unbranched; length $3 \times$ disc diameter; covering without granules/spines/tubercles. Arm combs absent. Dorsal arm plate present. Accessory dorsal arm plate absent. Ventral arm plate present. Accessory ventral arm plate absent. Girdle of tiny hooks on the arms absent. Spines all similar (Ophiomyces) or not similar in shape. The atypical spines are umbrella-shaped (Ophiotholia and Ophiohelus) (Fig. 2F). Arm spine cross section round (Ophiotholia), or oval (Ophiomyces). The ratio of thickness of distal $1 / 3$ of arm spine to maximum thickness (in a given cross-sectional plane) $0.2-0.6$, or 0.9-1. Arm spines tapering (conical), or flat (Ophiomyces), or cylindrical (Ophiotholia); mainly lateral; predominantly parallel to arm axis (adpressed). Longest arm spines between one and two segments long. Tentacle scales present; pores visible along most of the arm; slightly longer than wide; shorter than the spine nearby. Position of lateral arm plate (LAP) arched (wrapped around the arm). Dorsal and/or ventral edge(s) of LAPs with constriction (Ophiotholia), or without constriction (Ophiomyces). Ventral position of LAP projecting ventro-proximalwards. Ventro-distal tip of LAP projecting ventralwards (Fig. 2K). Arm spine articulation with dorsal and ventral lobes; without sigmoidal fold; arranged over entire distal LAP edge; ventralwards increasing in size. Distance between spine articulations equal. Nerve and muscle openings separated by small ridge if at all. Nerve opening smaller than muscle opening.

DoRSAL DISC. Disc circular; a sac-like shape (much higher than wide). Integument obscuring plates. Dorsal disc without granules; with concealed primary plates; with scales; with spines. Dorsal disc scale/plate without tubercles. Radial shield absent.

VentRAL DisC. Gonads restricted to the disc. Ventral interradii without granules/spines (Ophiotholia), or with spines (Ophiomyces). Scales on ventral interradii absent. Ventral teeth several (tooth papillae). Infradental papillae on oral plate present. Buccal scales on OP absent. Accessory oral papillae on OP absent. Lateral oral papillae on OP present; multiple rows of lateral papillae; paddle-shaped. Adoral shield spine absent. Lyman's ossicle absent. Oral shield covering less than one third of interradius; much longer than wide. Madreporite no data. Adoral shield separated. Abradial genital plate not twisted. Number of genital slits one per bursa. Genital slit longer than half the length of an interradius. Genital papillae absent. Dental plate ventral half widest; entire (single plate). Dental sockets circular; less than $50 \%$ of the width. At least one socket on DP as depression or perforation without septum. Teeth flat (with round or slightly pointed tip, but never spine-like). Teeth on DP arranged as a single row on $2 / 3$ and a cluster of tooth papillae on $1 / 3$ of dental plate.

VERTEBRAE. Vertebrae zygospondylous; beyond segment 5 with short keel; without oral bridge. 
Family Ophioscolecidae Lütken, 1869

\section{Type genus}

Ophioscolex Müller \& Troschel, 1842.

\section{Other genera}

Ophiocymbium Lyman, 1880; Ophiogeron Lyman, 1878; Ophiohyalus Matsumoto, 1915; Ophiohymen H.L. Clark, 1911; Ophioleptoplax H.L. Clark, 1911; Ophiologimus H.L. Clark, 1911; Ophiolycus Mortensen, 1933; Ophiophrura H.L. Clark, 1911; Ophioplexa Martynov, 2010; Ophioprium H.L. Clark, 1915; Ophiorupta Martynov, 2010; Ophiosyzygus H.L. Clark, 1911; Ophiuroconis Matsumoto, 1915.

\section{Description}

ARM. Arm shape unbranched; length 3-4× disc diameter; covering without granules/spines/tubercles. Arm combs absent. Dorsal arm plate present. Accessory dorsal arm plate absent. Ventral arm plate present. Accessory ventral arm plate absent. Girdle of tiny hooks on the arms absent. Spines all similar, or not all similar in shape (Ophiolycus). The atypical spines are hook-shaped. Arm spine cross section round. The ratio of thickness of distal $1 / 3$ of arm spine to maximum thickness (in a given cross-sectional plane) $0.2-0.6$, or 0.9-1 (Ophiolycus). Arm spines cylindrical (Ophiolycus) or tapering (conical); mainly lateral; predominantly erect, standing perpendicular to arm axis. Longest arm spines between one and two segments long. Tentacle scales present (Ophiolycus) or absent; pores visible along most of the arm; more than two times as long as wide; shorter than the spine nearby; cross section oval. Position of lateral arm plate (LAP) arched (wrapped around the arm). Dorsal and/or ventral edge(s) of LAPs with constriction. Ventral position of LAP projecting ventro-proximalwards. Ventro-distal tip of LAP projecting ventralwards. Arm spine articulation with dorsal and ventral lobes; without sigmoidal fold; arranged over entire distal LAP edge; dorsalwards increasing in size. Distance between spine articulations dorsalwards increasing. Nerve and muscle openings separated by small ridge if at all. Nerve opening smaller than muscle opening.

DorSAL DISC. Disc circular; flat (about same level as arms). Integument obscuring plates. Dorsal disc without granules; with concealed primary plates; with or without scales; without spines. However, in some species with granules and spines (O'Hara et al. 2018). Dorsal disc scale/plate without tubercles. Radial shield absent.

VENTRAL DISC. Gonads restricted to the disc. Ventral interradii without granules/spines. Scales on ventral interradii covering the whole area of an interradius. The number of scales on $\mathrm{H}$ line of an interradius about 14-21. Ventral teeth several (tooth papillae). Infradental papillae on oral plate present. Buccal scales on OP absent. Accessory oral papillae on OP present. Lateral oral papillae on OP absent. Adoral shield spine present. Lyman's ossicle absent. Oral shield covering less than one third of interradius; much wider than long. Madreporite one or multiple; with one pore or with numerous pores. Adoral shield meeting in front of the oral shield. Abradial genital plate not twisted. Number of genital slits one per bursa. Genital slit longer than half the length of an interradius. Genital papillae absent. Dental plate ventral half widest; entire (single plate). Dental sockets circular; equal to or more than $50 \%$ of the width. At least one socket on DP as depression or perforation without septum. Teeth spine-shaped. Teeth on DP arranged as a single row on half of dental plate and other half with a cluster of tooth papillae (ventral cluster), or a single row on $2 / 3$ and a cluster of tooth papillae on $1 / 3$ of dental plate (Ophiolycus).

VERTEBRAE. Vertebrae zygospondylous; beyond segment 5 with short keel; without oral bridge. 
GOHARIMANESH M. et al., Revised ophiuroid (Echinodermata) families and key

Order Ophiacanthida O’Hara, Hugall, Thuy, Stöhr \& Martynov, 2017

Suborder Ophiacanthina O’Hara, Hugall, Thuy, Stöhr \& Martynov, 2017

Family Ophiobyrsidae Matsumoto, 1915

\section{Type genus}

Ophiobyrsa Lyman, 1878.

\section{Other genera}

Ophiobyrsella Verrill, 1899; Ophiophrixus H.L. Clark, 1911; Ophiosmilax Matsumoto, 1915.

\section{Description}

ARM. Arm shape unbranched; length more than $4 \times$ disc diameter; covering without granules/spines/tubercles. Arm combs absent. Dorsal arm plate present. Accessory dorsal arm plate absent. Ventral arm plate present. Accessory ventral arm plate absent. Girdle of tiny hooks on the arms absent. Spines all similar in shape. Arm spine cross section round. The ratio of thickness of distal $1 / 3$ of arm spine to maximum thickness (in a given cross-sectional plane) $0.6-0.9$. Arm spines pointed; mainly lateral; predominantly erect, standing perpendicular to arm axis. Longest arm spines between half and one segment long. Tentacle scales absent. Position of lateral arm plate (LAP) arched (wrapped around the arm). Dorsal and/or ventral edge(s) of LAPs with constriction. Ventral position of LAP projecting ventro-proximalwards. Ventro-distal tip of LAP projecting ventralwards. Arm spine articulation with dorsal and ventral lobes; without sigmoidal fold; arranged over entire distal LAP edge; ventralwards increasing in size. Distance between spine articulations equal. Nerve and muscle openings separated by large, prominent ridge or regular stereom. Nerve opening smaller than muscle opening.

DORSAL DISC. Disc circular; flat (about same level as arms). Integument obscuring plates. Dorsal disc with granules; with concealed primary plates; without scales; with spines. Dorsal disc scale/plate without tubercles. Radial shield present; with granules.

VeNTRAL DISC. Gonads restricted to the disc. Ventral interradii without granules/spines. Scales on ventral interradii absent. Ventral teeth several (tooth papillae). Infradental papillae on oral plate present. Buccal scales on OP absent. Accessory oral papillae on OP absent. Lateral oral papillae on OP present. Adoral shield spine present. Lyman's ossicle present. Oral shield covering less than one third of interradius; about as long as wide. Madreporite no data. Adoral shield meeting in front of the oral shield. Abradial genital plate not twisted. Number of genital slits one per bursa. Genital slit longer than half the length of an interradius. Genital papillae absent. Dental plate of equal width all over; entire (single plate). Dental sockets circular; less than $50 \%$ of the width. At least one socket on DP as depression or perforation without septum. Teeth spine-shaped. Teeth on DP arranged as covering the entire dental plate evenly.

VERTEBRAE. Vertebrae hourglass-shaped (streptospondylous); beyond segment 5 with short keel; without oral bridge.

Family Ophiocamacidae O’Hara, Stöhr, Hugall, Thuy \& Martynov, 2018

\section{Type genus}

Ophiocamax Lyman, 1878. (No other genera) 


\section{Description}

ARM. Arm shape unbranched; length more than $4 \times$ disc diameter; covering tubercles grown out of scales/plates. Arm combs absent. Dorsal arm plate present. Accessory dorsal arm plate absent. Ventral arm plate present. Accessory ventral arm plate absent. Girdle of tiny hooks on the arms absent. Spines all similar in shape. Arm spine cross section round. The ratio of thickness of distal $1 / 3$ of arm spine to maximum thickness (in a given cross-sectional plane) 0.9-1. Arm spines cylindrical; mainly lateral; predominantly erect, standing perpendicular to arm axis. Longest arm spines longer than two segments. Tentacle scales present; pores visible along most of the arm; slightly longer than wide; shorter than the spine nearby; cross section oval. Position of lateral arm plate (LAP) only lateral. Dorsal and/or ventral edge(s) of LAPs without constriction. Ventral position of LAP projecting ventro-proximalwards. Ventrodistal tip of LAP projecting ventralwards. Arm spine articulation with dorsal and ventral lobes; without sigmoidal fold; arranged over entire distal LAP edge; dorsalwards increasing in size. Distance between spine articulations dorsalwards increasing. Nerve and muscle openings separated by small ridge if at all. Nerve opening smaller than muscle opening.

DoRSAL DISC. Disc circular; flat (about same level as arms). Integument not obscuring plates. Dorsal disc without granules; with concealed primary plates; with scales; with spines. Dorsal disc scale/plate without tubercles. Radial shield present; without granules/spines; length between one third and half of the disc radius; scalene (oblique) triangular.

VeNTRAL Disc. Gonads restricted to the disc. Ventral interradii with spines. Scales on ventral interradii absent. Ventral teeth several (tooth papillae). Infradental papillae on oral plate present. Buccal scales on OP absent. Accessory oral papillae on OP absent. Lateral oral papillae on OP present; multiple rows of lateral papillae; spiniform. Adoral shield spine present. Lyman's ossicle present. Oral shield covering more than one third of the length of an interradius; much wider than long. Madreporite one; with numerous pores. Adoral shield meeting in front of the oral shield. Abradial genital plate not twisted. Number of genital slits one per bursa. Genital slit longer than half the length of an interradius. Genital papillae absent. Dental plate of equal width all over; entire (single plate). Dental sockets slit-shaped and circular; equal to or more than $50 \%$ of the width. At least one socket on DP as depression or perforation without septum. Teeth spine-shaped. Teeth on DP arranged as a single row on $2 / 3$ and a cluster of tooth papillae on $1 / 3$ of dental plate.

VERTEBRAE. Vertebrae hourglass-shaped (streptospondylous); beyond segment 5 with short keel; without oral bridge.

Family Ophiotomidae Paterson, 1985

\section{Type genus}

Ophiotoma Lyman, 1883.

\section{Other genera}

Ophiocomina Koehler in Mortensen, 1920; Ophiocopa Lyman, 1883; Ophiomitra Lyman, 1869; Ophiopristis Verrill, 1899; Ophiotreta Verrill, 1899.

\section{Description}

ARM. Arm shape unbranched; length 3-4× disc diameter; covering without granules/spines/tubercles. Arm combs absent. Dorsal arm plate present. Accessory dorsal arm plate absent. Ventral arm plate present. Accessory ventral arm plate absent. Girdle of tiny hooks on the arms absent. Spines all similar in shape. Arm spine cross section oval. The ratio of thickness of distal $1 / 3$ of arm spine to maximum thickness 
(in a given cross-sectional plane) 0.6-0.9 to 0.9-1 (in Ophiocopa more pointed than in Ophiotreta). Arm spines flat; mainly lateral; predominantly erect, standing perpendicular to arm axis. Longest arm spines between one and two segments long, or longer than two segments (Ophiocopa). Tentacle scales present; pores visible along most of the arm; nearly as long as wide (Ophiotreta), or slightly longer than wide (Ophiocomina); shorter than the spine nearby; cross section oval. Position of lateral arm plate (LAP) arched (wrapped around the arm). Dorsal and/or ventral edge(s) of LAPs without constriction. Ventral position of LAP not projecting ventro-proximalwards. Ventro-distal tip of LAP not projecting ventralwards. Arm spine articulation with dorsal and ventral lobes; with a fully developed sigmoidal fold; arranged over entire distal LAP edge; dorsalwards increasing in size. Distance between spine articulations dorsalwards increasing. Nerve and muscle openings separated by small ridge if at all. Nerve opening smaller than muscle opening.

DoRSAL DISC. Disc circular; high (above arm level). Integument obscuring plates. Dorsal disc with granules; with concealed primary plates; with scales; with spines. Dorsal disc scale/plate without tubercles. Radial shield present; with granules; length less than one third of the disc radius; scalene (oblique) triangular.

VeNTRAL DISC. Gonads restricted to the disc. Ventral interradii with granules. Scales on ventral interradii covering the whole area of an interradius. The number of scales on $\mathrm{H}$ line of an interradius more than 21. Ventral teeth several (tooth papillae). Infradental papillae on oral plate present. Buccal scales on OP absent. Accessory oral papillae on OP absent. Lateral oral papillae on OP present; single row of lateral papillae; rounded (Ophiotreta) or spiniform (Ophiocomina). Adoral shield spine present. Lyman's ossicle present. Oral shield covering less than one third of interradius; about as long as wide (Ophiotreta), or much wider than long (Ophiocomina). Madreporite one; with one pore. Adoral shield meeting in front of the oral shield. Abradial genital plate not twisted. Number of genital slits one per bursa. Genital slit longer than half the length of an interradius. Genital papillae absent. Dental plate ventral half widest; entire (Ophiocomina) or fragmented (Ophiotreta, Ophiocopa). Dental sockets slit-shaped and circular; less than $50 \%$ of the width or equal to or more than $50 \%$ of the width. At least one socket on DP as depression or perforation without septum. Teeth spine-shaped. Teeth on DP arranged as a single row on $2 / 3$ and a cluster of tooth papillae on $1 / 3$ of dental plate.

VERTEBRAE. Vertebrae zygospondylous; beyond segment 5 with short keel; without oral bridge.

Family Ophiopteridae O’Hara, Stöhr, Hugall, Thuy \& Martynov, 2018

\section{Type genus}

Ophiopteris E.A. Smith, 1877. (No other genera)

\section{Description}

ARM. Arm shape unbranched; length 3-4× disc diameter; covering without granules/spines/tubercles. Arm combs absent. Dorsal arm plate present. Accessory dorsal arm plate absent. Ventral arm plate present. Accessory ventral arm plate present. Girdle of tiny hooks on the arms absent. Spines all similar in shape. Arm spine cross section round, or oval. The ratio of thickness of distal $1 / 3$ of arm spine to maximum thickness (in a given cross-sectional plane) $0.9-1$. Arm spines flat or cylindrical; mainly lateral; predominantly erect, standing perpendicular to arm axis. Longest arm spines longer than two segments. Tentacle scales present; pores visible along most of the arm; nearly as long as wide; shorter than the spine nearby; cross section round. Position of lateral arm plate (LAP) arched (wrapped around the arm). Dorsal and/or ventral edge(s) of LAPs without constriction. Ventral position of LAP projecting ventroproximalwards. Ventro-distal tip of LAP projecting ventralwards. Arm spine articulation with dorsal and ventral lobes; with a fully developed sigmoidal fold; arranged over entire distal LAP edge; larger 
in middle of arm. Distance between spine articulations equal. Nerve and muscle openings separated by small ridge if at all. Nerve opening smaller than muscle opening.

DoRSAL DISC. Disc pentagonal or circular; high (above arm level). Integument obscuring plates. Dorsal disc with granules; with concealed primary plates; with scales; without spines. Dorsal disc scale/plate without tubercles. Radial shield present; with granules; length more than half of the disc radius; scalene (oblique) triangular.

VeNTRAL DISC. Gonads restricted to the disc. Ventral interradii with spines. Scales on ventral interradii absent. Ventral teeth several (tooth papillae). Infradental papillae on oral plate present. Buccal scales on OP absent. Accessory oral papillae on OP absent. Lateral oral papillae on OP present; single row of lateral papillae; spiniform. Adoral shield spine present. Lyman's ossicle present. Oral shield covering more than one third of the length of an interradius; about as long as wide. Madreporite no data. Adoral shield separated. Abradial genital plate not twisted. Number of genital slits one per bursa. Genital slit longer than half the length of an interradius. Genital papillae absent. Dental plate dorsal half widest; entire. Dental sockets heart-shaped(?); equal to or more than $50 \%$ of the width. Teeth flat (with round or slightly pointed tip, but never spine-like).

VERTEBRAE. Vertebrae zygospondylous; beyond segment 5 with short keel; without oral bridge.

Family Clarkcomidae O’Hara, Stöhr, Hugall, Thuy \& Martynov, 2018

\section{Type genus}

Clarkcoma Devaney, 1970. (No other genera)

\section{Description}

ARM. Arm shape unbranched; length 3-4× disc diameter; covering without granules/spines/tubercles. Arm combs absent. Dorsal arm plate present. Accessory dorsal arm plate absent. Ventral arm plate present. Accessory ventral arm plate absent. Girdle of tiny hooks on the arms absent. Spines all similar in shape. Arm spine cross section oval. The ratio of thickness of distal $1 / 3$ of arm spine to maximum thickness (in a given cross-sectional plane) 0.6-0.9. Arm spines flat; mainly lateral; predominantly erect, standing perpendicular to arm axis. Longest arm spines longer than two segments. Tentacle scales present; pores visible along most of the arm; more than two times as long as wide; shorter than the spine nearby; cross section oval. Position of lateral arm plate (LAP) arched (wrapped around the arm). Dorsal and/or ventral edge(s) of LAPs with constriction. Ventral position of LAP projecting ventro-proximalwards. Ventrodistal tip of LAP not projecting ventralwards. Arm spine articulation with dorsal and ventral lobes; with a fully developed sigmoidal fold; arranged over entire distal LAP edge; dorsalwards increasing in size. Distance between spine articulations equal. Nerve and muscle openings separated by large, prominent ridge or regular stereom. Nerve opening smaller than muscle opening.

DorSAL DISC. Disc circular; flat (about same level as arms). Integument obscuring plates. Dorsal disc with granules; with concealed primary plates; with scales; without spines. Dorsal disc scale/plate without tubercles. Radial shield present; with granules; length more than half of the disc radius.

VENTRAL DISC. Gonads restricted to the disc. Ventral interradii with granules. Scales on ventral interradii covering the whole area of an interradius. The number of scales on $\mathrm{H}$ line of an interradius no data. Ventral teeth several (tooth papillae). Infradental papillae on oral plate present. Buccal scales on OP absent. Accessory oral papillae on OP absent. Lateral oral papillae on OP present; single row of lateral papillae; paddle-shaped. Adoral shield spine present. Lyman's ossicle present. Oral shield covering less than one third of interradius; about as long as wide. Madreporite no data. Adoral shield meeting in front of the 
oral shield. Abradial genital plate not twisted. Number of genital slits one per bursa. Genital slit longer than half the length of an interradius. Genital papillae absent. Dental plate of equal width all over; entire (single plate). Dental sockets slit-shaped and circular; equal to or more than $50 \%$ of the width. At least one socket on DP as perforation with septum. Teeth flat (with round or slightly pointed tip, but never spine-like). Teeth on DP arranged as a single row on $2 / 3$ and a cluster of tooth papillae on $1 / 3$ of dental plate.

VERTEBRAE. Vertebrae zygospondylous; beyond segment 5 with short keel; without oral bridge.

Family Ophiacanthidae Ljungman, 1867

\section{Type genus}

Ophiacantha Müller \& Troschel, 1842.

\section{Other genera}

Ophialcaea Verrill, 1899; Ophientrema Verrill, 1899; Ophiocanops Koehler, 1922; Ophiochondrus Lyman, 1869; Ophiohamus O’Hara \& Stöhr, 2006; Ophiolebes Lyman, 1878; Ophiolimna Verrill, 1899; Ophiomitrella Verrill, 1899; Ophiomoeris Koehler, 1904; 'Ophiophthalmus' Matsumoto, 1917; Ophioplinthaca Verrill, 1899; Ophioripa Koehler, 1922; Ophiosemnotes Matsumoto, 1917; Ophiurothamnus Matsumoto, 1917.

\section{Description}

ARM. Arm shape unbranched; length $3 \times$ disc diameter, or length $3-4 \times$ disc diameter, or length more than $4 \times$ disc diameter; covering without granules/spines/tubercles. Arm combs absent. Dorsal arm plate present. Accessory dorsal arm plate absent. Ventral arm plate present. Accessory ventral arm plate absent. Girdle of tiny hooks on the arms absent. Spines all similar in shape. Arm spine cross section round. The ratio of thickness of distal $1 / 3$ of arm spine to maximum thickness (in a given cross-sectional plane) 0.6-0.9, or 0.9-1 (Ophiochondrus). Arm spines pointed; mainly lateral; predominantly erect, standing perpendicular to arm axis. Longest arm spines between one and two segments long (Ophiolimna), or longer than two segments. Tentacle scales present; pores visible along most of the arm; nearly as long as wide; shorter than the spine nearby; cross section oval. Position of lateral arm plate (LAP) arched (wrapped around the arm). Dorsal and/or ventral edge(s) of LAPs with constriction. Ventral position of LAP not projecting ventro-proximalwards. Ventro-distal tip of LAP not projecting ventralwards. Arm spine articulation with dorsal and ventral lobes; with a fully developed sigmoidal fold; arranged over entire distal LAP edge; dorsalwards increasing in size (Ophiacantha bidentata (Bruzelius, 1805), Ophiolimna), or all similar ( Ophiacantha abyssicola G.O. Sars, 1872, Ophioplinthaca). Distance between spine articulations dorsalwards increasing. Nerve and muscle openings separated by small ridge if at all. Nerve opening smaller than muscle opening.

DorSAL DISC. Disc circular; flat (about same level as arms) or high (above arm level) (Ophiochondrus). Integument obscuring plates. Dorsal disc with granules (Ophioplinthaca, Ophiolimna); with concealed primary plates; with scales; with spines (Ophiacantha, Ophiolimna) or without spines. Dorsal disc scale/plate without tubercles. Radial shield present; with spines and with granules; length between one third and half of the disc radius (O. bidentata, Ophioplinthaca), or length more than half of the disc radius (O. abyssicola, Ophiochondrus); isosceles (mirror-symmetric) triangular to pear-shaped, or bar-like.

VENTRAL DISC. Gonads restricted to the disc or not restricted to the disc (Ophiocanops). Ventral interradii with spines (O. abyssicola) or with granules (O. bidentata, Ophiochondrus, with spine and granules in Ophiolimna). Scales on ventral interradii covering the whole area of an interradius. The number of scales on $\mathrm{H}$ line of an interradius about 7-14. Ventral teeth single. Infradental papillae on oral plate present. 
Buccal scales on OP absent. Accessory oral papillae on OP absent. Lateral oral papillae on OP present; single row of lateral papillae; spiniform. Adoral shield spine present. Lyman's ossicle present. Oral shield covering less than one third of interradius; much wider than long. Madreporite one or multiple; with one pore or with numerous pores. Adoral shield meeting in front of the oral shield. Abradial genital plate not twisted. Number of genital slits one per bursa. Genital slit longer than half the length of an interradius. Genital papillae absent. Dental plate of equal width all over, or dorsal half widest (Ophiolimna); entire (single plate). Dental sockets slit-shaped; equal to or more than $50 \%$ of the width. At least one socket on DP as depression or perforation without septum. Teeth flat (with round or slightly pointed tip, but never spine-like). Teeth on DP arranged as single row.

VERTEBRAE. Vertebrae zygospondylous; beyond segment 5 with short keel; without oral bridge.

Suborder Ophiodermatina Ljungman, 1867

Superfamily Ophiodermatoidea Ljungman, 1867

Family Ophiodermatidae Ljungman, 1867

\section{Type genus}

Ophioderma Müller \& Troschel, 1840.

\section{Other genera}

Bathypectinura H.L. Clark, 1909; Cryptopelta H.L. Clark, 1909; Diopederma H.L. Clark, 1913; Ophiarachnella Ljungman, 1872; Ophiochasma Grube, 1868; Ophiocormus H.L. Clark, 1915; Ophiocryptus H.L. Clark, 1915; Ophiocypris Koehler, 1930; Ophiomidas Koehler, 1904; Ophiopsammus Lütken, 1869.

\section{Description}

ARM. Arm shape unbranched; length 3-4× disc diameter; covering without granules/spines/tubercles. Arm combs absent. Dorsal arm plate present. Accessory dorsal arm plate absent. Ventral arm plate present. Accessory ventral arm plate absent. Girdle of tiny hooks on the arms absent. Spines all similar in shape. Arm spine cross section oval. The ratio of thickness of distal $1 / 3$ of arm spine to maximum thickness (in a given cross-sectional plane) $0.6-0.9$. Arm spines flat; mainly lateral; predominantly parallel to arm axis (adpressed). Longest arm spines shorter than half a segment. Tentacle scales present; pores visible along most of the arm; slightly longer than wide; shorter than the spine nearby; cross section oval. Position of lateral arm plate (LAP) arched (wrapped around the arm). Dorsal and/or ventral edge(s) of LAPs without constriction. Ventral position of LAP projecting ventro-proximalwards. Ventro-distal tip of LAP projecting ventralwards. Arm spine articulation with dorsal and ventral lobes; with a weakly developed sigmoidal fold; arranged over entire distal LAP edge; ventralwards increasing in size. Distance between spine articulations equal. Nerve and muscle openings separated by small ridge if at all. Nerve opening smaller than muscle opening.

DoRSAL DISC. Disc pentagonal to circular; flat (about same level as arms). Integument obscuring plates. Dorsal disc with granules; with concealed primary plates; with scales; without spines. Dorsal disc scale/plate without tubercles. Radial shield present; with granules; length less than one third of the disc radius; isosceles (mirror-symmetric) triangular to pear-shaped.

VENTRAL DISC. Gonads restricted to the disc. Ventral interradii with granules. Scales on ventral interradii absent. Ventral teeth several (tooth papillae). Infradental papillae on oral plate present. Buccal scales on OP absent. Accessory oral papillae on OP absent. Lateral oral papillae on OP present; single row of 
lateral papillae; spiniform. Adoral shield spine present. Lyman's ossicle present. Oral shield covering less than one third of interradius; much wider than long. Madreporite multiple; with one pore. Adoral shield meeting in front of the oral shield. Abradial genital plate not twisted. Number of genital slits two per bursa. Genital slit longer than half the length of an interradius. Genital papillae absent. Dental plate of equal width all over; fragmented. Dental sockets slit-shaped and circular; less than $50 \%$ of the width or equal to or more than $50 \%$ of the width. At least one socket on DP as depression or perforation without septum. Teeth block-like (with square tip). Teeth on DP arranged as a single row on $2 / 3$ and a cluster of tooth papillae on $1 / 3$ of dental plate.

VeRTEBRAE. Vertebrae zygospondylous; beyond segment 5 with short keel; without oral bridge.

Family Ophiopezidae O’Hara, Stöhr, Hugall, Thuy \& Martynov, 2018

\section{Type genus}

Ophiopeza Peters, 1851.

\section{Other genera}

Ophiochaeta Lütken, 1869.

\section{Description}

ARM. Arm shape unbranched; length more than $4 \times$ disc diameter; covering without granules/spines/tubercles. Arm combs absent. Dorsal arm plate present. Accessory dorsal arm plate absent. Ventral arm plate present. Accessory ventral arm plate absent. Girdle of tiny hooks on the arms absent. Spines all similar in shape. Arm spine cross section round. The ratio of thickness of distal $1 / 3$ of arm spine to maximum thickness (in a given cross-sectional plane) $0.6-0.9$. Arm spines pointed; mainly lateral; predominantly parallel to arm axis (adpressed). Longest arm spines shorter than half a segment. Tentacle scales present; pores visible along most of the arm; slightly longer than wide; shorter than the spine nearby. Dental plate ventral half widest; entire (single plate). Position of lateral arm plate (LAP) only lateral. Dorsal and/or ventral edge(s) of LAPs without constriction. Ventral position of LAP not projecting ventro-proximalwards. Ventro-distal tip of LAP not projecting ventralwards. Arm spine articulation with dorsal and thin ventral lobes and a fully developed sigmoidal fold; arranged over entire distal LAP edge; larger in middle of arm. Distance between spine articulations equal. Nerve and muscle openings separated by large, prominent ridge or regular stereom. Nerve opening smaller than muscle opening.

DoRSAL DISC. Disc pentagonal; flat (about same level as arms). Integument obscuring plates. Dorsal disc with granules; with concealed primary plates; without scales; with spines. Dorsal disc scale/plate without tubercles. Radial shield present; covering, length and shape no data.

VENTRAL DISC. Gonads restricted to the disc. Ventral interradii with granules. Scales on ventral interradii absent. Ventral teeth several (tooth papillae). Infradental papillae on oral plate present. Buccal scales on OP absent. Accessory oral papillae on OP absent. Lateral oral papillae on OP present; single row of lateral papillae; spiniform. Adoral shield spine present. Lyman's ossicle present. Oral shield covering less than one third of interradius; about as long as wide. Madreporite no data. Adoral shield separated. Abradial genital plate not twisted. Number of genital slits one per bursa. Genital slit longer than half the length of an interradius. Genital papillae absent. Dental sockets slit-shaped or circular; less than $50 \%$ of the width. At least one socket on DP as depression or perforation without septum. Teeth spine-shaped. Teeth on DP arranged as a single row on $2 / 3$ and a cluster of tooth papillae on $1 / 3$ of dental plate.

VERTEBRAE. Vertebrae zygospondylous; beyond segment 5 with short keel; without oral bridge. 
Family Ophiomyxidae Ljungman, 1867

\section{Type genus}

Ophiomyxa Müller \& Troschel, 1842.

\section{Other genera}

Neoplax Bell, 1884; Ophiarachna Müller \& Troschel, 1842; Ophioconis Lütken, 1869; Ophiostiba Matsumoto, 1915; Ophiurochaeta Matsumoto, 1915.

\section{Description}

ARM. Arm shape unbranched; length 3-4× disc diameter; covering without granules/spines/tubercles. Arm combs absent. Dorsal arm plate present. Accessory dorsal arm plate absent. Ventral arm plate present. Accessory ventral arm plate absent. Girdle of tiny hooks on the arms absent. Spines all similar in shape. Arm spine cross section round. The ratio of thickness of distal $1 / 3$ of arm spine to maximum thickness (in a given cross-sectional plane) 0.6-0.9. Arm spines pointed; mainly lateral; predominantly erect, standing perpendicular to arm axis. Longest arm spines shorter than half a segment, or longer than two segments (Ophiarachna). Tentacle scales present; pores visible along most of the arm; slightly longer than wide, or more than two times as long as wide; shorter than the spine nearby; cross section oval. Position of lateral arm plate (LAP) arched (wrapped around the arm). Dorsal and/or ventral edge(s) of LAPs without constriction. Ventral position of LAP projecting ventro-proximalwards. Ventro-distal tip of LAP projecting ventralwards. Arm spine articulation with dorsal and ventral lobes; without or with a weakly developed sigmoidal fold; arranged over entire distal LAP edge; ventralwards increasing in size. Distance between spine articulations equal. Nerve and muscle openings separated by small ridge if at all. Nerve opening approximately as large as muscle opening.

DoRSAL DISC. Disc pentagonal; flat (about same level as arms). Integument not obscuring plates. Dorsal disc with granules (Ophiarachna) or without granules; with concealed primary plates; with scales; without spines. Dorsal disc scale/plate without tubercles. Radial shield present; without granules/spines; length less than one third of the disc radius; isosceles (mirror-symmetric) triangular to pear-shaped.

VENTRAL DISC. Gonads restricted to the disc. Ventral interradii without granules/spines, or with granules (Ophiarachna). Scales on ventral interradii absent. Ventral teeth single or with several tooth papillae (Ophiarachna). Infradental papillae on oral plate present. Buccal scales on OP absent. Accessory oral papillae on OP absent. Lateral oral papillae on OP present; single row of lateral papillae; paddle-shaped. Adoral shield spine present. Lyman's ossicle present. Oral shield covering less than one third of interradius; about as long as wide. Madreporite one; with one pore. Adoral shield separated. Abradial genital plate not twisted. Number of genital slits one per bursa. Genital slit longer than half the length of an interradius. Genital papillae absent. Dental plate ventral half widest; fragmented. Dental sockets slit-shaped and circular; less than $50 \%$ of the width or equal to or more than $50 \%$ of the width. At least one socket on DP as perforation with septum. Teeth block-like (with square tip). Teeth on DP arranged as single row.

VERTEBRAE. Vertebrae zygospondylous; beyond segment 5 with short keel; without oral bridge.

Superfamily Ophiocomoidea Ljungman, 1867

Family Ophiocomidae Ljungman, 1867

\section{Type genus}

Ophiocoma L. Agassiz, 1836. 


\section{Other genera}

Breviturma Stöhr Stöhr, Boissin \& Hoareau, 2013; Ophiarthrum Peters, 1851; Ophiocomella A.H. Clark, 1939; Ophiomastix Müller \& Troschel, 1842.

\section{Description}

ARM. Arm shape unbranched; length 3-4× disc diameter; covering without granules/spines/tubercles. Arm combs absent. Dorsal arm plate present. Accessory dorsal arm plate absent. Ventral arm plate present. Accessory ventral arm plate absent. Girdle of tiny hooks on the arms absent. Spines all similar in shape. Arm spine cross section oval. The ratio of thickness of distal $1 / 3$ of arm spine to maximum thickness (in a given cross-sectional plane) $0.6-0.9$, or $0.9-1$. Arm spines flat, or cylindrical, or pointed; mainly lateral; predominantly erect, standing perpendicular to arm axis. Longest arm spines longer than two segments. Tentacle scales present; pores visible along most of the arm; nearly as long as wide; shorter than the spine nearby; cross section oval. Position of lateral arm plate (LAP) arched (wrapped around the arm). Dorsal and/or ventral edge(s) of LAPs without constriction. Ventral position of LAP projecting ventro-proximalwards. Ventro-distal tip of LAP not projecting ventralwards. Arm spine articulation with dorsal and ventral lobes; with a fully developed sigmoidal fold; arranged over entire distal LAP edge; dorsalwards increasing in size. Distance between spine articulations dorsalwards increasing. Nerve and muscle openings separated by small ridge if at all. Nerve opening smaller than muscle opening.

DoRSAL DISC. Disc pentagonal to circular; flat (about same level as arms). Integument obscuring plates. Dorsal disc with granules; with concealed primary plates; with scales; with smooth spines (O'Hara et al. 2018) or without spines. Dorsal disc scale/plate without tubercles. Radial shield present; with granules; length less than one third of the disc radius; scalene (oblique) triangular.

VeNTRAL DISC. Gonads restricted to the disc. Ventral interradii with granules. Scales on ventral interradii covering the whole area of an interradius. The number of scales on $\mathrm{H}$ line of an interradius more than 21. Ventral teeth several (tooth papillae). Infradental papillae on oral plate present. Buccal scales on OP absent. Accessory oral papillae on OP absent. Lateral oral papillae on OP present or absent; multiple rows of lateral papillae; rounded. Adoral shield spine present. Lyman's ossicle present. Oral shield covering less than one third of interradius; about as long as wide. Madreporite one; with one pore. Adoral shield separated. Abradial genital plate not twisted. Number of genital slits one per bursa. Genital slit longer than half the length of an interradius. Genital papillae absent. Dental plate of equal width all over; entire (single plate). Dental sockets circular to heart-shaped; equal to or more than $50 \%$ of the width. At least one socket on DP as perforation with septum. Teeth block-like (with square tip). Teeth on DP arranged as a single row on half of dental plate and other half with a cluster of tooth papillae (ventral cluster), or a single row on $2 / 3$ and a cluster of tooth papillae on $1 / 3$ of dental plate.

VERTEBRAE. Vertebrae zygospondylous; beyond segment 5 with short keel; without oral bridge.

Order Ophioleucida O’Hara, Hugall, Thuy, Stöhr \& Martynov, 2017

Family Ophiernidae O’Hara, Stöhr, Hugall, Thuy \& Martynov, 2018

\section{Type genus}

Ophiernus Lyman, 1878. (No other genera)

\section{Description}

ARM. Arm shape unbranched; length 3-4× disc diameter; covering without granules/spines/tubercles. Arm combs absent. Dorsal arm plate present. Accessory dorsal arm plate absent. Ventral arm plate present. 
Accessory ventral arm plate absent. Girdle of tiny hooks on the arms absent. Spines not all similar in shape. The atypical spines are bristles (Fig. 2H). Arm spine cross section oval. The ratio of thickness of distal $1 / 3$ of arm spine to maximum thickness (in a given cross-sectional plane) 0.6-0.9. Arm spines pointed; mainly lateral; predominantly parallel to arm axis (adpressed). Longest arm spines between half and one segment long. Tentacle scales present; pores visible along most of the arm; slightly longer than wide; shorter than the spine nearby; cross section oval. Position of lateral arm plate (LAP) only lateral. Dorsal and/or ventral edge(s) of LAPs with constriction. Ventral position of LAP not projecting ventro-proximalwards. Ventro-distal tip of LAP projecting ventralwards. Arm spine articulation without dorsal and ventral lobes or with weak lobes (O'Hara et al. 2018); arranged over entire distal LAP edge; dorsalwards increasing in size. Distance between spine articulations dorsalwards increasing. Nerve and muscle openings separated by large, prominent ridge or regular stereom. Nerve opening approximately as large as muscle opening.

DoRSAL DISC. Disc pentagonal to circular; flat (about same level as arms). Integument obscuring plates. Dorsal disc with granules; with concealed primary plates; with scales; without spines. Dorsal disc scale/plate without tubercles. Radial shield present; without granules/spines; length less than one third of the disc radius; isosceles (mirror-symmetric) triangular to pear-shaped.

VeNTRAL DISC. Gonads restricted to the disc. Ventral interradii with granules. Scales on ventral interradii covering the whole area of an interradius. The number of scales on $\mathrm{H}$ line of an interradius fewer than 7. Ventral teeth several (tooth papillae). Infradental papillae on oral plate present. Buccal scales on OP absent. Accessory oral papillae on OP absent. Lateral oral papillae on OP present; single row of lateral papillae; spiniform. Adoral shield spine present. Lyman's ossicle present. Oral shield covering less than one third of interradius; about as long as wide. Madreporite one; with one pore. Adoral shield meeting in front of the oral shield. Abradial genital plate not twisted. Number of genital slits one per bursa. Genital slit longer than half the length of an interradius. Genital papillae absent. Dental plate of equal width all over; entire (single plate). Dental sockets circular; equal to or more than $50 \%$ of the width. At least one socket on DP as depression or perforation without septum. Teeth flat (with round or slightly pointed tip, but never spine-like). Teeth on DP arranged as single row.

VERTEBRAE. Vertebrae zygospondylous; beyond segment 5 with short keel; without oral bridge.

Family Ophioleucidae Matsumoto, 1915

\section{Type genus}

Ophioleuce Koehler, 1904.

\section{Other genera}

Ophiopallas Koehler, 1904; Ophiopyren Lyman, 1878; Ophiostriatus Madsen, 1983.

\section{Description}

ARM. Arm shape unbranched; length more than $4 \times$ disc diameter; covering without granules/spines/tubercles. Arm combs absent. Dorsal arm plate present. Accessory dorsal arm plate absent. Ventral arm plate present. Accessory ventral arm plate absent. Girdle of tiny hooks on the arms absent. Spines all similar or not all similar in shape (Ophiopallas). The atypical spines are hook-shaped. Arm spine cross section round. The ratio of thickness of distal $1 / 3$ of arm spine to maximum thickness (in a given cross-sectional plane) 0.6-0.9. Arm spines pointed; mainly lateral; predominantly parallel to arm axis (adpressed). Longest arm spines between half and one segment long. Tentacle scales present; pores visible along most of the arm; nearly as long as wide; shorter than the spine nearby; cross section round. Position of lateral arm plate (LAP) 
arched (wrapped around the arm). Dorsal and/or ventral edge(s) of LAPs without constriction. Ventral position of LAP projecting ventro-proximalwards. Ventro-distal tip of LAP projecting ventralwards. Arm spine articulation with dorsal and ventral lobes; without sigmoidal fold; arranged over entire distal LAP edge; larger in middle of arm. Distance between spine articulations dorsalwards increasing, or not applicable (two spine articulations) (Ophioleuce seminudum Koehler, 1904). Nerve and muscle openings separated by small ridge if at all. Nerve opening smaller than muscle opening.

DorSAL DISC. Disc circular; flat (about same level as arms). Integument obscuring plates. Dorsal disc with granules; with concealed primary plates; with scales; without spines. Dorsal disc scale/plate without tubercles. Radial shield present; with granules; length less than one third of the disc radius; scalene (oblique) triangular.

VeNTRAL DISC. Gonads restricted to the disc. Ventral interradii with granules. Scales on ventral interradii absent. Ventral teeth several (tooth papillae). Infradental papillae on oral plate present. Buccal scales on OP absent. Accessory oral papillae on OP absent. Lateral oral papillae on OP absent. Adoral shield spine absent. Lyman's ossicle present. Oral shield covering less than one third of interradius; much longer than wide. Madreporite multiple; with numerous pores. Adoral shield meeting in front of the oral shield. Abradial genital plate not twisted. Number of genital slits one per bursa. Genital slit longer than half the length of an interradius. Genital papillae present (Ophiopallas) or absent. Dental plate ventral half widest; entire (single plate). Dental sockets slit-shaped; less than $50 \%$ of the width. At least one socket on DP as depression or perforation without septum. Teeth spine-shaped. Teeth on DP arranged as single row.

VERTEBRAE. Vertebrae hourglass-shaped (streptospondylous); beyond segment 5 with short keel; without oral bridge.

Order Amphilepidida O'Hara, Hugall, Thuy, Stöhr \& Martynov, 2017

Suborder Ophionereidina O'Hara, Hugall, Thuy, Stöhr \& Martynov, 2017

Superfamily Ophiolepidoidea Ljungman, 1867

Family Ophiolepididae Ljungman, 1867

\section{Type genus}

Ophiolepis Müller \& Troschel, 1840.

\section{Other genera}

Ophioteichus H.L. Clark, 1938; Ophiotypa Koehler, 1897.

\section{Description}

ARM. Arm shape unbranched; length $3 \times$ disc diameter; covering without granules/spines/tubercles. Arm combs absent. Dorsal arm plate present. Accessory dorsal arm plate present. Ventral arm plate present. Accessory ventral arm plate absent or present in other genera or species of Ophiolepis (Koehler 1922 and Pineda-Enriquez 2014). Girdle of tiny hooks on the arms absent. Spines all similar in shape. Arm spine cross section round. The ratio of thickness of distal $1 / 3$ of arm spine to maximum thickness (in a given cross-sectional plane) $0.6-0.9$. Arm spines pointed; mainly lateral; predominantly parallel to arm axis (adpressed). Longest arm spines shorter than half a segment. Tentacle scales present; pores visible along most of the arm; slightly longer than wide; shorter than the spine nearby; cross section oval. Position of lateral arm plate (LAP) arched (wrapped around the arm). Dorsal and/or ventral edge(s) of LAPs without constriction. Ventral position of LAP projecting ventro-proximalwards. Ventro-distal tip of LAP not projecting ventralwards. Arm spine articulation with dorsal and ventral lobes; without sigmoidal 
fold; arranged over entire distal LAP edge; larger in middle of arm. Distance between spine articulations dorsalwards increasing. Nerve and muscle openings separated by small ridge if at all. Nerve opening approximately as large as muscle opening.

DorSAL DISC. Disc pentagonal to circular; flat (about same level as arms). Integument not obscuring plates. Dorsal disc without granules; with obvious primary plates; with scales; without spines. Dorsal disc scale/plate without tubercles. Radial shield present; without granules/spines; length between one third and half of the disc radius; isosceles (mirror-symmetric) triangular to pear-shaped.

VENTRAL DISC. Gonads restricted to the disc. Ventral interradii without granules/spines. Scales on ventral interradii absent. Ventral teeth single. Infradental papillae on oral plate present. Buccal scales on OP present. Accessory oral papillae on OP absent. Lateral oral papillae on OP absent. Adoral shield spine present. Lyman's ossicle present. Oral shield covering less than one third of interradius; much longer than wide. Madreporite one. Adoral shield meeting in front of the oral shield. Abradial genital plate not twisted. Number of genital slits one per bursa. Genital slit longer than half the length of an interradius. Genital papillae absent. Dental plate of equal width all over, or dorsal half widest; entire (single plate). Dental sockets circular to heart-shaped; equal to or more than $50 \%$ of the width. At least one socket on DP as depression or perforation without septum. Teeth block-like (with square tip). Teeth on DP arranged as single row.

VERTEBRAE. Vertebrae zygospondylous; beyond segment 5 with short keel; without oral bridge.

Family Hemieuryalidae Verrill, 1899

\section{Type genus}

Hemieuryale von Martens, 1867.

\section{Other genera}

Actinozonella Stöhr, 2011; Astrogymnotes H.L. Clark, 1914; Ophioholcus H.L. Clark, 1915; Ophioplocus Lyman, 1861; Ophioplus Verrill, 1899; Ophiozonella Matsumoto, 1915; Ophiozonoida H.L. Clark, 1915; Quironia A.H. Clark, 1934; Sigsbeia Lyman, 1878.

\section{Description}

ARM. Arm shape unbranched; length more than $4 \times$ disc diameter; covering without granules/spines/tubercles. Arm combs absent. Dorsal arm plate present. Accessory dorsal arm plate present or absent (Actinozonella). Ventral arm plate present. Accessory ventral arm plate absent. Girdle of tiny hooks on the arms absent. Spines all similar in shape. Arm spine cross section round or oval (Sigbeia). The ratio of thickness of distal $1 / 3$ of arm spine to maximum thickness (in a given cross-sectional plane) $0.9-1$. Arm spines cylindrical; at proximal segments only on ventral side of arms; predominantly parallel to arm axis (adpressed). Longest arm spines shorter than half a segment (Sigsbeia, Ophiozonella falklandica Mortensen, 1936), or between half and one segment long (Hemieuryale, Ophiozonella longispina (H.L. Clark, 1908), Ophioplus). Tentacle scales present; pores visible along most of the arm; nearly as long as wide; shorter than the spine nearby; cross section oval. Position of lateral arm plate (LAP) only lateral or arched (wrapped around the arm) (Sigsbeia). Dorsal and/or ventral edge(s) of LAPs without constriction. Ventral position of LAP projecting ventro-proximalwards. Ventro-distal tip of LAP not projecting ventralwards. Arm spine articulation with dorsal and ventral lobes; without sigmoidal fold; restricted to (the ventral or central) portion of the distal edge; ventralwards increasing in size. Distance between spine articulations not applicable (two spine articulations). Nerve and muscle openings separated by small ridge if at all. Nerve opening smaller than muscle opening, or approximately as large as muscle opening (Ophiozonella). 
DorSAL DISC. Disc pentagonal to circular; high (above arm level). Integument not obscuring plates. Dorsal disc without granules; with obvious primary plates; with scales; without spines. Dorsal disc scale/plate with tubercles. Radial shield present; without granules/spines; length between one third and half of the disc radius, or length more than half of the disc radius (Ophioplus); isosceles (mirror-symmetric) triangular to pear-shaped.

VENTRAL DISC. Gonads restricted to the disc. Ventral interradii without granules/spines. Scales on ventral interradii covering the whole area of an interradius. The number of scales on $\mathrm{H}$ line of an interradius fewer than 7. Ventral teeth single. Infradental papillae on oral plate present. Buccal scales on OP absent. Accessory oral papillae on OP absent. Lateral oral papillae on OP present; one lateral papilla along each side of the jaw; block-shaped. Adoral shield spine present. Lyman's ossicle present. Oral shield covering less than one third of interradius; much wider than long. Madreporite no data. Adoral shield meeting in front of the oral shield. Abradial genital plate not twisted. Number of genital slits one per bursa. Genital slit shorter than half interradius. Genital papillae absent. Dental plate dorsal half widest; entire (single plate). Dental sockets slit-shaped and circular; equal to or more than $50 \%$ of the width. At least one socket on DP as depression or perforation without septum. Teeth flat (with round or slightly pointed tip, but never spine-like). Teeth on DP arranged as single row.

VeRTEBRAE. Vertebrae hourglass-shaped (streptospondylous) or zygospondylous (Ophiozonella longispina); beyond segment 5 with short keel; without oral bridge.

Superfamily Ophionereidoidea Ljungman, 1867

Family Amphilimnidae O’Hara, Stöhr, Hugall, Thuy \& Martynov, 2018

\section{Type genus}

Amphilimna Verrill, 1899. (No other genera)

\section{Description}

ARM. Arm shape unbranched; length more than $4 \times$ disc diameter; covering without granules/spines/tubercles. Arm combs absent. Dorsal arm plate present. Accessory dorsal arm plate absent. Ventral arm plate present. Accessory ventral arm plate absent. Girdle of tiny hooks on the arms absent. Spines all similar in shape. Arm spine cross section oval. The ratio of thickness of distal $1 / 3$ of arm spine to maximum thickness (in a given cross-sectional plane) 0.6-0.9. Arm spines flat; mainly lateral; predominantly erect, standing perpendicular to arm axis. Longest arm spines between one and two segments long. Tentacle scales present; pores visible along most of the arm; more than two times as long as wide; shorter than the spine nearby; cross section round. Position of lateral arm plate (LAP) arched (wrapped around the arm). Dorsal and/or ventral edge(s) of LAPs without constriction. Ventral position of LAP projecting ventroproximalwards. Ventro-distal tip of LAP projecting ventralwards. Arm spine articulation with dorsal and ventral lobes; without sigmoidal fold; arranged over entire distal LAP edge; ventralwards increasing in size. Distance between spine articulations dorsalwards increasing. Nerve and muscle openings separated by small ridge if at all. Nerve opening approximately as large as muscle opening.

DoRSAL DISC. Disc pentagonal or circular; flat (about same level as arms). Integument obscuring plates. Dorsal disc without granules; with concealed primary plates; with scales; with spines. Dorsal disc scale/plate without tubercles. Radial shield present; without granules/spines; length between one third and half of the disc radius; scalene (oblique) triangular or bar-like.

Ventral Disc. Gonads restricted to the disc. Ventral interradii with spines. Scales on ventral interradii covering the whole area of an interradius. The number of scales on $\mathrm{H}$ line of an interradius about 14-21. 
Ventral teeth single. Infradental papillae on oral plate present. Buccal scales on OP present. Accessory oral papillae on OP absent. Lateral oral papillae on OP present; single row of lateral papillae; rounded and spiniform. Adoral shield spine present. Lyman's ossicle present. Oral shield covering less than one third of interradius; about as long as wide. Madreporite no data. Adoral shield meeting in front of the oral shield. Abradial genital plate twisted. Number of genital slits one per bursa. Genital slit longer than half the length of an interradius. Genital papillae absent. Dental plate dorsal half widest; entire (single plate). Dental sockets slit-shaped and circular; equal to or more than $50 \%$ of the width. At least one socket on DP as depression or perforation without septum. Teeth flat (with round or slightly pointed tip, but never spine-like). Teeth on DP arranged as single row.

VERTEBRAE. Vertebrae zygospondylous; beyond segment 5 with short keel; without oral bridge.

Family Ophionereididae Ljungman, 1867

\section{Type genus}

Ophionereis Lütken, 1859.

\section{Other genera}

Ophiochiton Lyman, 1878; Ophiodoris Koehler, 1904; Ophioneroides Cherbonnier \& Guille, 1978; Ophioplax Lyman, 1875.

\section{Description}

ARM. Arm shape unbranched; length more than $4 \times$ disc diameter; covering without granules/spines/tubercles. Arm combs absent. Dorsal arm plate present. Accessory dorsal arm plate present or sometimes absent (Ophiodoris sp.). Ventral arm plate present. Accessory ventral arm plate absent. Girdle of tiny hooks on the arms absent. Spines all similar in shape. Arm spine cross section round. The ratio of thickness of distal $1 / 3$ of arm spine to maximum thickness (in a given cross-sectional plane) 0.6-0.9, or 0.9-1 (Ophioplax, Ophiodoris). Arm spines pointed or cylindrical (Ophioplax, Ophiodoris); mainly lateral; predominantly erect, standing perpendicular to arm axis. Longest arm spines between half and one segment long, or between one and two segments long (Ophioplax). Tentacle scales present; pores visible along most of the arm; slightly longer than wide; shorter than the spine nearby; cross section oval or round. Position of lateral arm plate (LAP) arched (wrapped around the arm). Dorsal and/or ventral edge(s) of LAPs without constriction. Ventral position of LAP projecting ventro-proximalwards. Ventro-distal tip of LAP not projecting ventralwards. Arm spine articulation with dorsal and ventral lobes; without sigmoidal fold; arranged over entire distal LAP edge; larger in middle of arm. Distance between spine articulations dorsalwards increasing. Nerve and muscle openings separated by small ridge if at all. Nerve opening smaller than muscle opening.

DorSAL DISC. Disc pentagonal to circular; flat (about same level as arms) to high (above arm level). Integument obscuring plates. Dorsal disc without granules or with granules along the genital slit, extending onto disc edge; with concealed primary plates; with scales; with spines (Ophiodoris) or without spines. Dorsal disc scale/plate without tubercles. Radial shield present; without granules/spines; length less than one third of the disc radius; isosceles (mirror-symmetric) triangular to pear-shaped.

VENTRAL DISC. Gonads restricted to the disc. Ventral interradii without granules/spines or with granules (Ophioplax). Scales on ventral interradii covering the whole area of an interradius or absent (Ophioplax, Ophiodoris). The number of scales on $\mathrm{H}$ line of an interradius about 14-21. Ventral teeth single. Infradental papillae on oral plate present. Buccal scales on OP present. Accessory oral papillae on OP absent. Lateral oral papillae on OP absent. Adoral shield spine present. Lyman's ossicle present. Oral shield covering 
less than one third of interradius; about as long as wide. Madreporite one; with one pore. Adoral shield separated. Abradial genital plate not twisted. Number of genital slits one per bursa. Genital slit longer than half the length of an interradius. Genital papillae present. Dental plate of equal width all over, or ventral half widest (Ophioplax); entire (single plate). Dental sockets circular to heart-shaped; equal to or more than $50 \%$ of the width. At least one socket on DP as perforation with septum. Teeth block-like (with square tip). Teeth on DP arranged as single row.

VERTEBRAE. Vertebrae zygospondylous; beyond segment 5 with extended keel, or with short keel; without oral bridge.

Suborder Ophiopsilina Matsumoto, 1915

Superfamily Ophiopsiloidea Matsumoto, 1915

Family Ophiopsilidae Matsumoto, 1915

\section{Type genus}

Ophiopsila Forbes, 1843. (No other genera)

\section{Description}

ARM. Arm shape unbranched; length more than $4 \times$ disc diameter; covering without granules/spines/tubercles. Arm combs absent. Dorsal arm plate present. Accessory dorsal arm plate absent. Ventral arm plate present. Accessory ventral arm plate absent. Girdle of tiny hooks on the arms absent. Spines all similar in shape. Arm spine cross section oval. The ratio of thickness of distal $1 / 3$ of arm spine to maximum thickness (in a given cross-sectional plane) $0.9-1$. Arm spines flat; mainly lateral; predominantly erect, standing perpendicular to arm axis. Longest arm spines between one and two segments long. Tentacle scales present; pores visible along most of the arm; more than two times as long as wide; longer than the spine nearby; cross section oval. Position of lateral arm plate (LAP) arched (wrapped around the arm). Dorsal and/or ventral edge(s) of LAPs without constriction. Ventral position of LAP projecting ventroproximalwards. Ventro-distal tip of LAP projecting ventralwards. Arm spine articulation with dorsal and ventral lobes; without sigmoidal fold; arranged over entire distal LAP edge; ventralwards increasing in size. Distance between spine articulations dorsalwards increasing. Nerve and muscle openings separated by small ridge if at all. Nerve opening approximately as large as muscle opening.

DoRSAL DISC. Disc circular; flat (about same level as arms). Integument obscuring plates. Dorsal disc without granules; with concealed primary plates; with scales; without spines. Dorsal disc scale/plate without tubercles. Radial shield present; without granules/spines; length between one third and half of the disc radius; bar-like.

VeNTRAL DISC. Gonads restricted to the disc. Ventral interradii without granules/spines. Scales on ventral interradii covering the whole area of an interradius. The number of scales on $\mathrm{H}$ line of an interradius more than 21. Ventral teeth several (tooth papillae). Infradental papillae on oral plate present. Buccal scales on OP present. Accessory oral papillae on OP absent. Lateral oral papillae on OP absent. Adoral shield spine present. Lyman's ossicle present. Oral shield covering more than one third of the length of an interradius; about as long as wide. Madreporite multiple; with numerous pores. Adoral shield meeting in front of the oral shield. Abradial genital plate not twisted. Number of genital slits one per bursa. Genital slit longer than half the length of an interradius. Genital papillae absent. Dental plate dorsal half widest; entire (single plate). Dental sockets slit-shaped; equal to or more than $50 \%$ of the width. At least one socket on DP as perforation with septum. Teeth block-like (with square tip). Teeth on DP arranged as a single row on $2 / 3$ and a cluster of tooth papillae on $1 / 3$ of dental plate. 
VERTEBRAE. Vertebrae zygospondylous; beyond segment 5 with short keel; without oral bridge.

Suborder Gnathophiurina Matsumoto, 1915

Superfamily Amphiuroidea Ljungman, 1867

Family Amphiuridae Ljungman, 1867

\section{Type genus}

Amphiura Forbes, 1843.

\section{Other genera}

Acrocnida Gislén, 1926; Amphichondrius Nielsen, 1932; Amphicontus Hill, 1940; Amphigyptis Nielsen, 1932; Amphiodia Verrill, 1899; Amphiomya H.L. Clark, 1939; Amphioncus H.L. Clark, 1939; Amphioplus Verrill, 1899; Amphipholis Ljungman, 1866; Amphipholizona H.L. Clark, 1915; Amphistigma H.L. Clark, 1938; Dougaloplus A.M. Clark, 1970; Microphiopholis Turner, 1985; Nannophiura Mortensen, 1933; Nudamphiura Tommasi, 1965; Ophiocentrus Ljungman, 1867; Ophiocnida Lyman, 1865; Ophiodaphne Koehler, 1930; Ophionephthys Lütken, 1869; Ophiophragmus Lyman, 1865; Ophiosphaera Brock, 1888; Ophiostigma Lütken, 1856; Paracrocnida Mortensen, 1940; Paramphichondrius Guille \& Wolff, 1984; Paramphiura Koehler, 1895; Triplodia Turner \& Hallan, 2011.

\section{Description}

Arm. Arm shape unbranched; length $3-4 \times$ or more than $4 \times$ disc diameter; covering without granules/spines/tubercles. Arm combs absent. Dorsal arm plate present. Accessory dorsal arm plate absent. Ventral arm plate present. Accessory ventral arm plate absent. Girdle of tiny hooks on the arms absent. Spines all similar in shape. Arm spine cross section round. The ratio of thickness of distal $1 / 3$ of arm spine to maximum thickness (in a given cross-sectional plane) $0.6-0.9$, or $0.9-1$. Arm spines tapering (conical), cylindrical, or pointed; mainly lateral; predominantly parallel to arm axis (adpressed). Longest arm spines between half and one, or between one and two segments long. Tentacle scales present or absent (Ophiophragmus); pores only proximally visible along the arm; nearly as long as wide; shorter than the spine nearby; cross section oval. Position of lateral arm plate (LAP) only lateral. Dorsal and/or ventral edge(s) of LAPs without constriction. Ventral position of LAP not projecting ventro-proximalwards. Ventro-distal tip of LAP not projecting ventralwards. Arm spine articulation without dorsal and ventral lobes, or with dorsal and ventral lobes; without sigmoidal fold; arranged over entire distal LAP edge; ventralwards increasing in size. Distance between spine articulations dorsalwards increasing.. Nerve and muscle openings separated by small ridge if at all. Nerve opening approximately as large as muscle opening.

DoRSAL DISC. Disc pentagonal to circular; flat (about same level as arms) to high (above arm level). Integument not obscuring plates. Dorsal disc without granules; with obvious primary plates or with concealed primary plates; without scales; without spines or with spines, granules and tubercles in some genera (O’Hara et al. 2018). Dorsal disc scale/plate without tubercles. Radial shield present; without granules/spines; length between one third and half of the disc radius; scalene (oblique) triangular, or isosceles (mirror-symmetric) triangular to pear-shaped, or bar-like.

VeNTRAL DISC. Gonads restricted to the disc. Ventral interradii without granules/spines or with spines. Scales on ventral interradii covering the whole area of interradius or absent. The number of scales on $\mathrm{H}$ line of an interradius about 14-21. Ventral teeth single. Infradental papillae on oral plate present. Buccal scales on OP present. Accessory oral papillae on OP absent. Lateral oral papillae on OP absent. Adoral shield spine present. Lyman's ossicle present. Oral shield covering less than one third of interradius; 
much wider than long or about as long as wide (Amphipholis). Madreporite one; with one pore or with numerous pores. Adoral shield separated or meeting in front of the oral shield. Abradial genital plate not twisted. Number of genital slits one per bursa. Genital slit longer than half the length of an interradius. Genital papillae absent. Dental plate dorsal half widest, entire (single plate). Dental sockets slit-shaped to heart-shaped, equal to or more that $50 \%$ of the width of dental plate. At least one socket on DP as perforation with septum. Teeth block-like (with square tip). Teeth on DP arranged as single column.

VERTEBRAE. Vertebrae zygospondylous; beyond segment 5 with short keel; without oral bridge.

Family Amphilepididae Matsumoto, 1915

\section{Type genus}

Amphilepis Ljungman, 1867.

\section{Other genera}

Ophiomonas Djakonov, 1952.

\section{Description}

ARM. Arm shape unbranched; length more than $4 \times$ disc diameter; covering without granules/spines/tubercles. Arm combs absent. Dorsal arm plate present. Accessory dorsal arm plate absent. Ventral arm plate present. Accessory ventral arm plate absent. Girdle of tiny hooks on the arms absent. Spines all similar in shape. Arm spine cross section round. The ratio of thickness of distal $1 \frac{1}{3}$ of arm spine to maximum thickness (in a given cross-sectional plane) 0.6-0.9. Arm spines pointed; mainly lateral; predominantly erect, standing perpendicular to arm axis. Longest arm spines between one and two segments long. Tentacle scales absent. Position of lateral arm plate (LAP) arched (wrapped around the arm). Dorsal and/or ventral edge(s) of LAPs without constriction. Ventral position of LAP projecting ventro-proximalwards. Ventro-distal tip of LAP not projecting ventralwards. Arm spine articulation with dorsal and ventral lobes; without sigmoidal fold; arranged over entire distal LAP edge; ventralwards increasing in size. Distance between spine articulations dorsalwards increasing. Nerve and muscle openings separated by small ridge if at all. Nerve opening smaller than muscle opening.

DorSAL DISC. Disc pentagonal to circular; flat (about same level as arms). Integument not obscuring plates. Dorsal disc without granules; with obvious primary plates; with scales; without spines. Dorsal disc scale/plate without tubercles. Radial shield present; without granules/spines; length more than half of the disc radius; scalene (oblique) triangular.

VENTRAL DISC. Gonads restricted to the disc. Ventral interradii without granules/spines. Scales on ventral interradii covering the whole area of an interradius. The number of scales on $\mathrm{H}$ line of an interradius about 14-21. Ventral teeth single. Infradental papillae on oral plate present. Buccal scales on OP present. Accessory oral papillae on OP absent. Lateral oral papillae on OP absent. Adoral shield spine present. Lyman's ossicle present. Oral shield covering less than one third of interradius; much wider than long. Madreporite one; with one pore. Adoral shield meeting in front of the oral shield. Abradial genital plate not twisted. Number of genital slits one per bursa. Genital slit longer than half the length of an interradius. Genital papillae absent. Dental plate of equal width all over; entire (single plate). Dental sockets slit-shaped and heart-shaped; less than $50 \%$ of the width. At least one socket on DP as depression or perforation without septum. Teeth flat (with round or slightly pointed tip, but never spine-like). Teeth on DP arranged as single row.

VERTEBRAE. Vertebrae zygospondylous; beyond segment 5 with short keel; without oral bridge. 
Superfamily Ophiactoidea Ljungman, 1867

Family Ophiothamnidae O’Hara, Stöhr, Hugall, Thuy \& Martynov, 2018

\section{Type genus}

Ophiothamnus Lyman, 1869.

\section{Other genera}

Histampica A.M. Clark, 1970; Ophioleila A.H. Clark, 1949.

\section{Description}

ARM. Arm shape unbranched; length more than $4 \times$ disc diameter; covering without granules/spines/tubercles. Arm combs absent. Dorsal arm plate present. Accessory dorsal arm plate absent. Ventral arm plate present. Accessory ventral arm plate absent. Girdle of tiny hooks on the arms absent. Spines all similar in shape. Arm spine cross section round. The ratio of thickness of distal $1 \frac{1}{3}$ of arm spine to maximum thickness (in a given cross-sectional plane) 0.6-0.9. Arm spines pointed; mainly lateral; predominantly erect, standing perpendicular to arm axis. Longest arm spines between one and two segments long. Tentacle scales present; pores visible along most of the arm; nearly as long as wide; shorter than the spine nearby; cross section oval. Position of lateral arm plate (LAP) arched (wrapped around the arm). Dorsal and/or ventral edge(s) of LAPs without constriction. Ventral position of LAP projecting ventro-proximalwards. Ventro-distal tip of LAP not projecting ventralwards. Arm spine articulation with dorsal and ventral lobes; without sigmoidal fold; arranged over entire distal LAP edge; larger in middle of arm. Distance between spine articulations dorsalwards increasing. Nerve and muscle openings separated by small ridge if at all. Nerve opening approximately as large as muscle opening.

DorSAL DISC. Disc pentagonal to circular; flat (about same level as arms). Integument not obscuring plates. Dorsal disc without granules; with concealed primary plates; with scales; with spines or without spines. Dorsal disc scale/plate without tubercles. Radial shield present; without granules/spines; length between one third and half of the disc radius; scalene (oblique) triangular.

VeNTRAL DISC. Gonads restricted to the disc. Ventral interradii without granules/spines. Scales on ventral interradii covering the whole area of an interradius. The number of scales on $\mathrm{H}$ line of an interradius about 7-14. Ventral teeth single. Infradental papillae on oral plate present. Buccal scales on OP present. Accessory oral papillae on OP absent. Lateral oral papillae on OP absent. Adoral shield spine present. Lyman's ossicle present. Oral shield covering less than one third of interradius; about as long as wide. Madreporite one; with one pore. Adoral shield meeting in front of the oral shield. Abradial genital plate not twisted. Number of genital slits one per bursa. Genital slit longer than half the length of an interradius. Genital papillae absent. Dental plate ventral half widest; entire (single plate). Dental sockets circular; less than $50 \%$ of the width. At least one socket on DP as depression or perforation without septum. Teeth flat (with round or slightly pointed tip, but never spine-like). Teeth on DP arranged as single row.

VERTEBRAE. Vertebrae zygospondylous; beyond segment 5 with short keel; without oral bridge.

Family Ophiactidae Matsumoto, 1915

\section{Type genus}

Ophiactis Lütken, 1856. 


\section{Other genera}

Hemipholis Lyman, 1865.

\section{Description}

ARM. Arm shape unbranched; length 3-4× disc diameter, or length more than $4 \times$ disc diameter; covering without granules/spines/tubercles. Arm combs absent. Dorsal arm plate present. Accessory dorsal arm plate absent. Ventral arm plate present. Accessory ventral arm plate absent. Girdle of tiny hooks on the arms absent. Spines all similar in shape. Arm spine cross section round. The ratio of thickness of distal $1 / 3$ of arm spine to maximum thickness (in a given cross-sectional plane) $0.6-0.9$, or $0.9-1$. Arm spines pointed; mainly lateral; predominantly erect, standing perpendicular to arm axis. Longest arm spines between half and one segment long, or between one and two segments long. Tentacle scales present; pores visible along most of the arm; slightly longer than wide; shorter than the spine nearby; cross section oval. Position of lateral arm plate (LAP) arched (wrapped around the arm). Dorsal and/or ventral edge(s) of LAPs without constriction. Ventral position of LAP projecting ventro-proximalwards. Ventro-distal tip of LAP not projecting ventralwards. Arm spine articulation with dorsal and ventral lobes; without sigmoidal fold; arranged over entire distal LAP edge; larger in middle of arm. Distance between spine articulations dorsalwards increasing. Nerve and muscle openings separated by small ridge if at all. Nerve opening approximately as large as muscle opening.

DORSAL DISC. Disc pentagonal or circular; high (above arm level). Integument not obscuring plates. Dorsal disc without granules; with obvious primary plates; with scales; with spines. Dorsal disc scale/plate without tubercles. Radial shield present; without granules/spines; length more than half of the disc radius; scalene (oblique) triangular.

VENTRAL DISC. Gonads restricted to the disc. Ventral interradii without granules/spines. Scales on ventral interradii covering the whole area of an interradius. The number of scales on $\mathrm{H}$ line of an interradius about 14-21. Ventral teeth single. Infradental papillae on oral plate present. Buccal scales on OP present. Accessory oral papillae on OP absent. Lateral oral papillae on OP absent. Adoral shield spine present. Lyman's ossicle present. Oral shield covering less than one third of interradius; much longer than wide or about as long as wide. Madreporite one; with one pore. Adoral shield meeting in front of the oral shield. Abradial genital plate not twisted. Number of genital slits one per bursa. Genital slit longer than half the length of an interradius. Genital papillae absent. Dental plate of equal width all over, or dorsal half widest; entire (single plate). Dental sockets slit-shaped; equal to or more than $50 \%$ of the width. At least one socket on DP as perforation with septum. Teeth block-like (with square tip). Teeth on DP arranged as single row.

VERTEBRAE. Vertebrae zygospondylous; beyond segment 5 with short keel; without oral bridge.

Family Ophiopholidae O’Hara, Stöhr, Hugall, Thuy \& Martynov, 2018

\section{Type genus}

Ophiopholis Müller \& Troschel, 1842. (No other genera)

\section{Description}

ARM. Arm shape unbranched; length 3-4× disc diameter; covering without granules/spines/tubercles. Arm combs absent. Dorsal arm plate present. Accessory dorsal arm plate present. Ventral arm plate present. Accessory ventral arm plate present. Girdle of tiny hooks on the arms absent. Spines not all similar in shape. The atypical spines are hook-shaped. Arm spine cross section round. The ratio of thickness of distal $1 / 3$ of arm spine to maximum thickness (in a given cross-sectional plane) $0.6-0.9$. Arm spines 
pointed; mainly lateral; predominantly erect, standing perpendicular to arm axis. Longest arm spines between one and two segments long. Tentacle scales present; pores visible along most of the arm; nearly as long as wide; shorter than the spine nearby; cross section oval. Position of lateral arm plate (LAP) arched (wrapped around the arm). Dorsal and/or ventral edge(s) of LAPs with constriction. Ventral position of LAP projecting ventro-proximalwards. Ventro-distal tip of LAP not projecting ventralwards. Arm spine articulation with dorsal and ventral lobes; without sigmoidal fold; arranged over entire distal LAP edge; larger in middle of arm. Distance between spine articulations dorsalwards increasing. Nerve and muscle openings separated by small ridge if at all. Nerve opening approximately as large as muscle opening.

Dorsal DISC. Disc circular; flat (about same level as arms). Integument not obscuring plates. Dorsal disc with granules; with obvious primary plates; with scales; with spines. Dorsal disc scale/plate with tubercles. Radial shield present; with granules and with tubercles grown out of plate; length between one third and half of the disc radius; scalene (oblique) triangular.

Ventral Disc. Gonads restricted to the disc. Ventral interradii with spines. Scales on ventral interradii absent. Ventral teeth single. Infradental papillae on oral plate present. Buccal scales on OP present. Accessory oral papillae on OP absent. Lateral oral papillae on OP absent. Adoral shield spine present. Lyman's ossicle present. Oral shield covering less than one third of interradius; much wider than long. Madreporite one; with one pore. Adoral shield meeting in front of the oral shield. Abradial genital plate not twisted. Number of genital slits one per bursa. Genital slit longer than half the length of an interradius. Genital papillae absent. Dental plate ventral half widest; entire (single plate). Dental sockets circular; equal to or more than $50 \%$ of the width. At least one socket on DP as perforation with septum. Teeth block-like (with square tip). Teeth on DP arranged as a single row on $2 / 3$ and a cluster of tooth papillae on $1 / 3$ of dental plate.

VERTEBRAE. Vertebrae zygospondylous; beyond segment 5 with extended keel; without oral bridge.

Family Ophiotrichidae Ljungman, 1867

\section{Type genus}

Ophiothrix Müller \& Troschel, 1840.

\section{Other genera}

Gymnolophus Brock, 1888; Lissophiothrix H.L. Clark, 1938; Macrophiothrix H.L. Clark, 1938; Ophiocnemis Müller \& Troschel, 1842; Ophiogymna Ljungman, 1866; Ophiolophus MarktannerTurneretscher, 1887; Ophiomaza Lyman, 1871; Ophiophthirius Döderlein, 1898; Ophiopsammium Lyman, 1874; Ophiopteron Ludwig, 1888; Ophiothela Verrill, 1867; Ophiotrichoides Ludwig, 1882.

\section{Description}

ARM. Arm shape unbranched; length more than $4 \times$ disc diameter; covering without granules/spines/tubercles. Arm combs absent. Dorsal arm plate present. Accessory dorsal arm plate absent. Ventral arm plate present. Accessory ventral arm plate absent. Girdle of tiny hooks on the arms absent. Spines all similar in shape. Arm spine cross section round. The ratio of thickness of distal $1 / 3$ of arm spine to maximum thickness (in a given cross-sectional plane) $0.6-0.9$. Arm spines pointed; mainly lateral; predominantly erect, standing perpendicular to arm axis. Longest arm spines longer than two segments long. Tentacle scales present; pores visible along most of the arm; more than two times as long as wide; as long as the spine nearby; cross section round. Position of lateral arm plate (LAP) arched (wrapped around the arm). Dorsal and/or ventral edge(s) of LAPs without constriction. Ventral position of LAP projecting ventro-proximalwards. Ventro-distal tip of LAP not projecting ventralwards. Arm spine articulation with dorsal and ventral lobes; 
without sigmoidal fold; arranged over entire distal LAP edge; larger in middle of arm. Distance between spine articulations dorsalwards increasing. Nerve and muscle openings separated by small ridge if at all. Nerve opening approximately as large as muscle opening.

Dorsal DISC. Disc circular; flat (about same level as arms). Integument not obscuring plates. Dorsal disc without granules; with concealed primary plates; with scales; with spines. Dorsal disc scale/plate without tubercles. Radial shield present; with spines; length more than half of the disc radius; scalene (oblique) triangular.

VENTRAL DISC. Gonads restricted to the disc. Ventral interradii with spines. Scales on ventral interradii absent. Ventral teeth single or with several tooth papillae (O'Hara et al. 2018). Infradental papillae on oral plate absent. Buccal scales on OP present. Accessory oral papillae on OP absent. Lateral oral papillae on OP absent. Adoral shield spine absent. Lyman's ossicle absent. Oral shield covering less than one third of interradius; much wider than long. Madreporite one; with one pore. Adoral shield separated. Abradial genital plate not twisted. Number of genital slits one per bursa. Genital slit longer than half the length of an interradius. Genital papillae absent. Dental plate ventral half widest; entire (single plate). Dental sockets slit-shaped and circular; less than $50 \%$ of the width of to equal to or more than $50 \%$ of the width. At least one socket on DP as perforation with septum. Teeth flat (with round or slightly pointed tip, but never spine-like). Teeth on DP arranged as a single row on half of dental plate and other half with a cluster of tooth papillae (ventral cluster).

VeRTEBRAE. Vertebrae zygospondylous; beyond segment 5 with extended keel; without oral bridge.

\section{Discussion}

One of the main results of this study is the analysis of previously introduced characters (Smith et al. 1995; Pomory 2007; Thuy \& Stöhr 2016; O'Hara et al. 2018) and selection of those most useful for family identification. To illustrate, the dental plate was described in greater detail in Thuy \& Stöhr (2016) than in Smith et al. (1995), i.e., the geometry of the dental plates, as well as the shape, depth, and size of its sockets. Moreover, the arrangement of teeth and the cluster of tooth papillae is here categorized into four groups to cover all available variations, regarding single/multiple columns and the ratio of teeth to tooth papillae for each family. In addition, dorsal and ventral covering of arm and disc are modified, following the terminology described above, to better define what 'scale', 'plate', 'tubercle' and 'granule' mean and how they are assessed in an organized classification. Although Pomory (2007) illustrated the arm spine shapes, it was not applicable at the family level, and still some details were overlooked. We revise the classification of the arm spine shapes by integrating the tip and cross-sectional shapes, to define all types of arm spine, including flat, tapering, pointed, and circular. Hendler's study (2018) was instrumental in clarifying the confusion about the development and homologies of the oral papillae, and for the first time his new terminology has been applied in the current identification key. Tentacle scales were termed 'podial scales' in some earlier publications (Pomory 2007) and ambiguously described with subjective terminology (Pomory 2007; O'Hara et al. 2018). Here, apart from the visibility of the tentacle pores along the arm, the tentacle scale length is described relative to the nearest spine to overcome subjective terms such as long or short. Moreover, different descriptions of shape suggested earlier (Thuy \& Stöhr 2016) are substituted by a comparison of the length of each tentacle scale with its width combined with the shape (oval/round) of its cross-section. The definition of 'keel' based on LeClair (1996) occurs only in Ophiopholis, Ophiotrichidae and Ophionereis. We use "extended keel" as an equivalent to LeClair's definition and "short keel" in the broader sense of an arrow-shaped projection. According to this definition, the families Ophiopholidae, Ophiotrichidae and Ophionereididae have an extended keel and all others with the exception of Euryalida (non-keeled) have a short keel. To conclude, our result of creating a functional key suggests that the chosen states for each family are in good agreement with those mentioned 
in previous studies (Mortensen 1927; Fell 1960; Clark \& Rowe 1971; Paterson 1985; Pomory 2007; Martynov 2010a; Gondim et al. 2013).

The possibilities offered by computer-based multi-access keys (interactive keys) have rarely been explored for brittle stars. Possibly the first of its kind was presented by Smirnov et al. (2006), for species of the Arctic and Antarctica, but he used a specially developed software that is unfortunately not available anymore. A key to Antarctic species created with DELTA was available on the website of the Melbourne museum but can no longer be accessed. The only interactive key to brittle stars still freely available online comprises 16 species from south-eastern Brazil (Alitto et al. 2016) and was created using the software Xper (Ung et al. 2010), which is similar in functionality to DELTA. Walter \& Winterson (2007) mentioned DELTA as a standard format for taxonomic descriptions and also as a database for interactive keys, despite the fact that the format is rather inflexible compared with the Structure of Descriptive Data (SDD) format, which was proposed as a standard for taxonomic descriptions by the association for biodiversity information standards, TDWG (www.tdwg.org). Coleman et al. (2010) also described the advantage of the software package DELTA for taxonomists and prepared an introduction to the software for beginners. The interactive identification key (Intkey) shows an advantage over conventional keys, due to its flexibility of applying characters in any order, interactive techniques such as automatically showing relevant images and allowing choice of states by clicking on an image, the possibility of updating the key (character deletion and change), when more data are available, and setting error tolerance and expressing uncertainty while using the intkey.

The keys presented in this study are the first conventional and interactive keys for the 33 currently accepted families, albeit still based on a limited selection of examined species, and the first release version still has limitations. Identification to the family level is more difficult than species identification, because many families are composed of a large number of species, usually grouped in several genera. The morphological diversity is thus considerably higher than within a species, and the delimitation of a family must be based on the selection of characteristics shared by as many species as possible. Pending the full taxonomic revision of each family, we attempted to delimit the families from one another by examination of selected species, but the (non-)availability of material (particularly of rare species) and a reasonable effort with highly time-consuming methods, limited the number of included species. Possibly, not all family-specific characters needed to correctly assign all species to a family have been recognized yet. While nomenclatural rules require that the type species of a family must be the basis of that family, the type species does not always share many characters with the majority of other included species. For example, the Ophiomyxidae as currently understood, include genera (e.g., Ophioconis) that are superficially more similar to Ophiodermatidae than to Ophiomyxa and were previously placed in that family. On the other hand, Ophiomusaidae and Ophiosphalmidae are separated by few characters. These limitations highlight the difficulty of collecting data from morphological characters and interpreting the available states. Direct observation (albeit on images) is a painstaking and highly time-consuming task. However, it has been shown that keys created from published data alone, without direct observation, are less accurate (Drinkwater 2009). Nevertheless, there might be some obstacles during the observation, since some characters might not be discriminate enough with different preservation methods, either wet or dried, e.g., thick/thin skin. We categorized the surface of the arm spine into five different states, but excluded them from our study in the end since the wet/dry preservation had an effect on arm spine surface shape. Technically, missing data are handled in DELTA Intkey and in conventional keys, but inadequate data can prevent the separation of some taxa. We tested the separability of taxa in Intkey (using diagnosis level 1) and the result showed that the tested taxa were separated using the current characters and chosen states. Given the above considered limitations, the result from such an analysis should of course be treated with considerable caution. 
The polychotomous conventional key created by DELTA from the full dataset is limited to a single entry point and a single pathway that must be followed to identify a specimen to family level. If any of the choices are impossible, because the specimen is incomplete or lacks the character in question (which can be the case with species not included in this study), an identification may not be possible. To facilitate its use in the field, where computers may not be available and preparations and microscopy may be difficult, the conventional key was built with priority on external characters, which may make it less accurate, though, because recent studies have emphasized the taxonomic importance of internal and microscopic features (Martynov 2010a; Thuy \& Stöhr 2016; O'Hara et al. 2018). In contrast, a tabular key has multiple entry points and may be a better alternative. The full data matrix can serve as a tabular key, but with 77 characters and 33 taxa, it is unwieldy. A condensed tabular key was created with DELTA as a more manageable compromise (Appendix 2).

Our approach should lend itself well for use by both general users of the key and specialist researchers. We conclude that an interactive software-based key is a practical and effective alternative to the conventional printed key. Further work should look into finding new characters and further observation of more genera from each family to construct a reliable and up to date identification key. We compared two different types of freely available software for the creation of identification keys and conclude that both are sufficient for this purpose, although users may favor one of them for particular features.

The family descriptions derived from this study are more detailed than the diagnoses provided by O'Hara et al. (2018), but they are still based on a small number of species and genera, and will need to be updated in the future. Some families were newly created by O'Hara et al. (2018) and consequently, they have never been described in detail before.

\section{Acknowledgments}

We gratefully acknowledge Dr Mike Dallwitz for his generous help regarding the DELTA program and all detailed comments on our data matrix. We also thank Dr Ben Thuy for his generosity in providing the SEM images of several species, we appreciate Dr Tim O'Hara for providing images of Ophiobyrsa and also Dr Yves Samyn for the possibility of examining RBINS specimens. Thanks go also to Usha Parameswaran for testing an earlier version of the key. This project was partly sponsored by INSF (No.97012132) and Ferdowsi University of Mashhad (No. 3/46018). We also appreciate the Biology Department at FUM for their logistic support.

\section{References}

Alitto R.A.S., Bueno M.L., Guilherme P.D.B., Domenico M.D., Beardsley Christensen A. \& Borges M. 2018. Shallow-water brittle stars (Echinodermata: Ophiuroidea) from Araçá Bay (Southeastern Brazil), with spatial distribution considerations. Zootaxa 4405: 1-66. https://doi.org/10.11646/zootaxa.4405.1.1

Clark A.M. \& Rowe F.W.E. 1971. Monograph of Shallow-water Indo-West Pacific Echinoderms. Trustees of the British Museum (Natural History), London.

Coleman C.O., Lowry J.K. \& Macfarlane T. 2010. DELTA for beginners: an introduction into the taxonomy software package DELTA. ZooKeys 45: 1-75. https://doi.org/10.3897/zookeys.45.263

Dallwitz M.J. 2019. Descriptions, Illustrations, Interactive Identification, and Information Retrieval from DELTA Databases. Available from https://www.delta-intkey.com/www/data.htm [accessed 15 Jul. 2021].

Dallwitz M.J. 2000. A Comparison of Interactive Identification Programs. Available from https://www.delta-intkey.com/www/comparison.htm [accessed 15 Jul. 2021].

Dallwitz M.J, Paine T. \& Zurcher E. 2000. Principles of Interactive Keys. Available from https://www.delta-intkey.com/www/interactivekeys.htm [accessed 15 Jul. 2021]. 
DallwitzM.J.,PaineT.\&ZurcherE. 2006. User 's Guide to the DELTA System:A General System for Processing Taxonomic Descriptions. Available from https://www.delta-intkey.com/www/uguide.pdf [accessed 15 Jul. 2021].

Devaney D.M. 1970. Studies on ophiocomid brittlestars. I. A new genus (Clarkcoma) of Ophiocominae with a reevaluation of the genus Ophiocoma. Smithsonian Contributions to Zoology 51: 1-41. https://doi.org/10.5479/si.00810282.51

Drinkwater R.E. 2009. Insights into the development of online plant identification keys based on literature review: an exemplar electronic key to Australian Drosera. Bioscience Horizons 2 (1): 90-96. https://doi.org/10.1093/biohorizons/hzp007

Fell H.B. 1960. Synoptic Keys to the Genera of Ophiuroidea. Victoria University, Wellington.

Gondim A.I., Alonso C., Dias T.L, Manso C.L. \& Christoffersen M.L. 2013. A taxonomic guide to the brittle-stars (Echinodermata, Ophiuroidea) from the State of Paraíba continental shelf, Northeastern Brazil. ZooKeys 307:45-96. https://doi.org/10.3897/zookeys.307.4673

Hendler G. 2018. Armed to the teeth: a new paradigm for the buccal skeleton of brittle stars (Echinodermata: Ophiuroidea). Contributions in Science 526: 189-311.

Koehler R. 1922. Ophiurans of the Philippine Seas and Adjacent Waters. US Government Printing Office, Washington. https://doi.org/10.5962/bhl.title.32917

LeClair E.E. 1996. Arm joint articulations in the ophiuran brittlestars (Echinodermata: Ophiuroidea): a morphometric analysis of ontogenetic, serial, and interspecific variation. Journal of Zoology, London 240: $245-275$.

LeClair E.E. \& LaBarbera M.C. 1997. An in vivo comparative study of intersegmental flexibility in the ophiuroid arm. The Biological Bulletin 193 (1):77-89. https://doi.org/10.2307/1542737

Lucidcentral 2012. Australian Aquatic Invertebrates. Available from https://keys.lucidcentral.org [accessed 17 Aug. 2021].

Ludwig H. 1899. Jugendformen von Ophiuren. Sitzungsberichte der Preussischen Akademie der Wissenschaften: 210-235.

Martynov A. 2010a. Reassessment of the classification of the Ophiuroidea (Echinodermata), based on morphological characters. I. General character evaluation and delineation of the families Ophiomyxidae and Ophiacanthidae. Zootaxa 2697 (1):1-154. https://doi.org/10.11646/zootaxa.2697.1.1

Martynov A. 2010b. Structure of the arm spine articulation ridges as a basis for taxonomy of Ophiuroidea (a preliminary report). In: Harris L., Böttger S.A., Walker C.W. \& Lesser M.P. (eds.) Echinoderms: Durham. Proceedings of the $12^{\text {th }}$ International Echinoderm Conference, Durham, New Hampshire, USA: 233-239.

Martynov A., Ishida Y., Irimura S., Tajiri R., O’Hara T. \& Fujita T. 2015. When Ontogeny Matters: A new Japanese species of brittle star illustrates the importance of considering both adult and juvenile characters in taxonomic practice. PloS One 10: e0139463. https://doi.org/10.1371/journal.pone.0139463

Matsumoto H. 1915. A new classification of the Ophiuroidea: with descriptions of new genera and species. Proceedings of the Academy of Natural Sciences, Philadelphia 67: 43-92.

Matsumoto H. 1917. A monograph of Japanese Ophiuroidea, arranged according to a new classification. Journal of the College of Science, Imperial University, Tokyo 38: 1-408.

Mortensen T. 1927. Handbook of the Echinoderms of the British Isles. Oxford University Press, London. https://doi.org/10.5962/bhl.title.6841 
Murakami S. 1963. The dental and oral plates of Ophiuroidea. Transactions of the Royal Society of New Zealand, Zoology 4: 1-48.

O’Hara T.D., Hugall A.F., Thuy B. \& Moussalli A. 2014. Phylogenomic resolution of the class Ophiuroidea unlocks a global microfossil record. Current Biology 24: 1874-1879.

https://doi.org/10.1016/j.cub.2014.06.060

O’Hara T.D., Hugall A.F., Thuy B., Stöhr S. \& Martynov A.V. 2017. Restructuring higher taxonomy using broad-scale phylogenomics: the living Ophiuroidea. Molecular Phylogenetics and Evolution 107: 415-430. https://doi.org/10.1016/j.ympev.2016.12.006

O’Hara T.D., Stöhr S., Hugall A.F., Thuy B. \& Martynov A. 2018. Morphological diagnoses of higher taxa in Ophiuroidea (Echinodermata) in support of a new classification. European Journal of Taxonomy 416: 1-35. https://doi.org/10.5852/ejt.2018.416

Okanishi M., Fujita T., Maekawa Y. \& Sasaki T. 2017. Non-destructive morphological observations of the fleshy brittle star, Asteronyx loveni using micro-computed tomography (Echinodermata, Ophiuroidea, Euryalida). ZooKeys 663: 1-19. https://doi.org/10.3897/zookeys.663.11413

Paterson G.L.J. 1985. The deep-sea Ophiuroidea of the North Atlantic Ocean. Bulletin of the British Museum (Natural History), Zoology Series 49: 1-162.

Pineda-Enriquez T., Solis-Marin F. A. \& Laguarda-Figueras A. 2014. Revision of the genus Ophioteichus H.L. Clark, 1938 (Ophiuroidea: Ophiolepididae). Zootaxa 3784 (3): 241-250.

https://doi.org/10.11646/zootaxa.3784.3.3

Pomory C.M. 2007. Key to the common shallow-water brittle stars (Echinodermata: Ophiuroidea) of the Gulf of Mexico and Caribbean Sea. Caribbean Journal of Sciences Special Publication 10: 1-42.

Shackleton J.D. 2005. Skeletal homologies, phylogeny and classification of the earliest asterozoan echinoderms. Journal of Systematic Palaeontology 3 (1): 29-114.

https://doi.org/10.1017/S1477201905001525

Smirnov I.S., Lobanov A.L., Kirejtshuk A.G. \& Vakhitov A.T. 2006. Creation on-line illustration keys of polar brittle stars with help webkey-X system. In: Harris L., Böttger S.A., Walker C.W. \& Lesser M.P. (eds.) Echinoderms: Durham. Proceedings of the $12^{\text {th }}$ International Echinoderm Conference, Durham, New Hampshire, USA: 255-257.

Smith A.B., Paterson G.L. \& Lafay B. 1995. Ophiuroid phylogeny and higher taxonomy: morphological, molecular and palaeontological perspectives. Zoological Journal of the Linnean Society 114 (2): 213-243. https://doi.org/10.1006/zjls.1995.0024

Stöhr S. 2012. Ophiuroid (Echinodermata) systematics - where do we come from, where do we stand and where should we go? Zoosymposia 7 (1): 147-162. https://doi.org/10.11646/zoosymposia.7.1.14

Stöhr S. \& Martynov A. 2016. Paedomorphosis as an evolutionary driving force: insights from deep-sea brittle stars. PloS One 11 (11): e0164562. https://doi.org/10.1371/journal.pone.0164562

Stöhr S., O’Hara T. \& Thuy B. 2012. Global diversity of brittle stars (Echinodermata: Ophiuroidea). PLoS One 7 (3): e31940. https://doi.org/10.1371/journal.pone.0031940

Stöhr S., O’Hara T., Thuy B. (eds) 2020. World Ophiuroidea Database. Available from http://www.marinespecies.org/ophiuroidea [accessed 20 Jul. 2020]. http://doi.org/10.14284/358

Thuy B. \& Stöhr S. 2011. Lateral arm plate morphology in brittle stars (Echinodermata: Ophiuroidea): new perspectives for ophiuroid micropalaeontology and classification. Zootaxa 3013 (1): 1-47. https://doi.org/10.11646/zootaxa.3013.1.1 
Thuy B. \& Stöhr S. 2016. A new morphological phylogeny of the Ophiuroidea (Echinodermata) accords with molecular evidence and renders microfossils accessible for cladistics. PloS One 11 (5): e0156140. https://doi.org/10.1371/journal.pone.0156140

Thuy B. \& Stöhr S. 2018. Unravelling the origin of the basket stars and their allies (Echinodermata, Ophiuroidea, Euryalida). Scientific Reports 8: 8493. https://doi.org/10.1038/s41598-018-26877-5

Ung V., Dubus G., Zaragüeta-Bagils R. \& Vignes-Lebbe R. 2010. Xper²: introducing $e$-taxonomy. Bioinformatics 26: 703-704. https://doi.org/10.1093/bioinformatics/btp715

Walter D.E. \& Winterton S. 2007. Keys and the crisis in taxonomy: extinction or reinvention? Annual Review of Entomology 52: 193-208. https://doi.org/10.1146/annurev.ento.51.110104.151054

Manuscript received: 15 September 2020

Manuscript accepted: 21 June 2021

Published on: 31 August 2021

Topic editor: Rudy C.A.M. Jocqué

Section editor: Didier VandenSpiegel

Desk editor: Radka Rosenbaumová

Printed versions of all papers are also deposited in the libraries of the institutes that are members of the EJT consortium: Muséum national d'histoire naturelle, Paris, France; Meise Botanic Garden, Belgium; Royal Museum for Central Africa, Tervuren, Belgium; Royal Belgian Institute of Natural Sciences, Brussels, Belgium; Natural History Museum of Denmark, Copenhagen, Denmark; Naturalis Biodiversity Center, Leiden, the Netherlands; Museo Nacional de Ciencias Naturales-CSIC, Madrid, Spain; Real Jardín Botánico de Madrid CSIC, Spain; Zoological Research Museum Alexander Koenig, Bonn, Germany; National Museum, Prague, Czech Republic.

\section{Supplementary material}

Supp. file 1. Condensed tabular key to the ophiuroid families. Only diagnostic characters for each family are included. Usage: find the family whose characters concur with your specimen.

https://doi.org/10.5852/ejt.2021.766.1483.4955

Supp. file 2. The full matrix of characters and items in ophiuroid family identification (tabular key). https://doi.org/10.5852/ejt.2021.766.1483.4957

Supp. file 3. Conventional key for ophiuroid family identification (OFID) exported from Xper3 (online application).

https://doi.org/10.5852/ejt.2021.766.1483.4959

Supp. file 4. Comparison of Xper2 and Xper3 with DELTA (CSIRO and ALA) platforms in providing conventional and interactive keys in taxonomy. https://doi.org/10.5852/ejt.2021.766.1483.4961 
Appendix I. Character list

\section{Arm}

\#1. Arm $<$ simple/branched $>$ /

1. shape unbranched/

2. shape branched/

\#2. Arm $<$ relative length $>$ /

1. length less than $2 \mathrm{x}$ disc diameter/

2. length $3 \mathrm{x}$ disc diameter/

3 . length $3-4 \mathrm{x}$ disc diameter/

4. length more than $4 \mathrm{x}$ disc diameter/

\#3. Arm < covering/structure $>$ /

1. covering without granules/spines/tubercles/

2. covering with granules/

3. covering with tubercles grown out of scales/plates/

\#4. Arm combs < presence/absence $>$ /

1. present/

2. absent/

\#5. Dorsal arm plate $<$ absence/presence $>$ /

1. present/

2. absent/

\#6. Accessory dorsal arm plate $<$ absence/presence $>/$

1. present/

2. absent/

\#7. Ventral arm plate $<$ absence/presence $>/$

1. present/

2. absent/

\#8. Accessory ventral arm plate $<$ absence/presence $>$ /

1. present/

2. absent/

\#9. Girdle of tiny hooks on the arms $<$ hook girdle $>$ /

1. present/

2. absent/

Note: The hooks are not arm spines and they do not occur anywhere else, these are tiny hooks in bands across the dorsal arm.

\#10. Spines $<$ shape $>/$

1. all similar in shape/

2. not all similar in shape/

\#11. The atypical spines $<$ hooks/bristles $>/$

1. are hook-shaped/

2. are bristles/

3. are umbrella-shaped/ 
\#12. Arm spine cross section $<$ shape $>/$

1. round/

2. oval/

$\# 13$. The ratio of thickness of distal $1 / 3$ of arm spine to maximum thickness (in a given cross-sectional plane) $<$ arm spine $>$ /
1. $0.2-0.6 /$
2. $0.6-0.9 /$
3. $0.9-1 /$

$\# 14$. Arm spines $<$ shape $>/$

1. tapering (conical) $<$ distally $1 / 3$ as thick as proximal diameter with round cross section $>$ /

2. flat $<$ distally half as thick as proximal diameter or same with oval cross section $>$ /

3. cylindrical $<$ same thickness at both ends with flat/round tip $>/$

4. pointed $<$ distally half as thick as proximal diameter with round cross section $>$ /

\#15. Arm spines $<$ position $>$ /

1. mainly lateral/

2. at proximal segments only on ventral side of arms/

\#16. Arm spines $<$ direction $>/$

1. predominantly parallel to arm axis (adpressed)/

2. predominantly erect, standing perpendicular to arm axis/

\#17. Longest arm spines $<$ relative length $>/$

1. shorter than half a segment/

2. between half and one segment long/

3. between one and two segments long/

4. longer than two segments/

\#18. Tentacle scales $<$ absence/presence $>$ /

1. present/

2. absent/

\#19. Tentacle pores $<$ visibility $>$

1. visible only on proximal arm /

2. visible along most of the arm /

$\# 20$. Tentacle scales $<$ length $>$ /

1. nearly as long as wide/

2. slightly longer than wide/

3. more than two times as long as wide/

\#21. Tentacle scales $<$ length compared with the spine nearby $>$ /

1. shorter than the spine nearby/

2. as long as the spine nearby/

3. longer than the spine nearby/

\#22. Tentacle scales $<$ oval/round $>$ /

1. cross section round/

2. cross section oval/ 
\#23. Position of lateral arm plate (LAP) <lateral/arched $>$ /

1. only lateral/

2. arched (wrapped around the arm)/

\#24. Dorsal and/or ventral edge(s) of LAPs $<$ with/without constriction=concave $>$ /

1. with constriction/

2. without constriction/

\#25. Ventral position of LAP < projecting ventro-proximalwards $>$ /

1. projecting ventro-proximalwards/

2. not projecting ventro-proximalwards/

\#26. Ventro-distal tip of LAP < projecting ventralwards, e.g., Ophiopallas >/

1. projecting ventralwards/

2. not projecting ventralwards/

\#27. Arm spine articulation <with/without dorsal and ventral lobes $>$ /

1. without dorsal and ventral lobes/

2. with dorsal and ventral lobes/

\#28. Arm spine articulation $<$ with/without sigmoidal fold $>$ /

1. without sigmoidal fold/

2. with a weakly developed sigmoidal fold/

3. with a fully developed sigmoidal fold/

\#29. Arm spine articulation $<$ central/entire $>$ /

1. restricted to (the ventral or central) portion of the distal edge/

2. arranged over entire distal LAP edge/

\#30. Arm spine articulation $<$ size $>$ /

1. dorsalwards increasing in size/

2. ventralwards increasing in size/

3. larger in middle/

4. all similar/

\#31. Distance between spine articulations/

1. dorsalwards increasing/

2. ventralwards increasing/

3. equal/

4. not applicable (two spine articulations)/

\#32. Nerve and muscle openings separated <related to arm spine articulation $>$ /

1. by small ridge if at all/

2. by large, prominent ridge or regular stereom/

\#33. Nerve opening < size - related to arm spine articulation>/

1. smaller than muscle opening/

2. approximately as large as muscle opening/

\section{Dorsal disc}

\#34. Disc < circular/pentagonal $>$ /

1. pentagonal/

2. circular/ 
\#35. Disc $<$ flat/high $>$ /

1. flat (about same level as arms)/

2. high (above arm level)/

3. a sac-like shape (much higher than wide)/

\#36. integument $<$ skin obscuring plates $>$ /

1. not obscuring plates/

2. obscuring plates/

\#37. Dorsal disc $<$ cover - granules $>/$

1. with granules/

2. without granules/

\#38. Dorsal disc $<$ cover - primary plates $>/$

1. with obvious primary plates/

2. with concealed primary plates/

\#39. Dorsal disc $<$ cover - scale $>$ /
1. with scales/
2. without scales/

\#40. Dorsal disc $<$ cover - spines $>/$
1. with spines/
2. without spines/

\#41. Dorsal disc scale/plate $<$ tubercles growing out of scales/plates $>/$
1. with tubercles/
2. without tubercles/

\#42. Radial shield $<$ absence/presence $>$ /

1. present/

2. absent/

\#43. Radial shield $<$ covering $>$ /

1. without granules/spines/

2. with spines/

3. with granules/

4. with tubercles grown out of plate/

\#44. Radial shield $<$ length $>$ /

1. length less than one third of the disc radius/

2. length between one third and half of the disc radius/

3. length more than half of the disc radius/

\#45. Radial shield $<$ shape $>$ /

1. scalene (oblique) triangular/

2. isosceles (mirror-symmetric) triangular to pear-shaped/

3. bar-like/

\section{Ventral disc}

\#46. Gonads < position>/

1. restricted to the disc/

2. not restricted to the disc (extending into the basal portion of the arms)/ 
\#47. Ventral interradii $<$ cover $>$ /

1. without granules/spines/

2. with spines/

3. with granules/

\#48. Scales on ventral interradii < covering - from disc edge $>$ /

1. covering the whole area of an interradius/

2. covering half/less than half of an interradius/

3. absent/

\#49. The number of scales on $\mathrm{H}$ line of an interradius $<$ the interradius is assumed as a triangle and $\mathrm{H}$ gives its height $>/$

1. fewer than $7 /$

2. 7-14/

3. $14-21 /$

4. more than $21 /$

\#50. Ventral teeth $<$ the number of oral papillae sensu lato on DP $>/$

1. single/

2. several (tooth papillae)/

A cluster is not the same as the tooth papillae but in some species, the cluster is large and very similar to tooth papillae.

\#51. Infradental papillae on oral plate $<$ absence/presence $>$ /

1. present/

2. absent/

\#52. Buccal scales on OP $<$ absence/presence $>$ /

1. present/

2. absent/

\#53. Accessory oral papillae on OP $<$ absence/presence $>$ /

1. present/

2. absent/

\#54. Lateral oral papillae on OP $<$ absence/presence $>$ /

1. present/

2. absent/

\#55. Lateral oral papillae $<$ number $>/$

1. one lateral papilla along each side of the jaw/

2. single row of lateral papillae/

3. multiple rows of lateral papillae/

\#56. Lateral oral papillae $<$ shape $>/$

1. block-shaped/

2. rounded/

3. paddle-shaped/

4. spiniform/ 
\#57. Adoral shield spine $<$ absence/presence $>/$

1. present/

2. absent/

\#58. Lyman's ossicle <absence/presence $>/$

1. present/

2. absent/

\#59. Oral shield $<$ length - distance between proximal tip of OS and disc margin $>$ /

1. covering less than one third of interradius/

2. covering more than one third of the length of an interradius/

\#60. Oral shield $<$ shape $>/$

1. much longer than wide/

2. about as long as wide/

3. much wider than long/

\#61. Madreporite < number $>/$

1. one/

2. multiple/

3. absent/

\#62. Madreporite $<$ number of pores on each maderporte $>$ /

1. with one pore/

2. with numerous pores/

\#63. Adoral shield $<$ separated or meeting in front of oral shield $>$ /

1. separated/

2. meeting in front of the oral shield/

\#64. Abradial genital plate $<$ shape $>$ /

1. twisted/

2. not twisted/

\#65. Number of genital slits $<1 / 2$ slits per bursa $>$ /

1. one per bursa/

2. two per bursa/

\#66. Genital slit <length $>$ /

1. shorter than half interradius/

2. longer than half the length of an interradius/

\#67. Genital papillae <absence/presence $>$ /

1. present/

2. absent/

\#68. Dental plate <geometry $>$ /

1. of equal width all over/

2. ventral half widest/

3. dorsal half widest/ 
\#69. Dental plate $<$ entire/fragmented $>/$

1. entire (single plate)/

2. fragmented/

\#70. Dental sockets $<$ shape $>$ /

1. slit-shaped/

2. circular/

3. heart-shaped/

\#71. Dental sockets $<$ size $>/$

1. less than $50 \%$ of the width/

2. equal to or more than $50 \%$ of the width/

\#72. At least one socket on DP as $<$ depression/perforation - with/without septum $>$ /

1. depression or perforation without septum/

2. perforation with septum/

\#73. Teeth $<$ shape $>/$

1. spine-shaped/

2. flat (with round or slightly pointed tip, but never spine-like)/

3. block-like (with square tip)/

$\# 74$. Teeth on DP arranged as $<$ the ratio of teeth and tooth papillae on dental plate $>$ /

1. single column/

2. a single column on half of dental plate and other half with a cluster of tooth papillae (ventral cluster) <e.g., Ophiotrichidae, Ophiopholidae $>$ /

3. a single column on $2 / 3$ and a cluster of tooth papillae on $1 / 3$ of dental plate $<$ e.g., Ophiuridae $>$ /

4. covering the entire dental plate evenly $<$ e.g., Gorgonocephalidae $>/$

\section{Vertebrae}

$\# 75$. Vertebrae <streptospondylous/zygospondylous $>$ /

1. hourglass-shaped (streptospondylous)/

2. zygospondylous/

\#76. Vertebrae beyond segment $5<$ keeled/non-keeled $>$ /

1. with extended keel/

2. with short keel/

3. non-keeled/

\#77. Vertebrae < with/without oral bridge $>$ /

1. with oral bridge/

2. without oral bridge/ 
Appendix 2 (continued on next page). Condensed tabular key to the ophiuroid families (modified from the prt file exported from DELTA). Heteromorphic families appear more than once in the table below (e.g., Ophiopyrgidae $=4$ ) and the number of occurrences in the table is indicated in the second column (No. occ.). Each occurrence represents a different set of diagnostic characters and heteromorphic families can be identified from species with different morphology. This offers multiple entry points to the key. Next to a taxon name and its occurrence, there is a list of the characters that separate it from the other taxa in the key. The characters are presented by numbers combined with a letter for the state. State 1,2, 3 and 4 become state A, B, C and D; for example, 17A corresponds to state 1 in character 17 (see Appendix 1). The table can also be used to compare families by morphological similarity.

\begin{tabular}{|c|c|c|}
\hline Family & No. occ. & Diagnostic characters \\
\hline Ophiopyrgidae & 4 & $17 \mathrm{~A}, 14 \mathrm{~A}, 4 \mathrm{~A}, 5 \mathrm{~A}, 10 \mathrm{~A}, 15 \mathrm{~A}$ \\
\hline Asteronychidae & 1 & $17 \mathrm{~A}, 14 \mathrm{~A}, 4 \mathrm{~B}, 5 \mathrm{~B}, 10 \mathrm{~B}, 15 \mathrm{~B}$ \\
\hline Ophiodermatidae & 1 & $17 \mathrm{~A}, 14 \mathrm{~B}$ \\
\hline Astrophiuridae & 2 & $17 \mathrm{~A}, 14 \mathrm{C}, 45 \mathrm{~A}$ \\
\hline Ophiopyrgidae & 4 & $17 \mathrm{~A}, 14 \mathrm{C}, 45 \mathrm{~B}, 4 \mathrm{~A}, 15 \mathrm{~A}, 20 \mathrm{C}, 41 \mathrm{~B}$ \\
\hline Hemieuryalidae & 2 & $17 \mathrm{~A}, 14 \mathrm{C}, 45 \mathrm{~B}, 4 \mathrm{~B}, 15 \mathrm{~B}, 20 \mathrm{~A}, 41 \mathrm{~A}$ \\
\hline Euryalidae & 1 & $17 \mathrm{~A}, 14 \mathrm{C}, 45 \mathrm{C}$ \\
\hline Ophiosphalmidae & 1 & $17 \mathrm{~A}, 14 \mathrm{D}, 20 \mathrm{~A}, 21 \mathrm{~A}, 22 \mathrm{~A}, 34 \mathrm{~A}, 40 \mathrm{~A}$ \\
\hline Astrophiuridae & 2 & $17 \mathrm{~A}, 14 \mathrm{D}, 20 \mathrm{~A}, 21 \mathrm{~B}, 22 \mathrm{~B}, 34 \mathrm{~B}, 40 \mathrm{~B}$ \\
\hline Ophiolepididae & 1 & $17 \mathrm{~A}, 14 \mathrm{D}, 20 \mathrm{~B}, 6 \mathrm{~A}, 38 \mathrm{~A}, 63 \mathrm{~B}, 31 \mathrm{~A}$ \\
\hline Ophiopezidae & 1 & $17 \mathrm{~A}, 14 \mathrm{D}, 20 \mathrm{~B}, 6 \mathrm{~B}, 38 \mathrm{~B}, 63 \mathrm{~A}, 31 \mathrm{C}, 16 \mathrm{~A}, 36 \mathrm{~B}, 39 \mathrm{~B}, 40 \mathrm{~A}$ \\
\hline Ophiomyxidae & 3 & $17 \mathrm{~A}, 14 \mathrm{D}, 20 \mathrm{~B}, 6 \mathrm{~B}, 38 \mathrm{~B}, 63 \mathrm{~A}, 31 \mathrm{C}, 16 \mathrm{~B}, 36 \mathrm{~A}, 39 \mathrm{~A}, 40 \mathrm{~B}$ \\
\hline Ophiopyrgidae & 4 & $17 \mathrm{~A}, 14 \mathrm{D}, 20 \mathrm{C}, 4 \mathrm{~A}, 34 \mathrm{~B}, 67 \mathrm{~A}, 31 \mathrm{~A}$ \\
\hline Ophiomusaidae & 1 & $17 \mathrm{~A}, 14 \mathrm{D}, 20 \mathrm{C}, 4 \mathrm{~B}, 34 \mathrm{~A}, 67 \mathrm{~B}, 31 \mathrm{C}, 16 \mathrm{~A}, 21 \mathrm{C}, 19 \mathrm{~A}, 38 \mathrm{~A}$ \\
\hline Ophiomyxidae & 3 & $17 \mathrm{~A}, 14 \mathrm{D}, 20 \mathrm{C}, 4 \mathrm{~B}, 34 \mathrm{~A}, 67 \mathrm{~B}, 31 \mathrm{C}, 16 \mathrm{~B}, 21 \mathrm{~A}, 19 \mathrm{~B}, 38 \mathrm{~B}$ \\
\hline Hemieuryalidae & 2 & $17 \mathrm{~B}, 16 \mathrm{~A}, 20 \mathrm{~A}, 14 \mathrm{C}, 45 \mathrm{~B}, 13 \mathrm{C}, 15 \mathrm{~B}$ \\
\hline Ophioleucidae & 1 & $17 \mathrm{~B}, 16 \mathrm{~A}, 20 \mathrm{~A}, 14 \mathrm{D}, 45 \mathrm{~A}, 13 \mathrm{~B}, 15 \mathrm{~A}$ \\
\hline Ophiuridae & 2 & $17 \mathrm{~B}, 16 \mathrm{~A}, 20 \mathrm{~B}, 4 \mathrm{~A}, 10 \mathrm{~A}, 12 \mathrm{~A}, 36 \mathrm{~A}$ \\
\hline Ophiernidae & 1 & $17 \mathrm{~B}, 16 \mathrm{~A}, 20 \mathrm{~B}, 4 \mathrm{~B}, 10 \mathrm{~B}, 12 \mathrm{~B}, 36 \mathrm{~B}$ \\
\hline Ophiopyrgidae & 4 & $17 \mathrm{~B}, 16 \mathrm{~A}, 20 \mathrm{C}$ \\
\hline Amphiuridae & 2 & $17 \mathrm{~B}, 16 \mathrm{~B}, 36 \mathrm{~A}, 33 \mathrm{~B}, 20 \mathrm{~A}, 44 \mathrm{~B}, 30 \mathrm{~B}$ \\
\hline Ophiactidae & 2 & $17 \mathrm{~B}, 16 \mathrm{~B}, 36 \mathrm{~A}, 33 \mathrm{~B}, 20 \mathrm{~B}, 44 \mathrm{C}, 30 \mathrm{C}$ \\
\hline Ophionereididae & 2 & $17 \mathrm{~B}, 16 \mathrm{~B}, 36 \mathrm{~B}, 33 \mathrm{~A}, 3 \mathrm{~A}, 12 \mathrm{~A}, 15 \mathrm{~A}, 66 \mathrm{~B}, 18 \mathrm{~A}, 39 \mathrm{~A}, 43 \mathrm{~A}, 50 \mathrm{~A}$ \\
\hline Ophiobyrsidae & 1 & $17 \mathrm{~B}, 16 \mathrm{~B}, 36 \mathrm{~B}, 33 \mathrm{~A}, 3 \mathrm{~A}, 12 \mathrm{~A}, 15 \mathrm{~A}, 66 \mathrm{~B}, 18 \mathrm{~B}, 39 \mathrm{~B}, 43 \mathrm{C}, 50 \mathrm{~B}$ \\
\hline Gorgonocephalidae & 1 & $17 \mathrm{~B}, 16 \mathrm{~B}, 36 \mathrm{~B}, 33 \mathrm{~A}, 3 \mathrm{~B}, 12 \mathrm{~B}, 15 \mathrm{~B}, 66 \mathrm{~A}$ \\
\hline Ophiuridae & 2 & $17 \mathrm{C}, 36 \mathrm{~A}, 44 \mathrm{~B}, 4 \mathrm{~A}, 16 \mathrm{~A}, 20 \mathrm{~B}, 50 \mathrm{~B}$ \\
\hline Ophiopholidae & 1 & $17 \mathrm{C}, 36 \mathrm{~A}, 44 \mathrm{~B}, 4 \mathrm{~B}, 16 \mathrm{~B}, 20 \mathrm{~A}, 50 \mathrm{~A}, 6 \mathrm{~A}, 8 \mathrm{~A}, 10 \mathrm{~B}, 24 \mathrm{~A}$ \\
\hline Ophiothamnidae & 1 & $17 \mathrm{C}, 36 \mathrm{~A}, 44 \mathrm{~B}, 4 \mathrm{~B}, 16 \mathrm{~B}, 20 \mathrm{~A}, 50 \mathrm{~A}, 6 \mathrm{~B}, 8 \mathrm{~B}, 10 \mathrm{~B}, 24 \mathrm{~B}, 49 \mathrm{~B}$ \\
\hline Amphiuridae & 2 & $17 \mathrm{C}, 36 \mathrm{~A}, 44 \mathrm{~B}, 4 \mathrm{~B}, 16 \mathrm{~B}, 20 \mathrm{~A}, 50 \mathrm{~A}, 6 \mathrm{~B}, 8 \mathrm{~B}, 10 \mathrm{~A}, 24 \mathrm{~B}, 49 \mathrm{C}$ \\
\hline Ophiactidae & 2 & $17 \mathrm{C}, 36 \mathrm{~A}, 44 \mathrm{C}, 18 \mathrm{~A}, 40 \mathrm{~A}, 30 \mathrm{C}, 33 \mathrm{~B}$ \\
\hline Amphilepididae & 1 & $17 \mathrm{C}, 36 \mathrm{~A}, 44 \mathrm{C}, 18 \mathrm{~B}, 40 \mathrm{~B}, 30 \mathrm{~B}, 33 \mathrm{~A}$ \\
\hline Ophiotomidae & 3 & $17 \mathrm{C}, 36 \mathrm{~B}, 20 \mathrm{~A}, 14 \mathrm{~B}, 49 \mathrm{D}, 12 \mathrm{~B}, 50 \mathrm{~B}$ \\
\hline Ophiacanthidae & 3 & $17 \mathrm{C}, 36 \mathrm{~B}, 20 \mathrm{~A}, 14 \mathrm{D}, 49 \mathrm{~B}, 12 \mathrm{~A}, 50 \mathrm{~A}$ \\
\hline Ophiohelidae & 1 & $17 \mathrm{C}, 36 \mathrm{~B}, 20 \mathrm{~B}, 16 \mathrm{~A}, 42 \mathrm{~B}, 47 \mathrm{~B}, 26 \mathrm{~A}$ \\
\hline Ophiotomidae & 3 & $17 \mathrm{C}, 36 \mathrm{~B}, 20 \mathrm{~B}, 16 \mathrm{~B}, 42 \mathrm{~A}, 47 \mathrm{C}, 26 \mathrm{~B}, 45 \mathrm{~A}, 49 \mathrm{D}, 12 \mathrm{~B}, 43 \mathrm{C}$ \\
\hline Ophionereididae & 2 & $17 \mathrm{C}, 36 \mathrm{~B}, 20 \mathrm{~B}, 16 \mathrm{~B}, 42 \mathrm{~A}, 47 \mathrm{C}, 26 \mathrm{~B}, 45 \mathrm{~B}, 49 \mathrm{C}, 12 \mathrm{~A}, 43 \mathrm{~A}$ \\
\hline Ophioscolecidae & 1 & $17 \mathrm{C}, 36 \mathrm{~B}, 20 \mathrm{C}, 21 \mathrm{~A}, 49 \mathrm{C}, 59 \mathrm{~A}, 72 \mathrm{~A}, 12 \mathrm{~A}, 22 \mathrm{~B}, 42 \mathrm{~B}, 47 \mathrm{~A}$ \\
\hline Amphilimnidae & 1 & $17 \mathrm{C}, 36 \mathrm{~B}, 20 \mathrm{C}, 21 \mathrm{~A}, 49 \mathrm{C}, 59 \mathrm{~A}, 72 \mathrm{~A}, 12 \mathrm{~B}, 22 \mathrm{~A}, 42 \mathrm{~A}, 47 \mathrm{~B}$ \\
\hline
\end{tabular}


Appendix 2 (continued).

\begin{tabular}{lcl}
\hline Family & No. occ. & Diagnostic characters \\
\hline Ophiopsilidae & 1 & $17 \mathrm{C}, 36 \mathrm{~B}, 20 \mathrm{C}, 21 \mathrm{C}, 49 \mathrm{D}$, 59B, 72B \\
Ophiocomidae & 1 & $17 \mathrm{D}, 44 \mathrm{~A}, 45 \mathrm{~A}, 12 \mathrm{~B}, 36 \mathrm{~B}, 43 \mathrm{C}, 63 \mathrm{~A}, 25 \mathrm{~A}, 35 \mathrm{~A}, 55 \mathrm{C}$ \\
Ophiotomidae & 3 & $17 \mathrm{D}, 44 \mathrm{~A}, 45 \mathrm{~A}, 12 \mathrm{~B}, 36 \mathrm{~B}, 43 \mathrm{C}, 63 \mathrm{~B}, 25 \mathrm{~B}, 35 \mathrm{~B}, 55 \mathrm{~B}$ \\
Ophiomyxidae & 3 & $17 \mathrm{D}, 44 \mathrm{~A}, 45 \mathrm{~B}, 12 \mathrm{~A}, 36 \mathrm{~A}, 43 \mathrm{~A}$ \\
Ophiacanthidae & 3 & $17 \mathrm{D}, 44 \mathrm{~B}, 3 \mathrm{~A}, 14 \mathrm{D}, 20 \mathrm{~A}, 36 \mathrm{~B}$ \\
Ophiocamacidae & 1 & $17 \mathrm{D}, 44 \mathrm{~B}, 3 \mathrm{C}, 14 \mathrm{C}, 20 \mathrm{~B}, 36 \mathrm{~A}$ \\
Ophiopteridae & 1 & $17 \mathrm{D}, 44 \mathrm{C}, 20 \mathrm{~A}, 8 \mathrm{~A}, 22 \mathrm{~A}, 48 \mathrm{C}, 50 \mathrm{~B}$ \\
Ophiacanthidae & 3 & $17 \mathrm{D}, 44 \mathrm{C}, 20 \mathrm{~A}, 8 \mathrm{~B}, 22 \mathrm{~B}, 48 \mathrm{~A}, 50 \mathrm{~A}$ \\
Clarkcomidae & 1 & $17 \mathrm{D}, 44 \mathrm{C}, 20 \mathrm{C}, 14 \mathrm{~B}, 21 \mathrm{~A}, 12 \mathrm{~B}, 22 \mathrm{~B}$ \\
Ophiotrichidae & 1 & $17 \mathrm{D}, 44 \mathrm{C}, 20 \mathrm{C}, 14 \mathrm{D}, 21 \mathrm{~B}, 12 \mathrm{~A}, 22 \mathrm{~A}$ \\
\hline
\end{tabular}

